Wagner Marques Rossini

\title{
Identificação de Parâmetros de Motor de Indução Linear Tubular para Extração de Petróleo
}

Dissertação apresentada à Escola Politécnica da Universidade de São Paulo para obtenção do

Título de Mestre em Engenharia Elétrica.

Área de Concentração: Engenharia de Sistemas

Orientador: Prof. Dr. José Jaime da Cruz

São Paulo 
Este exemplar foi revisado e alterado em relação à versão original, sob responsabilidade única do autor e com anuência de seu orientador.

São Paulo, 14 de março de 2008.

Assinatura do autor

Assinatura do orientador

FICHA CATALOGRÁFICA

Rossini, Wagner Marques

Identificação de Parâmetros de Motor de Indução Linear Tubular para Extração de Petróleo / Wagner Marques Rossini ed.rev. - São Paulo, 2008.

$127 p$.

Tese (Mestrado) - Escola Politécnica da Universidade de São Paulo. Departamento de Engenharia de Telecomunicações e Controle.

1. Identificação de parâmetros de motores 2. Sistema de controle e supervisório de motor linear tubular 3. Método da Busca Exaustiva 4. Automação e controle de máquinas lineares 5. Motores de indução 6. Petróleo (Extração) I. Universidade de São Paulo. Escola Politécnica. Departamento de Engenharia de Telecomunicações e Controle II.t. 
Ao inesquecível astro do Rock.

Freddie Mercury 


\section{AGRADECIMENTOS}

Seguem abaixo em ordem cronológica dos acontecimentos a quem devo agradecer pela dissertação apresentada:

Aos docentes da FEl o Prof. Dr. Aldo Arthur Belardi, o Prof. Dr. Orlando Del Bianco Filho, o Prof. Dr. Marcelo Bellodi e a Profa. Dra. Maria Claudia Ferrari de Castro por terem acreditado no meu potencial.

Ao Prof. Dr. Fabrizio Leonardi que viu em mim esse potencial convidando-me para cursar Mestrado na USP e apresentando-me uma grande pessoa lá dentro o Prof. Dr. José Jaime da Cruz.

Ao meu orientador de Mestrado o Prof. Dr. José Jaime da Cruz, esse é o cara que acreditou em mim! Do jeito que eu sou! Uma pessoa formidável, inigualável não tem igual. Não estou puxando o saco! Estou apenas dizendo o que dizem. Pessoa que apresentou-me o Prof. Dr. Bernardo Pinheiro de Alvarenga, e ao pessoal do LMAG para participar do projeto MATÆEOS.

Ao Prof. Dr. Bernardo Pinheiro de Alvarenga que me deu carta branca para tocar o projeto e incentivo para defender o Mestrado no projeto MATÆEOS.

Ao Prof. Dr. Ivan Eduardo Chabu o pai do MATÆEOS. A pessoa que deu a luz ao MATÆOS!!! Ajudou-me dentro do possível com o meu trabalho de Mestrado.

Ao Prof. Dr. Roberto Moura Sales que me ajudou dentro do possível na automação da bancada do MATEEOS.

Ao vice-diretor da EPUSP o Prof. Dr. José Roberto Cardoso. Esse foi o cara que mais aprontou comigo!!! Não vou esquecer as suas palavras "Freddie, você ainda trabalha na casa!!!" Eu trabalho!! Grande "figura" o Cardoso, adorei tê-lo conhecido.

Ao Cnpq pela bolsa de estudos concebida. 


\section{RESUMO}

O presente trabalho apresenta a identificação de parâmetros de motor de indução linear tubular para a extração de petróleo, denominado de MATÆEOS — Motor Assíncrono Tubular para Aplicação na Extração de Óleo Subterrâneo. O primeiro passo para a identificação de parâmetros do motor foi a implementação da bancada de testes com o seu sistema de controle e supervisório. O modelo adotado corresponde à situação de operação em regime estacionário e consiste no circuito contendo resistores e indutores tradicionalmente utilizado para representar motores de indução. A identificação dos parâmetros foi realizada por meio de um procedimento de otimização tomando por base o balanço de potência do motor. Para isso, em função dos parâmetros do modelo, definiu-se e minimizou-se uma medida de erro entre as potências medidas e as calculadas pelo modelo para um conjunto pré-fixado de escorregamentos. A solução desse problema de otimização foi obtida por meio de uma busca exaustiva, uma vez que o número de variáveis independentes do problema é pequeno e uma região contendo o ponto de mínimo é conhecida com razoável confiança. Os resultados obtidos indicam que os valores dos parâmetros nominais a quente apresentam algumas diferenças em relação àqueles produzidos pelo método de identificação. Essas diferenças se devem possivelmente a variações nas características térmicas do motor e a erros introduzidos pelos instrumentos de medida. O modelo identificado apresentou uma menor disponibilidade de força e um pior rendimento quando comparado com os valores de projeto do modelo nominal a quente. Apesar disto, verificou-se uma boa proximidade entre a curva característica do modelo e as obtidas experimentalmente. 


\begin{abstract}
This work presents the identification of parameters of the tubular linear induction motor for the extraction of oil, called MATÆES - which is the Portuguese acronym for Asynchronous Tubular Motor for Application to Subterranean Oil Extraction. The first step to the identification of the motor parameters was the implementation of the supervisory and control system for the test bench. The model, which is the usual one containing resistors and inductors, represents the motor operating in steady-state. The parameter identification problem was written as an optimization problem based on the motor power balance. An error between the measured power and the one given by the model was defined and minimized with respect to the model parameters in correspondence to a given set of slipping frequencies. The numerical solution to this problem was obtained by an exhaustive search algorithm. This choice was made because the number of independent variables is small and a region containing the solution is known with a significant degree of confidence. The results obtained show that the nominal values of the model parameters differ slightly from those produced by the identification method. Possibly, such differences are due to the variations in the model caused by temperature changes and to the measurement errors. The identified model presented both a lower available force and a worst efficiency when compared to the nominal design values for the warm motor. Despite this the characteristic curve of the model was quite close to the nominal design one.
\end{abstract}




\section{SUMÁRIO}

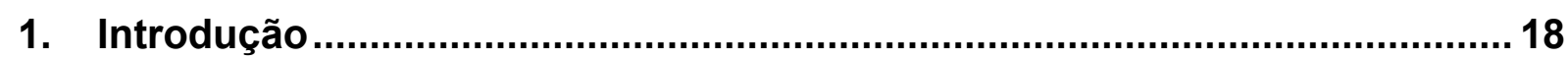

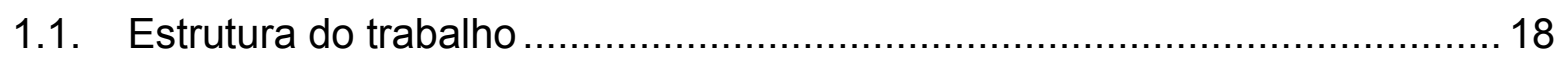

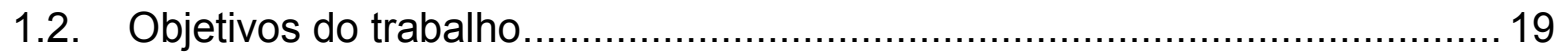

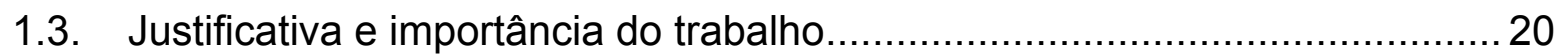

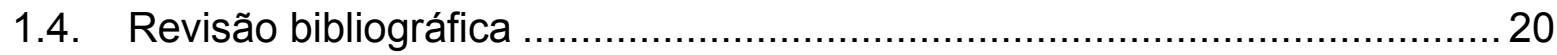

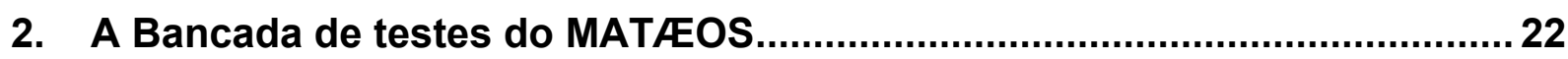

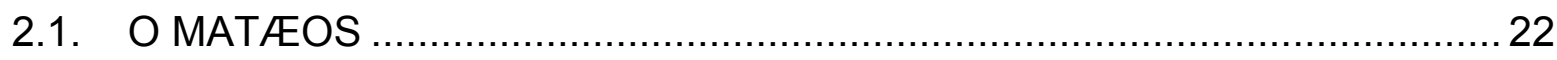

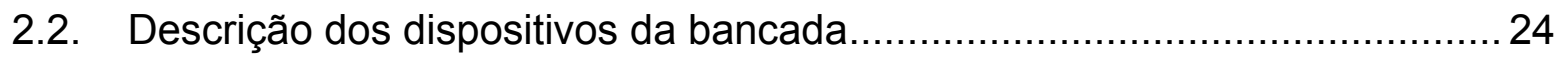

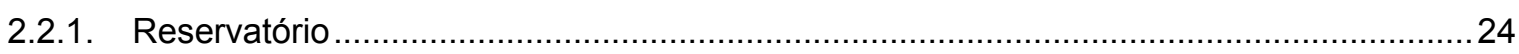

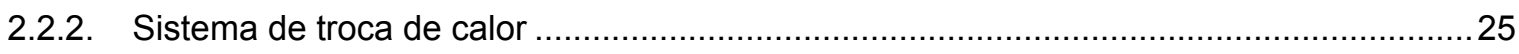

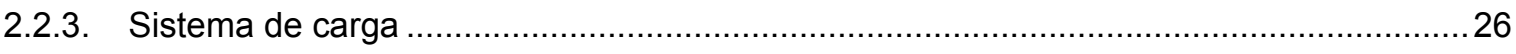

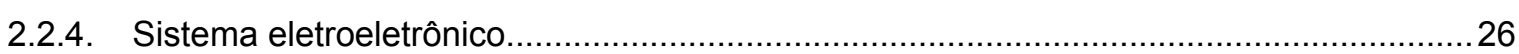

3. Sistema de controle e supervisório do MAT/EOS ….......................................29

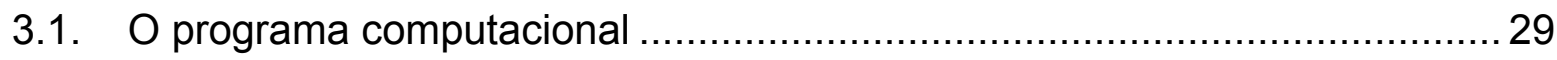

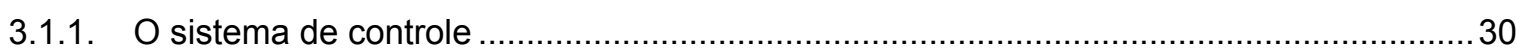

3.1.2. O sistema supervisório......................................................................................

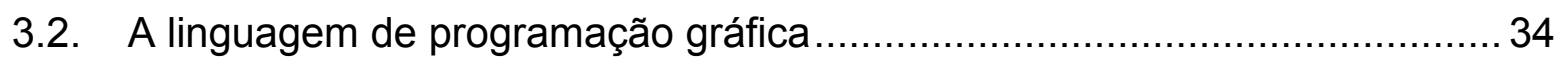

3.2.1. Estrutura de programação do sistema de controle ..........................................................34

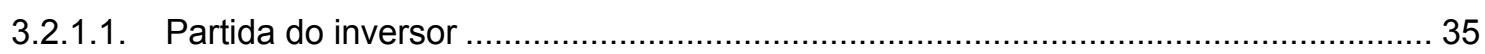

3.2.1.2. Medição da posição do secundário ...................................................................... 35

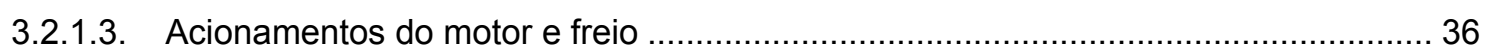

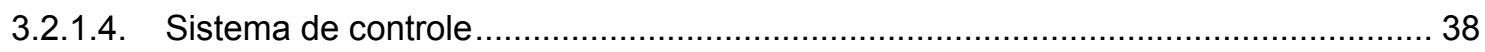

3.2.2. Estrutura de programação do sistema supervisório ………………………………......48

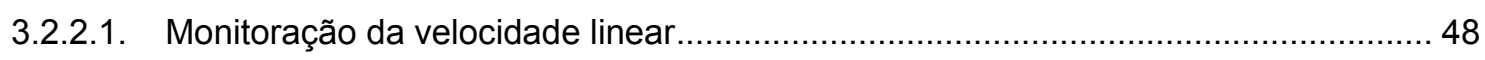

3.2.2.2. Monitoração da posição e curva dinamométrica.................................................... 51

3.2.2.3. Monitoração das variéveis eletromecânicas ........................................................ 52

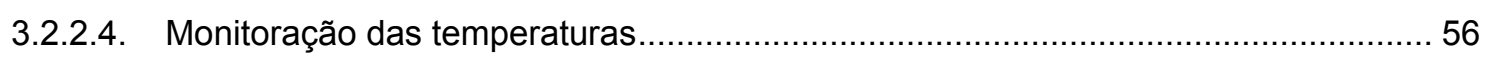

3.2.3. Estrutura de programação dos valores médios medidos ...............................................58

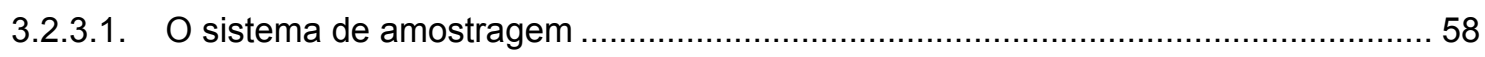

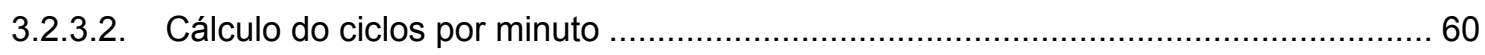

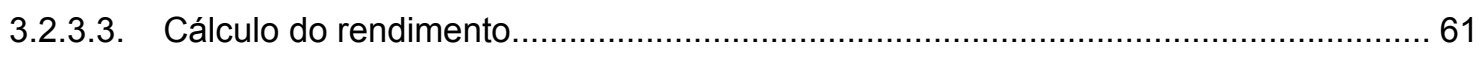

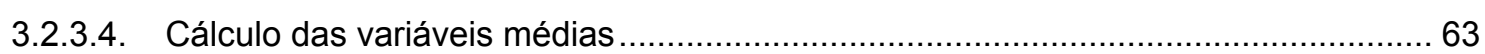

3.2.4. Estrutura de programação do sistema de aquisição de dados.........................................67

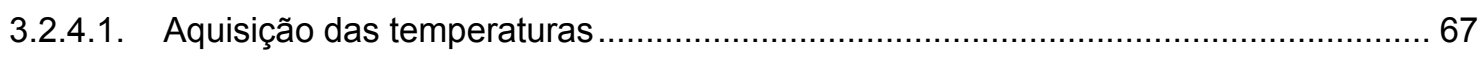

3.2.4.2. Aquisição de dados ...................................................................................... 70 


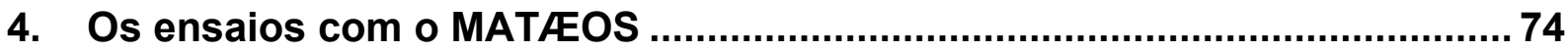

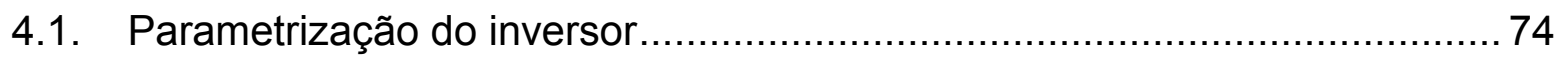

4.2. Ajuste da freqüência de operação ........................................................ 74

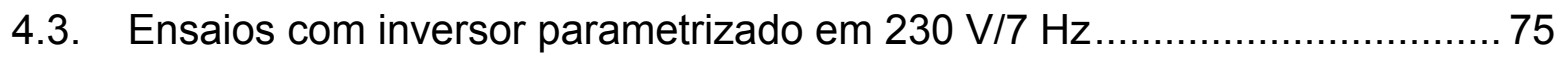

4.3.1. Resultados obtidos com freqüência de operação em $7,0 \mathrm{~Hz}$.........................................76

4.3.2. Resultados obtidos com freqüência de operação em $6,5 \mathrm{~Hz}$.......................................77

4.3.3. Resultados obtidos com freqüência de operação em $6,0 \mathrm{~Hz} \ldots \ldots \ldots \ldots \ldots \ldots \ldots \ldots \ldots \ldots \ldots \ldots \ldots \ldots \ldots . . .78$

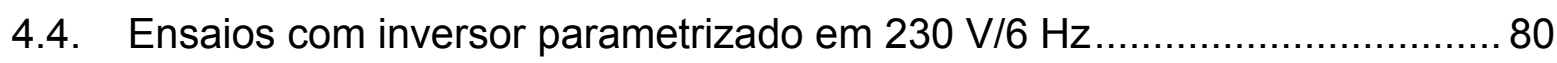

4.4.1. Resultados obtidos com freqüência de operação em $6,5 \mathrm{~Hz}$.......................................... 80

4.4.2. Resultados obtidos com freqüência de operação em $6,0 \mathrm{~Hz}$.......................................81

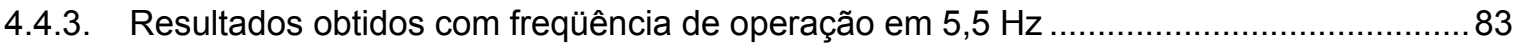

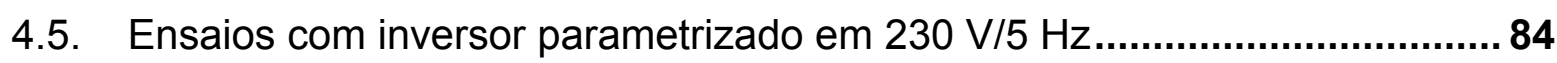

4.5.1. Resultados obtidos com freqüência de operação em $5,5 \mathrm{~Hz}$......................................... 84

4.5.2. Resultados obtidos com freqüência de operação em $5,0 \mathrm{~Hz}$......................................8 86

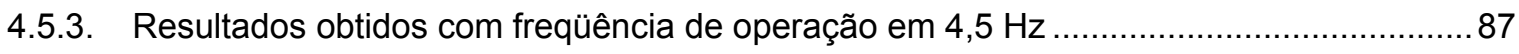

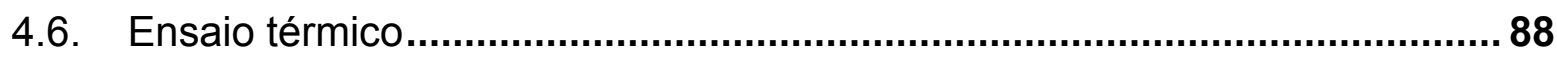

4.7. Curva característica experimental ........................................................90

4.8. Análises e conclusões preliminares......................................................90

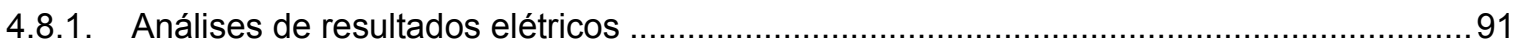

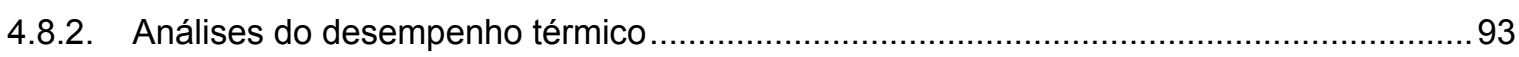

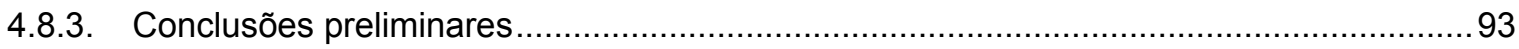

5. Identificação de parâmetros do MAT/EOS …..............................................95

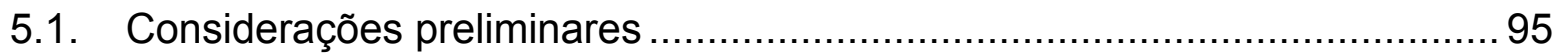

5.2. O problema de identificação ............................................................. 97

5.3. Solução do problema de otimização......................................................... 99

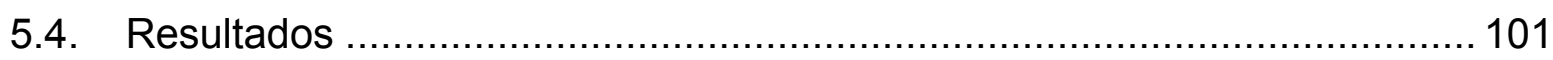

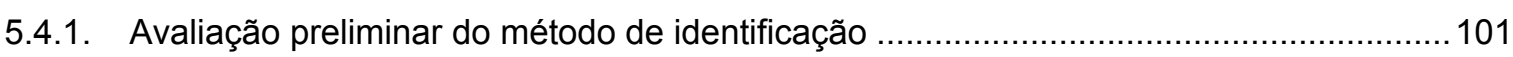

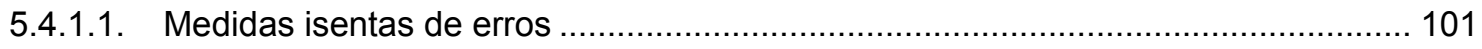

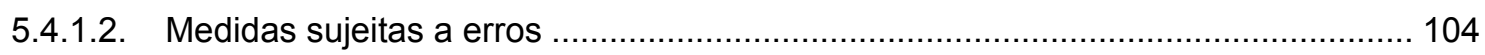

5.4.2. Aplicação do método de identificação ao caso real........................................................ 105

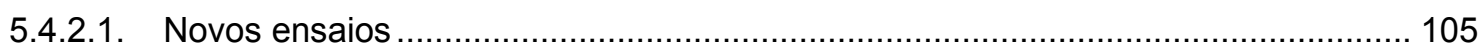

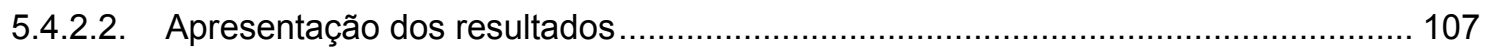

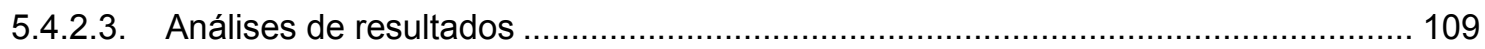

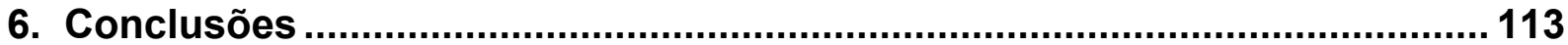

Anexo A. Circuito equivalente do motor ……..............................................116

Anexo B. Sistema de monitoração em "Off" do MAT/EOS.............................119 


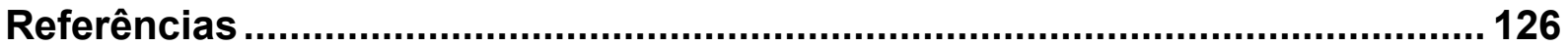




\section{LISTA DE FIGURAS}

Fig. 2.1. Protótipo do motor de indução linear tubular.....

Fig. 2.2. Bancada de testes de motor linear tubular.

Fig. 2.3. Reservatório

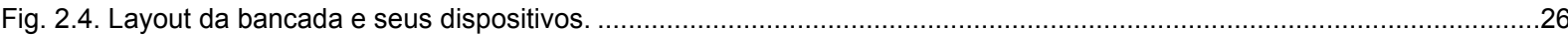

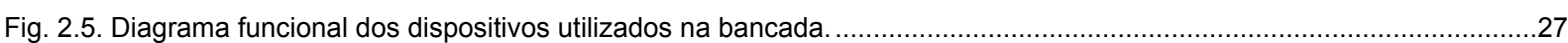

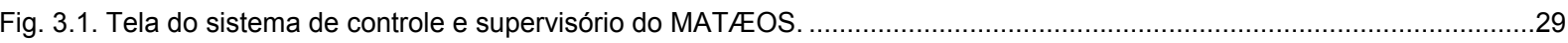

Fig. 3.2. Representação gráfica do ciclo de movimento por "histerese" ........................................................................30

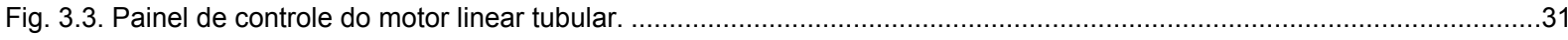

Fig. 3.4 Símbolos dos termômetros virtuais e carta dinamométrica. ....................................................................................

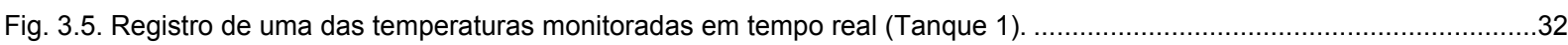

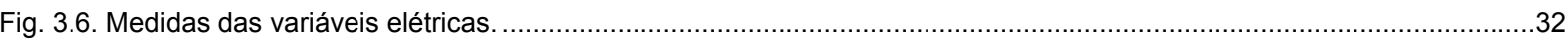

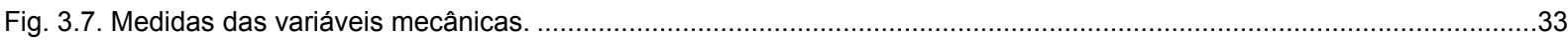

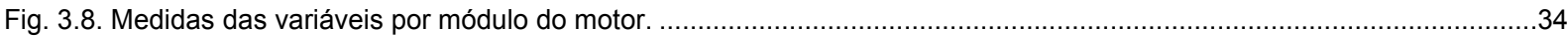

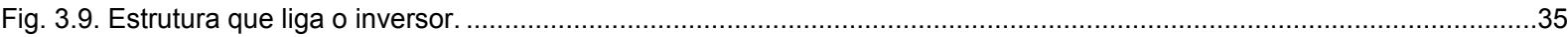

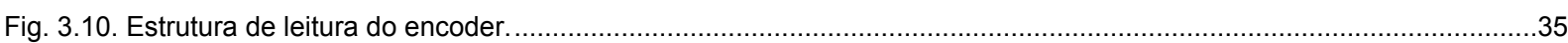

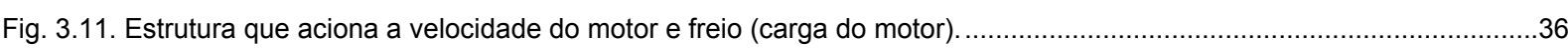

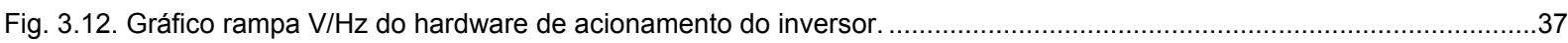

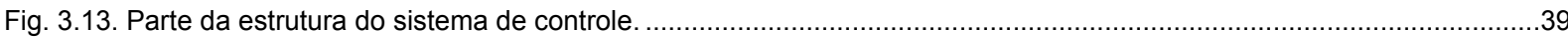

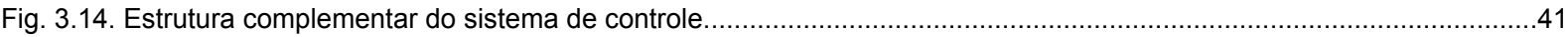

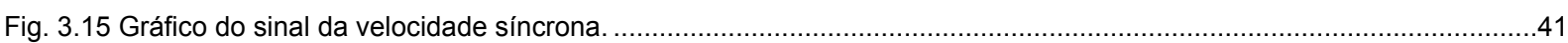

Fig. 3.16. Estrutura para evitar paradas durante a inversão do movimento para subida. ...................................................42

Fig. 3.17. Estrutura para evitar paradas durante a inversão do movimento para descida. ..................................................42

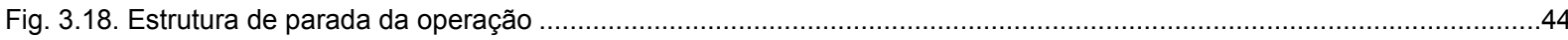

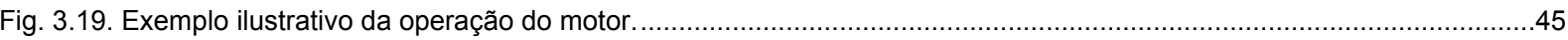

Fig. 3.20. Estruturas que representam a seqüência do ciclo de Histerese ...........................................................................47

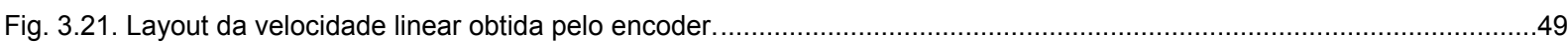

Fig. 3.22. Estrutura que implementa o cálculo da velocidade linear do motor. ..................................................................50

Fig. 3.23. Estrutura que supervisiona a excursão e plota a carta dinamométrica do motor...............................................52

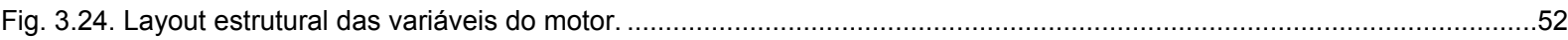

Fig. 3.25. Estrutura que implementa a leitura das variáveis elétricas e mecânicas. .............................................................53

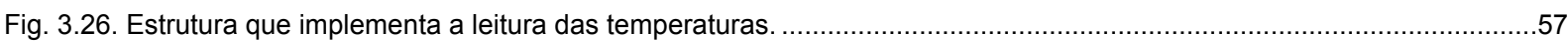

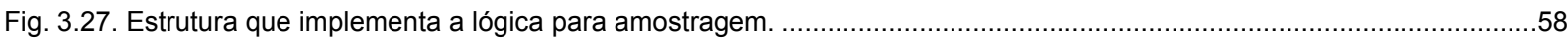

Fig. 3.28. Ilustração da amostragem para o cálculo dos valores médios. ............................................................................60

Fig. 3.29. Estrutura de programação utilizada para o cálculo dos ciclos por minuto do motor.................................................60

Fig. 3.30. Estrutura de programação utilizada para o cálculo do rendimento do motor. ..........................................................62 
Fig. 3.31. Estrutura de programação utilizada para o cálculo das variáveis médias do motor................................................64

Fig. 3.32. Estrutura de programação complementar utilizada no cálculo das variáveis médias. ..............................................66

Fig. 3.33. Estrutura de programação de monitoração gráfica e aquisição das temperaturas. ...............................................68

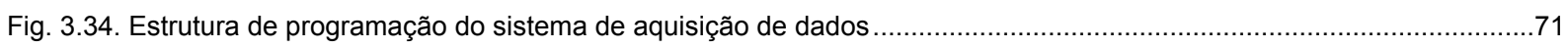

Fig. 4.1. Curva dinamométrica. Parametrização em 230 V/7 Hz. Freqüência de operação 7 Hz; Carga: 190 Kgf. .....................76

Fig. 4.2. Curva dinamométrica. Parametrização em 230 V/7 Hz. Freqüência de operação 7 Hz; Carga: 160 Kgf. .....................77

Fig. 4.3. Curva dinamométrica. Parametrização em 230 V/7 Hz. Freqüência de operação 6,5 Hz; Carga: 160 Kgf. ...................78

Fig. 4.4. Curva dinamométrica. Parametrização em 230 V/7 Hz. Freqüência de operação 6,5 Hz; Carga: 160 Kgf. ...................78

Fig. 4.5. Curva dinamométrica. Parametrização em 230 V/7 Hz. Freqüência de operação 6,0 Hz; Carga: 160 Kgf. ...................79

Fig. 4.6. Curva dinamométrica. Parametrização em 230 V/7 Hz. Freqüência de operação 6,0 Hz; Carga: 160 Kgf. ...................79

Fig. 4.7. Curva dinamométrica. Parametrização em 230 V/6 Hz. Freqüência de operação 6,5 Hz; Carga: 200 Kgf. ...................81

Fig. 4.8. Curva dinamométrica. Parametrização em 230 V/6 Hz. Freqüência de operação 6,5 Hz; Carga: 175 Kgf. ..................81

Fig. 4.9. Curva dinamométrica. Parametrização em 230 V/6 Hz. Freqüência de operação 6,0 Hz; Carga: 195 Kgf. ..................82

Fig. 4.10. Curva dinamométrica. Parametrização em 230 V/6 Hz. Freqüência de operação 6,0 Hz; Carga: 170 Kgf. .................82

Fig. 4.11. Curva dinamométrica. Parametrização em 230 V/6 Hz. Freqüência de operação 5,5 Hz; Carga: 160 Kgf. .................83

Fig. 4.12. Curva dinamométrica. Parametrização em 230 V/6 Hz. Freqüência de operação 5,5 Hz; Carga: 160 Kgf. ................84

Fig. 4.13. Curva dinamométrica. Parametrização em 230 V/5 Hz. Freqüência de operação 5,5 Hz; Carga: 230 Kgf. ................85

Fig. 4.14. Curva dinamométrica. Parametrização em 230 V/5 Hz. Freqüência de operação 5,5 Hz; Carga: 200 Kgf. .................85

Fig. 4.15. Curva dinamométrica. Parametrização em 230 V/5 Hz. Freqüência de operação 5,0 Hz; Carga: 245 Kgf. .................86

Fig. 4.16. Curva dinamométrica. Parametrização em 230 V/5 Hz. Freqüência de operação 5,0 Hz; Carga: 200 Kgf. .................87

Fig. 4.17. Curva dinamométrica. Parametrização em 230 V/5 Hz. Freqüência de operação 4,5 Hz; Carga: 235 Kgf. .................88

Fig. 4.18. Curva dinamométrica. Parametrização em 230 V/5 Hz. Freqüência de operação 4,5 Hz; Carga: 200 Kgf. ................88

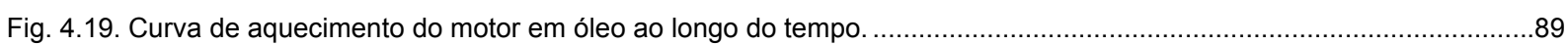

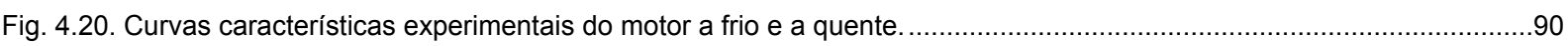

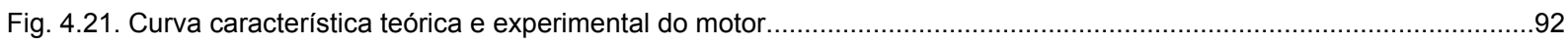

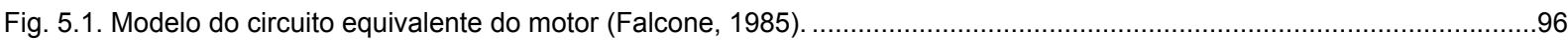

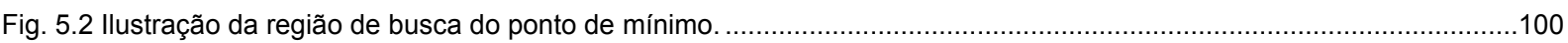

Fig. 5.3. Curvas características do modelo nominal e do modelo identificado para medidas isentas de erros.........................103

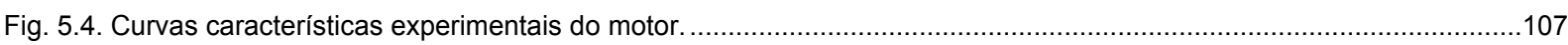

Fig. 5.5. Curvas características do três ensaios e do modelo identificada .....................................................................109

Fig. 5.6. Curva característica nominal a quente e do modelo identificado ……..........................................................110

Fig. A.1. Circuito equivalente do motor de indução linear tubular..................................................................................116

Fig. B.1. Tela que monitora de forma virtual o sistema de controle e supervisório do Matæos. ..........................................119

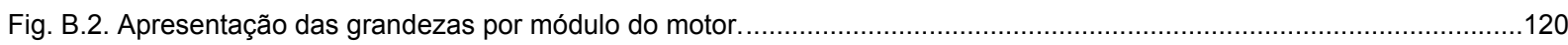

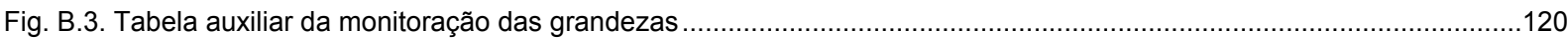

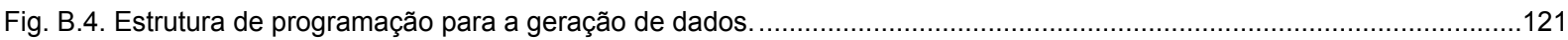

Fig. B.5. Estrutura de programação para a visualização de dados na tabela auxiliar. ...........................................................122

Fig. B.6. Tela que monitora de forma virtual o sistema de aquisição de temperaturas do MATÆEOS....................................123 
Fig. B.7. Tabela auxiliar da monitoração das temperaturas...

Fig. B.8. Estrutura de programação para a geração das temperaturas

Fig. B.9. Estrutura de programação para a visualização das temperaturas na. 


\section{LISTA DE TABELAS}

Tabela 2.1. Dados do Matæos.

Tabela 3.1. Operacionalização do sistema de controle. .46

Tabela 4.1. Parametrização 230 V/7 Hz. Freqüência de operação 7,0 Hz. ...............................................76

Tabela 4.2. Parametrização 230 V/7Hz. Freqüência de operação 6,5 Hz. ..............................................77

Tabela 4.3. Parametrização 230 V/7 Hz. Freqüência de operação 6,0 Hz. ...............................................79

Tabela 4.4. Parametrização 230 V/6 Hz. Freqüência de operação $6,5 \mathrm{~Hz}$...................................................80

Tabela 4.5. Parametrização 230 V/6 Hz. Freqüência de operação $6,0 \mathrm{~Hz}$................................................82

Tabela 4.6. Parametrização 230 V/6 Hz. Freqüência de operação 5,5 Hz. .....................................................83

Tabela 4.7. Parametrização 230 V/5 Hz. Freqüência de operação 5,5 Hz. ...................................................85

Tabela 4.8. Parametrização 230 V/5 Hz. Freqüência de operação 5,0 Hz. ............................................... 86

Tabela 4.9. Parametrização 230 V/5 Hz. Freqüência de operação 4,5 Hz. …..........................................8

Tabela 4.10. Medição de temperaturas. Parametrização: 230 V/7 Hz. Freqüência de operação 7,0 Hz...............89

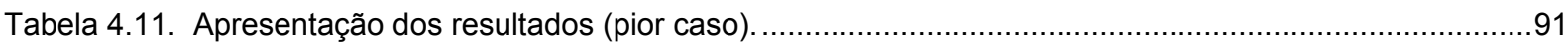

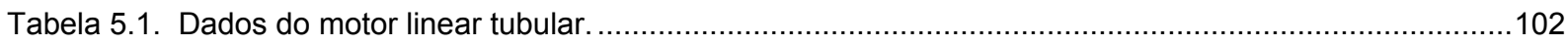

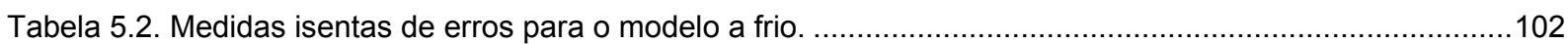

Tabela 5.3. Parâmetros identificados para as medidas isentas de erros......................................................103

Tabela 5.4. Resultados com os ensaios simulados sujeitos a erros de medidas para o modelo a frio...............104

Tabela 5.5. Medidas extraídas dos três novos ensaios com o motor. .....................................................106

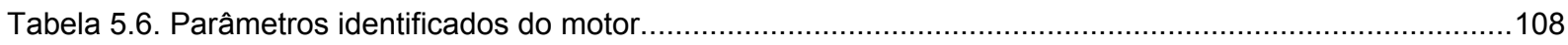

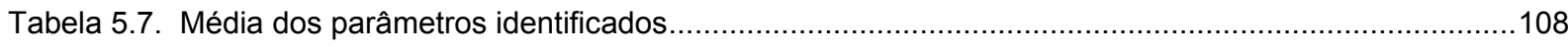

Tabela 5.8. Parâmetros nominais a quente e identificados........................................................................ 110

Tabela 5.9. Apresentação dos resultados do desempenho do motor. .............................................................111

Tabela A.1. Dados de pojeto do circuito equivalente do motor de indução linear tubular (Matæos)...................117 


\section{LISTA DE SÍMBOLOS}

\begin{tabular}{|c|c|}
\hline$A, B$ & Coeficientes do RTD \\
\hline$A_{I}$ & Ajuste inferior \\
\hline$A j_{d}$ & Ajuste na base decimal \\
\hline$A M$ & Amostragem \\
\hline$A_{S}$ & Ajuste superior \\
\hline AUTOM. & Automático \\
\hline$C_{N_{A}}$ & Contagem do número de amostras \\
\hline$C / M$ & Ciclos por minuto \\
\hline$C_{M}$ & Carga do motor \\
\hline$E M$ & Excursão do motor \\
\hline$E X_{d}$ & Excursão do motor na base decimal \\
\hline$E X_{m}$ & Excursão do motor em metros \\
\hline$E X S_{d}$ & Excursão superior do motor \\
\hline$E X I_{d}$ & Excursão inferior do motor \\
\hline$f_{E}$ & Freqüência do encoder \\
\hline$F_{F R E I O}$ & Força freio \\
\hline$F_{M}$ & Força média \\
\hline$f_{N}$ & Freqüência nominal do motor \\
\hline$f_{O P}$ & Freqüência de operação \\
\hline$F S$ & Freqüência síncrona \\
\hline$g$ & Constante gravitacional \\
\hline$I_{e}$ & Corrente de excitação do RTD \\
\hline$I_{F_{M}}$ & Corrente média \\
\hline$I_{F}$ & Corrente por fase \\
\hline$I_{m}$ & Fasor da corrente de magnetização \\
\hline$I_{p}$ & Fasor da corrente de perda no ferro \\
\hline
\end{tabular}




\begin{tabular}{ll}
$I_{p m}$ & Fasor da corrente do ramo de magnetização \\
$I_{r}$ & Fasor da corrente no rotor (secundário) \\
$I_{s}$ & Fasor da corrente no estator (primário) \\
$I_{s}$ & Corrente do motor \\
$K_{C M}$ & Constante de proporcionalidade da carga do motor \\
$K_{E}$ & Constante de proporcionalidade do encoder \\
$K_{F}$ & Constante de proporcionalidade do freio \\
$K_{I F}$ & Constante de proporcionalidade da corrente por fase \\
$K_{P R}$ & Constante de proporcionalidade da potência reativa \\
$K_{P A}$ & Constante de proporcionalidade da potência ativa \\
$K_{V L}$ & Constante velocidade linear \\
$L E$ & Leitura do encoder \\
$N_{R}$ & Número de ranhuras do encoder \\
$P_{A}$ & Potência ativa \\
$P_{E_{F} / M}$ & Potência elétrica média \\
$P_{i n}$ & Potência elétrica \\
$P_{M_{F} M}$ & Potência mecânica média \\
$P M$ & Posição do motor \\
$P_{M}$ & Potência mecânica \\
$P_{o u t}$ & Potência mecânica \\
$P_{R}$ & Potência reativa \\
$P_{R_{P}}$ & Perdas no núcleo \\
$P_{R_{1}}$ & Perdas no primário \\
$P_{R_{2}}$ & Perdas secundário \\
$R_{0}$ & Resistência do RTD \\
$R_{P}$ & Raio da polia dentada \\
$R_{T}$ & Reset temperaturas. \\
$R E S E T_{A}$ & Reset amostras \\
\hline
\end{tabular}




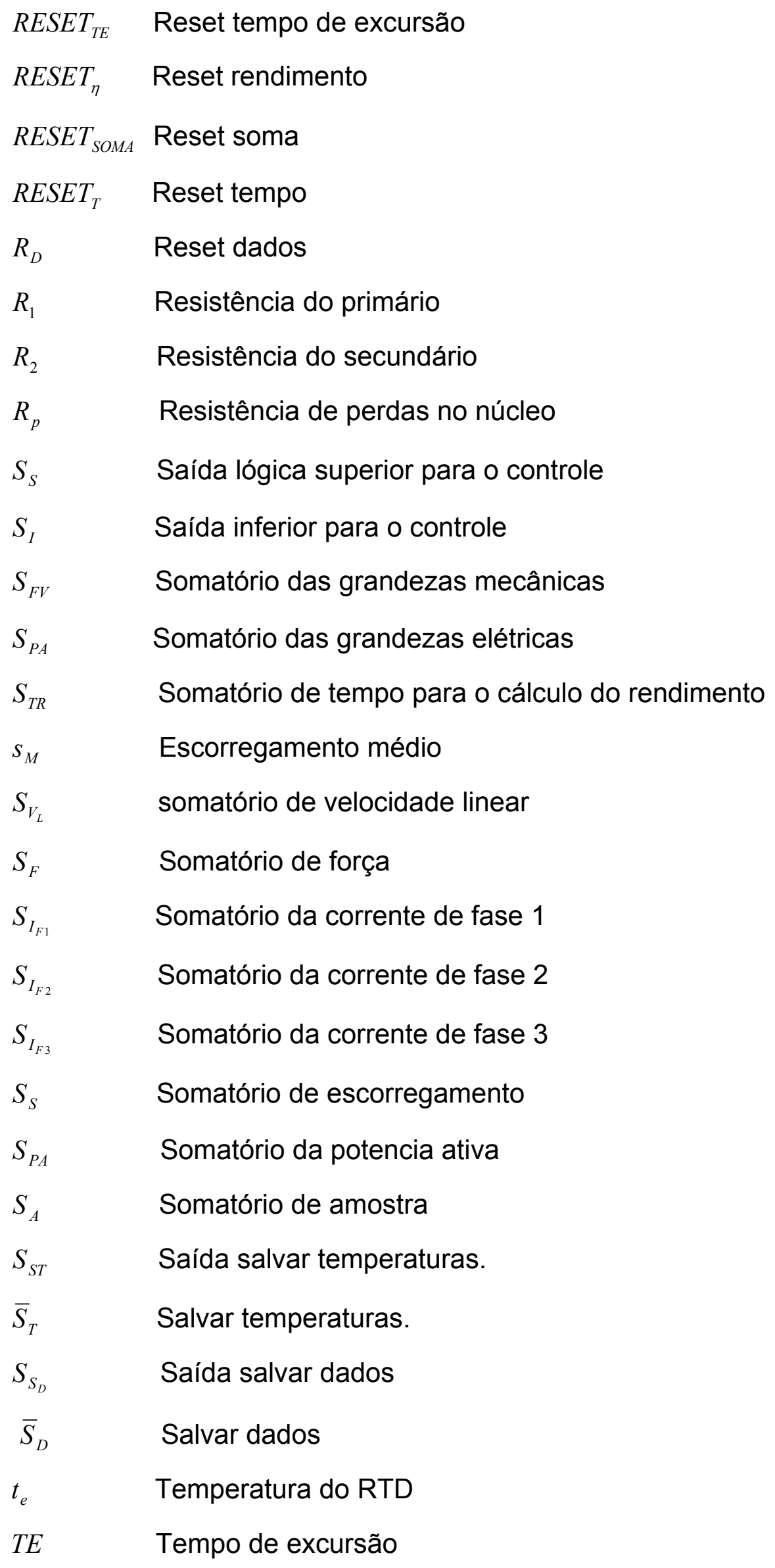




\begin{tabular}{ll}
$T_{\text {Temp }}$ & Contagem de tempo \\
$V_{V S}$ & Tensão velocidade síncrona \\
$V_{F}$ & Tensão freio \\
$V_{L}$ & Velocidade linear do secundário do motor \\
$V_{P R}$ & Tensão potência reativa \\
$V_{P A}$ & Tensão potência ativa \\
$V_{I F}$ & Tensão corrente por fase \\
$V_{C M}$ & Tensão carga do motor \\
$V_{0}$ & Voltagem do RTD \\
$V_{L_{M}}$ & Velocidade linear média \\
$V_{s}$ & Fasor da tensão aplicada no motor \\
$v_{s}$ & Velocidade síncrona do motor \\
$X_{1}$ & Reatância de dispersão do primário \\
$X_{2}$ & Reatância de dispersão \\
$X_{m}$ & Reatância de magnetização \\
$W_{E}$ & Velocidade angular do motor por ranhura \\
$Y_{0}$ & Parâmetros iniciais nominais do motor \\
$Y_{m i n .}$ & Parâmetros mínimos da busca exaustiva \\
$Y_{m a x .}$ & Parâmetros máximos da busca exaustiva \\
$\alpha$ & Coeficiente angular da reta da relação $\mathbf{V} / \mathrm{Hz}$ \\
$\eta$ & Rendimento do motor \\
& \\
\hline
\end{tabular}




\section{Introdução}

As máquinas de indução lineares estão sendo investigadas ativamente para um grande número de aplicações, incluindo os sistemas de transporte em terra (trens Maglev), as bombas de metal líquido, os guindastes, os sistemas de transporte de bagagem, teste de impacto em carros automotivos, dentre outras (Bagegni, Adams \& Hoft, 1993). Uma outra tecnologia que vem sendo investigada é a utilização de máquinas lineares tubulares na extração de petróleo em terra, denominada de MATÆEOS - Motor Assíncrono Tubular para Aplicação na Extração de Óleo Subterrâneo. Por iniciativa do Laboratório de Eletromagnetismo Aplicado da Escola Politécnica da Universidade de São Paulo — LMAG/EPUSP, foi construído um protótipo do motor de indução linear tubular para a extração de petróleo. Este protótipo tem uma tecnologia original desenvolvida pelo próprio LMAG/EPUSP com o secundário em gaiola anular (Alvarenga, Chabu, Cardoso, 2002). Esse novo sistema tem como propósito ser uma grande evolução no conceito de bombeamento de petróleo, por ser uma alternativa viável, dos pontos de vista técnico e econômico, quando comparadas com o sistema de extração tradicional chamado de "cavalomecânico".

A construção do protótipo foi motivada pela Petrobrás, e neste momento o protótipo do MAT\&EOS está instalado em bancada montada na EPUSP.

\subsection{Estrutura do trabalho}

O presente trabalho se inicia com os objetivos e a apresentação do estado da arte do problema. Em seguida é feita uma breve revisão bibliográfica sobre alguns métodos de identificação de parâmetros de máquinas.

No capítulo 2 faz-se uma breve exposição do MATÆEOS e da bancada de testes na qual o motor é ensaiado. É feita uma descrição da construção do motor, apresentando-se algumas vantagens e desvantagens desta tecnologia. São apresentados os dispositivos mecânicos e eletroeletrônicos utilizados na bancada. 
No capítulo 3 apresenta-se o programa computacional elaborado em "LABVIEW" utilizado na bancada. Através de uma linguagem de programação gráfica, descreve-se em detalhes todo o sistema de controle e supervisório da bancada.

No capítulo 4 são apresentados os ensaios realizados com o MATÆOS e os seus resultados. Os ensaios são realizados submetendo o motor a três ensaios, parametrizando o inversor em três freqüências nominais diferentes. Caberá apenas analisar os resultados para a freqüência de projeto. As análises em outras freqüências podem ser vistas em (Relatório de projeto, 2005).

No capítulo 5 descreve-se o método de identificação de parâmetros experimentais do MATÆES, através de um método denominado de MBE - Método da Busca Exaustiva.

No capítulo 6 apresentam-se as conclusões do trabalho.

Finalmente, para evitar a solução de continuidade do texto principal, tópicos relevantes são abordados na forma de anexos. Nos anexos A e B, respectivamente, são apresentados o circuito equivalente do motor de indução linear tubular e o sistema de monitoração em "off” do MATÆEOS.

\subsection{Objetivos do trabalho}

Os objetivos do trabalho são identificar os parâmetros de motor de indução linear tubular para extração de petróleo e implementar o sistema de controle e supervisório de bancada de testes no qual o motor foi submetido aos testes. $O$ levantamento de todas as grandezas elétricas e mecânicas relevantes do problema irá permitir analisar as características do motor para a aplicação, e através deste, dar continuidade nas pesquisas realizadas até o presente momento e permitir a identificação de parâmetros do motor de indução linear tubular. 


\subsection{Justificativa e importância do trabalho}

Através de ensaios realizados, verificou-se que o motor não apresentou desempenho eletromecânico previsto no projeto, não desenvolvendo a força esperada de $150 \mathrm{Kgf}$ por módulo e um rendimento em torno de $31 \%$.

Através do modelo identificado experimentalmente pode-se chegar a uma melhor compreensão desses desvios.

\subsection{Revisão bibliográfica}

O presente trabalho se inicia com uma breve revisão bibliográfica sobre alguns métodos utilizados para a identificação de parâmetros de máquinas elétricas.

Diversos estudos e análises vêm sendo realizados na busca de obtenção de modelos que melhor representem o motor linear, com o objetivo de obter circuitos equivalentes que resolvam problemas de efeitos de extremidade e de projeto. Vários trabalhos foram publicados até meados da década 80 (Boldea \& Nasar, 1976), (Bolton, 1969), (Ducan, 1983), (Freeman \& Bland, 1976), entre outros.

(Cullen \& Barton, 1958), (Greig \& Freeman, 1967) e (Freeman, 1968) aplica a máquinas de indução rotativas o chamado "método matricial" apresentando excelentes resultados.

Neste sentido, o método matricial é aperfeiçoado e aplicado na obtenção do circuito equivalente de dispositivos com geometria cilíndrica (Freeman \& Smith, 1970), (Freeman, 1974), (Freeman, 1976), (Freeman \& Bland, 1976). Após isso, conceitos do método matricial e do circuito equivalente resultante são aplicados a máquinas lineares tubulares (Eastham \& Alwash, 1972), (Freeman, 1975) e (Zagirnyak, 1985).

Diversos outros trabalhos vêm sendo publicados até o presente momento, dentre eles: (Vadher \& Smith, 1993), que retrata o desempenho de um motor de indução linear tubular (TLIM, em inglês), analisado com topologias do estator e do rotor diferentes. Com a análise teórica do TLIM e os parâmetros do circuito equivalente medidos, obtém-se um modelo apropriado. 
Um novo método na identificação de parâmetros do circuito equivalente de motores de indução é introduzido e discutido em (Gastli, 1999). O método proposto usa os resultados de teste "single-phase", calculando os parâmetros do circuito equivalente de motor de indução. $O$ teste "single-phase" é executado usando uma freqüência variável da fonte de alimentação (inversor). O teste foi conduzido em várias freqüências, enquanto a tensão, a corrente e a potência foram medidas. Após isso, os parâmetros do motor foram calculados. A precisão do cálculo dos parâmetros do motor é sensível à exatidão das medidas, a qual pode ser melhorada pelo uso do desempenho elevado dos microprocessadores.

(Vamvakari, Kandianis, Kladas, Manias \& Tegopoulos, 2001) analisa os efeitos da distorção da tensão da fonte na operação do motor de indução. Muitas aplicações modernas do motor de indução envolvem fontes não senoidais de tensão. Sob tais circunstâncias de operação, o desempenho do motor pode ser seriamente afetado, enquanto o circuito equivalente padrão não é mais adequado para a análise do motor. O trabalho mostra uma topologia modificada do circuito equivalente, colocada a fim de esclarecer as perdas aumentadas do ferro associadas com o fluxo e a saturação do motor, na presença de harmônicas de baixa ordem provenientes da fonte. $O$ circuito equivalente permite a predição do desempenho do motor sob a operação não senoidal.

(Alvarenga, 2004) adapta o método matricial de forma a produzir um circuito equivalente para o motor de indução linear tubular, obtendo assim um resultado tal que a solução deste circuito é exatamente igual à do circuito equivalente do motor de indução rotativo.

O presente trabalho apresentará a identificação de parâmetros experimentais do motor de indução linear tubular, à partir dos parâmetros nominais de projeto do circuito equivalente do motor e dos dados medidos experimentalmente do ensaio. Os dados serão levantados fixando a freqüência nominal do motor, enquanto a tensão, corrente, escorregamento e as potências serão medidas. Depois disso, os novos parâmetros serão calculados utilizando o Método da Busca Exaustiva. 


\section{A Bancada de testes do MATAOS}

Esta seção apresenta as características do MATÆEOS e da bancada de testes, onde o motor de indução linear tubular é submetido a testes. Ela se inicia com uma descrição da construção do motor, apresentando algumas vantagens e desvantagens desta tecnologia; em seguida, são apresentados os dispositivos mecânicos e eletroeletrônicos utilizados na bancada.

\subsection{O MATAOS}

O MATÆOS é o dispositivo sob testes (Fig. 2.1). O propósito é que este motor seja aplicado em poços de extração de petróleo em terra.

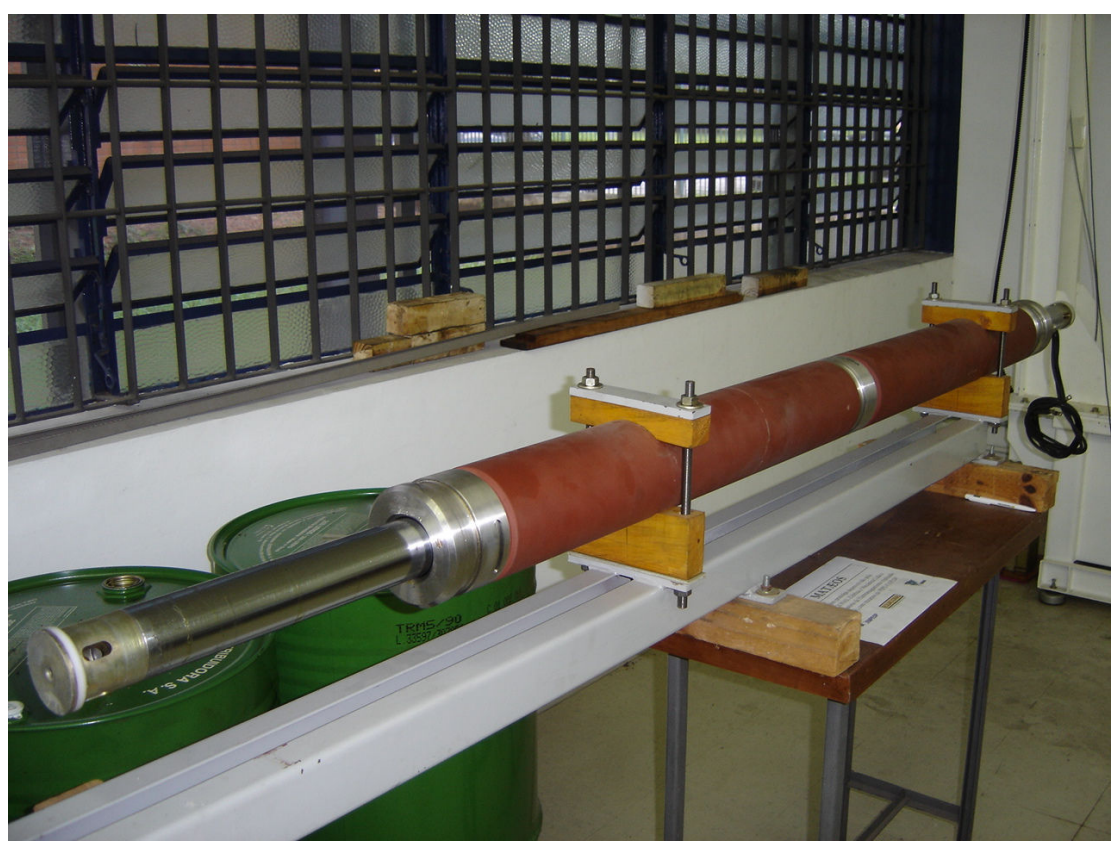

Fig. 2.1. Protótipo do motor de indução linear tubular

O MATÆOS possui característica de construção modular e apresenta algumas vantagens, tais como: o motor apresenta força constante por módulo. Isto permite adaptar o motor à força exigida pelo poço, simplesmente conectando mais ou menos módulos ao conjunto; a ligação série dos enrolamentos de fase faz com que a corrente necessária à operação do motor seja independente do número de 
módulos utilizados e, conseqüentemente, independente da força exigida pelo poço; a tensão de alimentação total do motor aumenta conforme se agregam mais módulos do motor para um dado poço. As desvantagens da construção modular são: é necessário garantir a estanqueidade dos enrolamentos nas conexões entre os módulos do motor; a tensão aplicada é a tensão nominal por módulo multiplicada pelo número de módulos. Dependendo da quantidade de módulos, é necessário utilizar um inversor em média tensão, ou utilizar um transformador elevador na saída do mesmo (Alvarenga, 2004).

Os principais dados do MAT/EOS são resumidos na Tabela 2.1 a seguir. Estas informações representam grandezas por módulo. (número de módulos agregados). A Fig. 2.1, mostra os dois módulos do motor juntos.

Tabela 2.1. Dados do Matæos

\begin{tabular}{|r|c|}
\hline Tensão nominal & $115 \mathrm{~V}$ trifásico \\
\hline Freqüência nominal & $7 \mathrm{~Hz}$ \\
\hline Força nominal & $150 \mathrm{Kgf}$ \\
\hline Velocidade síncrona do campo & $1,05 \mathrm{~m} / \mathrm{s}$ \\
\hline Diâmetro externo do primário & $112 \mathrm{~mm}$ \\
\hline Diâmetro externo do secundário & $60 \mathrm{~mm}$ \\
\hline Comprimento do primário & $780 \mathrm{~mm}$ \\
\hline Passo polar & $75 \mathrm{~mm}$ \\
\hline
\end{tabular}




\subsection{Descrição dos dispositivos da bancada}

A bancada de testes (Fig. 2.2) é composta por cinco elementos: o reservatório de óleo e os sistemas de troca de calor, de comando e proteção, supervisório e de controle.

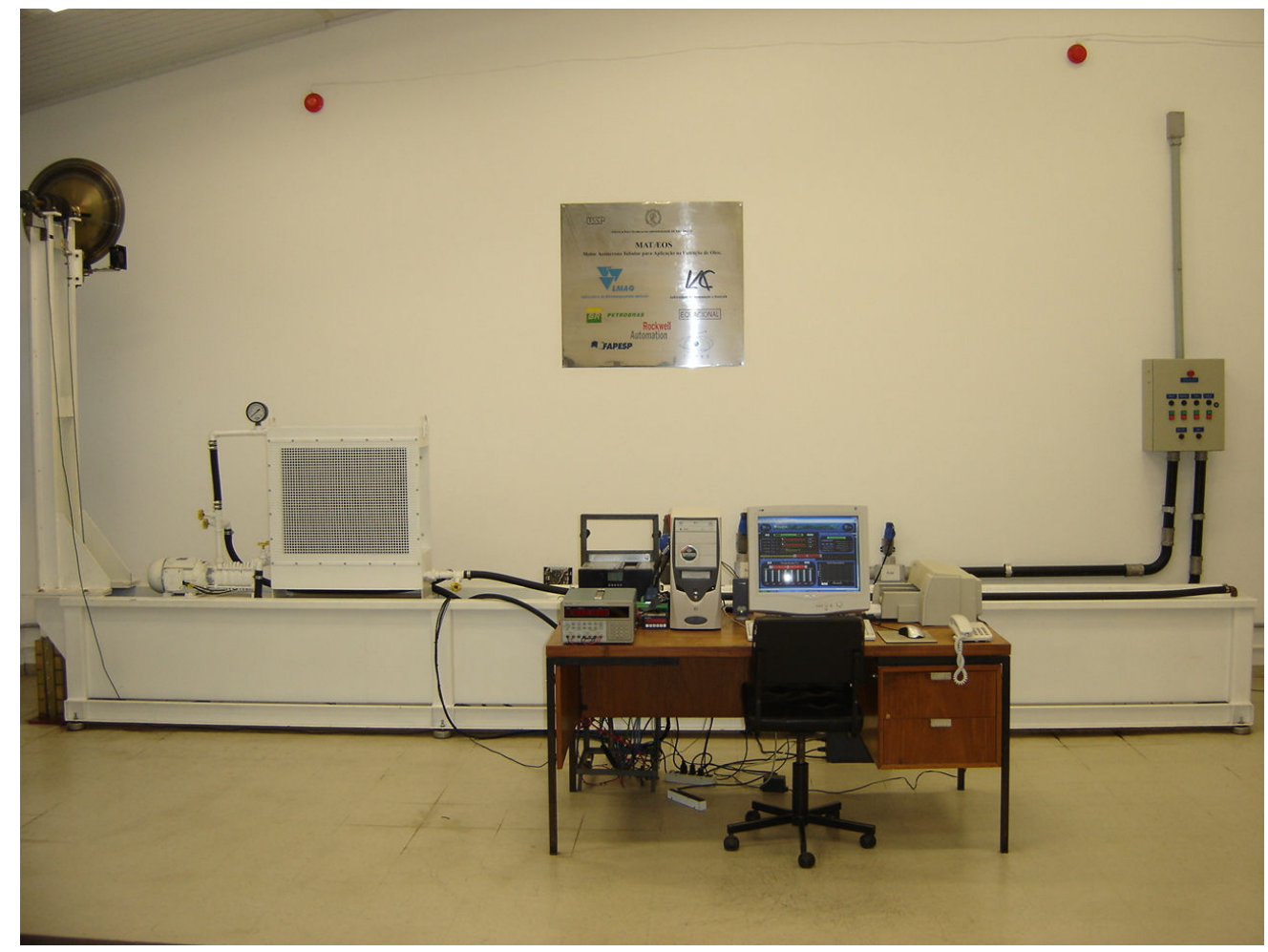

Fig. 2.2. Bancada de testes de motor linear tubular.

Para permitir a realização dos ensaios, a bancada foi construída com o motor operando na posição horizontal. No entanto, nas condições normais de operação no poço, o motor estará operando na posição vertical.

\subsubsection{Reservatório}

O reservatório ou tanque permite simular o ambiente físico no qual o motor se insere. O tanque tem um volume de cerca de 800 (oitocentos) litros. Nesta primeira etapa de ensaios, utiliza-se o óleo SAE90 como fluido. Posteriormente, será utilizada uma mistura de água e sal. A principal função do fluido é a de refrigerar o motor, 
simulando o ambiente térmico do poço. Na Fig. 2.3, observa-se o motor inserido no reservatório, sem e com a presença do fluido.

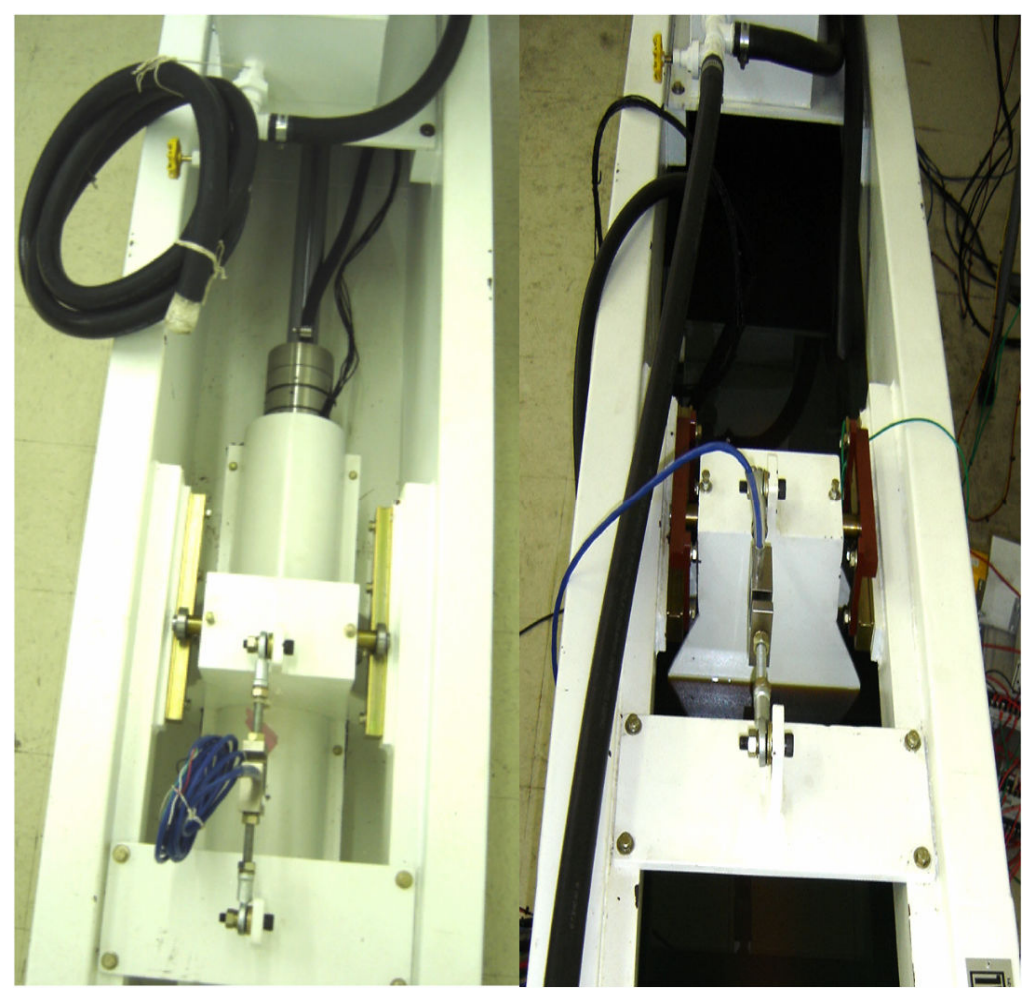

Fig. 2.3. Reservatório.

\subsubsection{Sistema de troca de calor}

O sistema de troca de calor instalado na bancada, visto na Fig. 2.4, é constituído por uma bomba, um ventilador, um radiador, além de tubulações que conduzem o fluido. O sistema realiza a circulação do fluido, estabelecendo uma vazão através do motor similar à que deverá ocorrer em condições normais de operação no poço. 


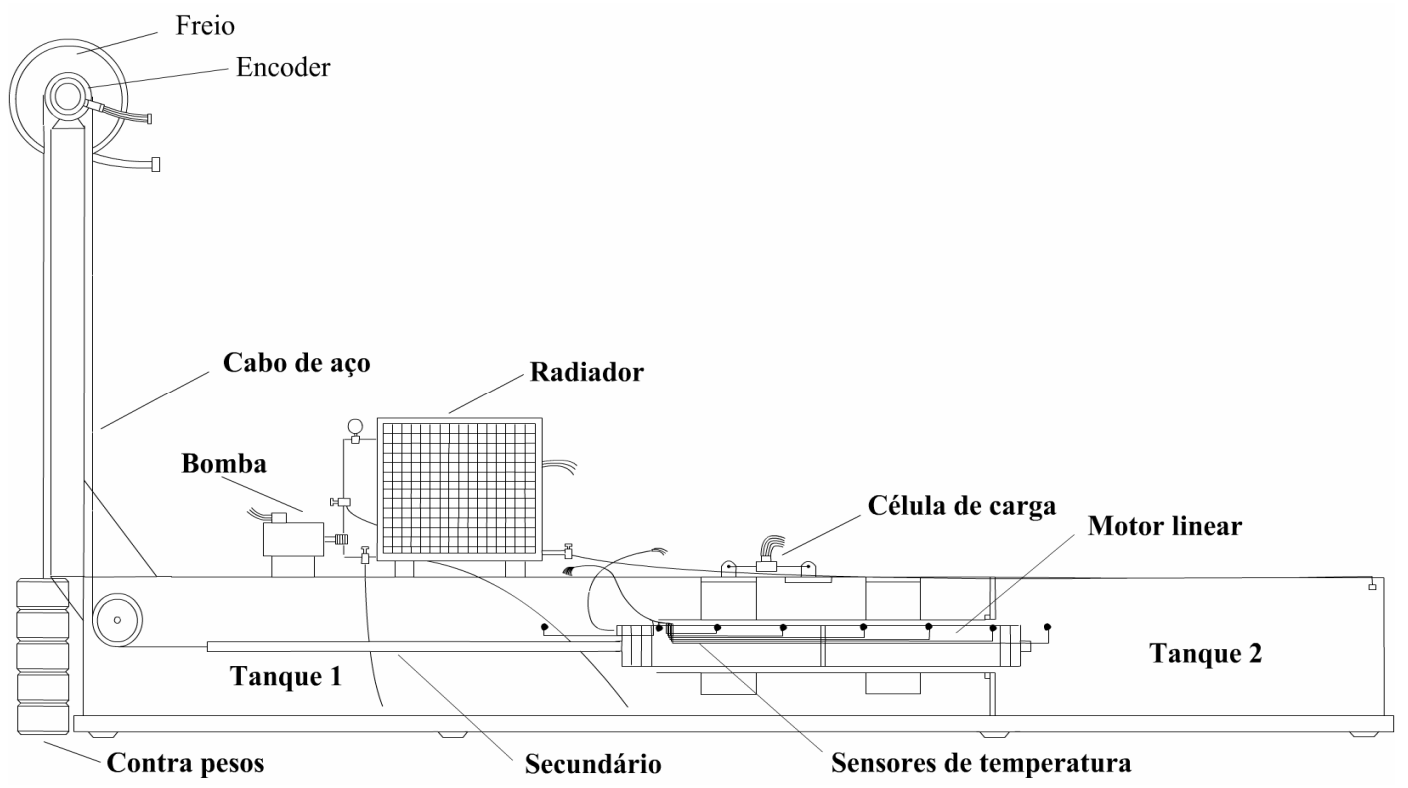

Fig. 2.4. Layout da bancada e seus dispositivos.

\subsubsection{Sistema de carga}

O sistema de carga (Fig. 2.4) é formado pelos contrapesos, o cabo de transmissão, a correia dentada, a roda dentada, o disco de frenagem, o freio, o acionador do freio e um suporte. Grande parte da carga no motor é aplicada pelo freio. O acionador do freio ajusta a carga através de um sinal provido pelo sistema de controle. O ajuste do sinal é realizado via "software". O freio possui um disco que sofre ação de frenagem por atrito.

Os contrapesos, além de realizar o efeito de carga, têm a tarefa de fazer o motor voltar à posição inicial do ciclo de bombeio.

O cabo de transmissão e a correia dentada transmitem a força desenvolvida pelo motor para o contrapeso. Também transmitem a carga do freio para a o motor por meio da roda dentada.

\subsubsection{Sistema eletroeletrônico}

Neste sistema, incluem-se o dispositivo de acionamento do motor, o inversor, os transdutores de posição, velocidade, força, potência ativa e reativa e de corrente; os sensores de temperatura (RTD's); os sinais de controle de freqüência e de carga; 
o computador com a placa de aquisição de dados ( $\mathrm{PCl}$ - 6221 e $\mathrm{PCl}$ - 4351) da "National Instruments" e o programa implementado em "LABVIEW".

Na Fig. 2.5, observa-se o diagrama funcional dos dispositivos utilizados na bancada.

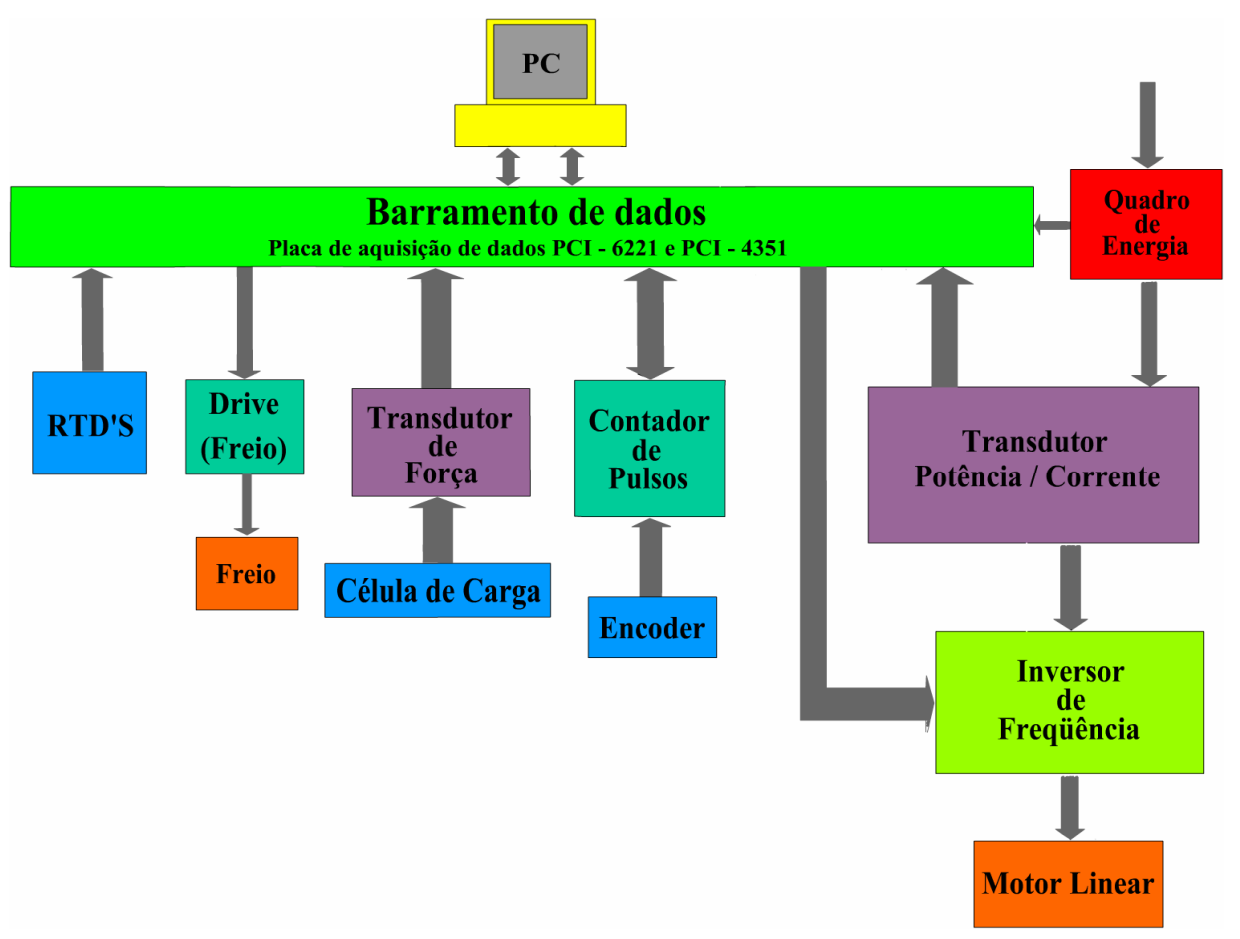

Fig. 2.5. Diagrama funcional dos dispositivos utilizados na bancada.

No diagrama acima o bloco de entrada chamado de quadro de energia, é composto pelo sistema de proteção que visa alimentar a bancada de testes como um todo, e proteger os dispositivos elétricos durante o funcionamento. Esta proteção é feita por relês térmicos, fusíveis, disjuntores e contatores.

Seguindo o diagrama, observa-se o bloco composto pelos transdutores de potência elétrica ativa e reativa e o transdutor de força, os quais têm a função de produzir sinais na faixa de $0-10 \mathrm{~V}$ proporcionais às grandezas medidas. Estes sinais são condicionados pela placa de aquisição de dados e monitorados instantaneamente pelo sistema computacional.

O próximo bloco representa o contador de pulsos. Este realiza contagem dos pulsos gerados pelo encoder incremental, fornecendo uma informação absoluta da posição do motor para o sistema de controle. 
O bloco drive executa o acionamento do freio sobre o sistema de carga. Este controle é feito por um sinal 0-10V proporcional ao carregamento desejado.

O bloco seguinte é o inversor de freqüência e pode ser parametrizado através de uma interface com um computador. O ajuste da freqüência de saída do inversor é feito através de um sinal 0-10V fornecido pelo sistema de controle.

Os sensores de temperatura (RTD'S) foram distribuídos da seguinte forma: seis ao longo da carcaça do motor (como pode ser visto na Fig. 2.4) e dois nos seus respectivos tanques. Estes sensores possuem características resistivas e são alimentados com fontes de corrente através da placa de aquisição de dados $(\mathrm{PCI}-$ 4351) de uso dedicado.

E por último, vêm a placa de aquisição de dados $\mathrm{PCl}$ - 6221, que executa todo o controle e parte do supervisório do sistema, e a placa $\mathrm{PCl}$ - 4351 que faz apenas a aquisição das temperaturas. Como também o programa computacional foi elaborado em "LABVIEW", estabeleceu-se assim a integração completa entre software e hardware. 


\section{Sistema de controle e supervisório do MAT/EOS}

Esta seção apresenta o programa computacional elaborado em "LABVIEW", através de uma linguagem de programação gráfica, descrevendo em detalhes todo $\mathrm{O}$ sistema de controle e supervisório da bancada.

\subsection{O programa computacional}

Nesta subseção apresenta-se o programa computacional dos sistemas de controle e supervisório da bancada de testes do MAT/EOS, implementado em "LABVIEW" (Fig. 3.1). A utilização do "LABVIEW" permite uma grande flexibilidade para o sistema de medição e controle. Nos tópicos seguintes são feitos comentários de cada parte do software, descrevendo as funções executadas pelo sistema de aquisição e manipulação de dados.

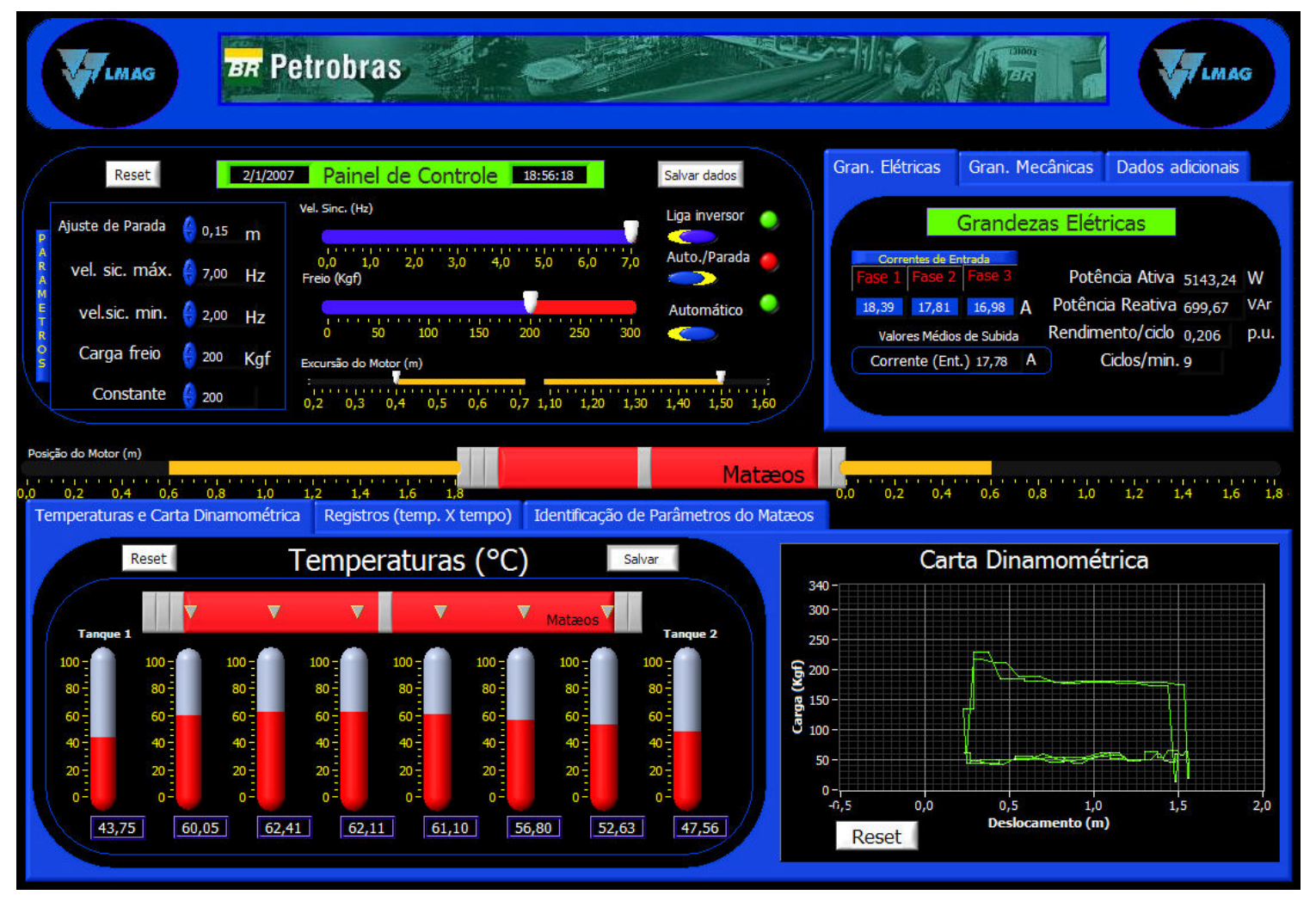

Fig. 3.1. Tela do sistema de controle e supervisório do MATÆOS. 


\subsubsection{O sistema de controle}

O sistema de controle implementado permite obter uma estimativa da posição do motor por meio das leituras dos encoders. A posição do motor ao longo do ciclo de movimento pode ser observada via software (vide Fig. 3.1, centro). Desta forma, como o acionamento do motor possui características intermitentes, optou-se por um controle de final de curso por "histerese", onde está fixada uma faixa de valores de posição (Fig. 3.2 ).

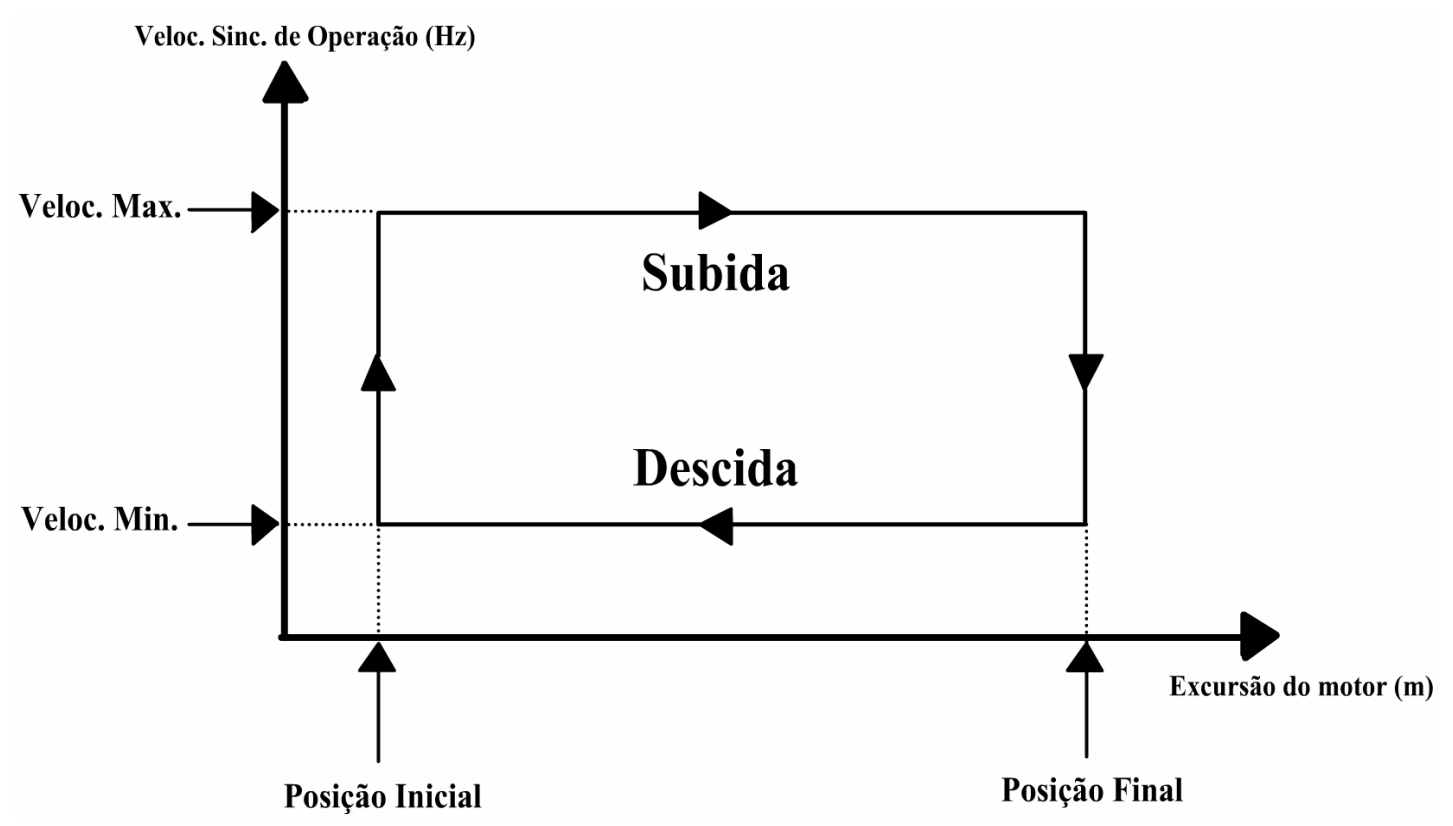

Fig. 3.2. Representação gráfica do ciclo de movimento por "histerese".

Para determinar a posição do motor e executar o ciclo de movimento (ou bombeamento) estabelece-se uma posição inicial e, fixando a freqüência síncrona máxima de operação do inversor junto com o sinal de carga, inicia-se o movimento de subida do secundário do motor. Chegando à posição final, retira-se o sinal de carga e fixa-se a freqüência síncrona mínima de operação. Desta forma, o secundário do motor inicia o movimento de descida, retornando à posição inicial. Atingida a posição inicial, o ciclo se reinicia.

A Fig. 3.3 mostra o painel de controle que realiza o controle do ciclo de movimento do motor. Existe uma grande flexibilidade no sistema de controle, podendo-se fixar excursões, parametrizar freqüência de operação (máxima e mínima) e ajustar cargas diferentes, submetendo o motor a escorregamentos distintos. Além 
disso, o sistema implementado exibe a data e horário atualizados em tempo real. O software desenvolvido permite também salvar todas as informações necessárias do ensaio, para futuras análises através do botão Salvar dados.

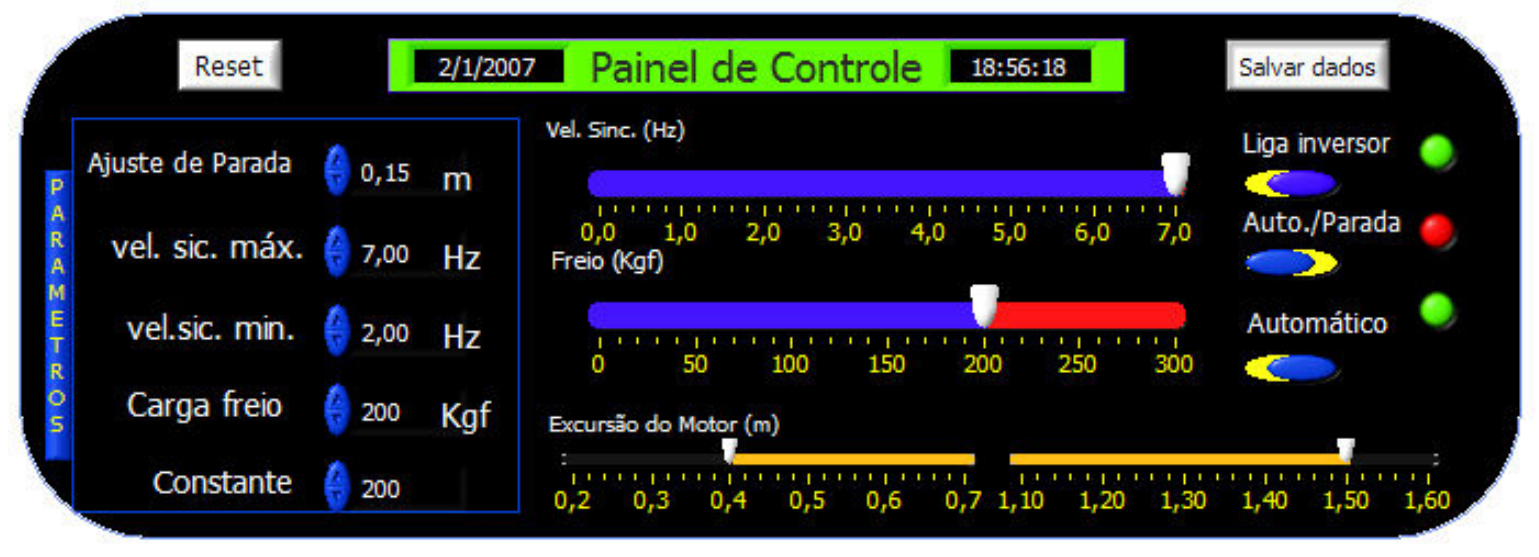

Fig. 3.3. Painel de controle do motor linear tubular.

\subsubsection{O sistema supervisório}

O sistema supervisório desenvolvido permite acompanhar o desempenho do motor ao longo dos ensaios. Nele é possível monitorar a temperatura em oito pontos distintos relacionados à carcaça do motor e ao fluido. As temperaturas também podem ser monitoradas em tempo real e salvas. A Fig. 3.4 mostra os símbolos dos termômetros virtuais e a Fig. 3.5, os registros dos mesmos ao longo do tempo.

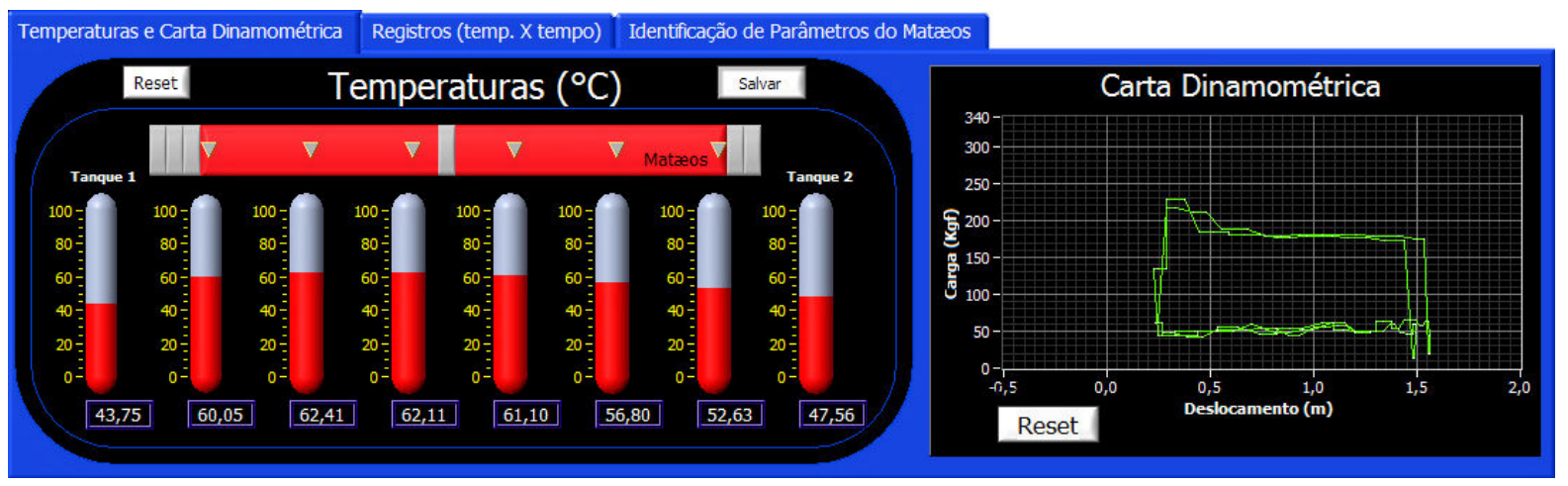

Fig. 3.4 Símbolos dos termômetros virtuais e carta dinamométrica. 


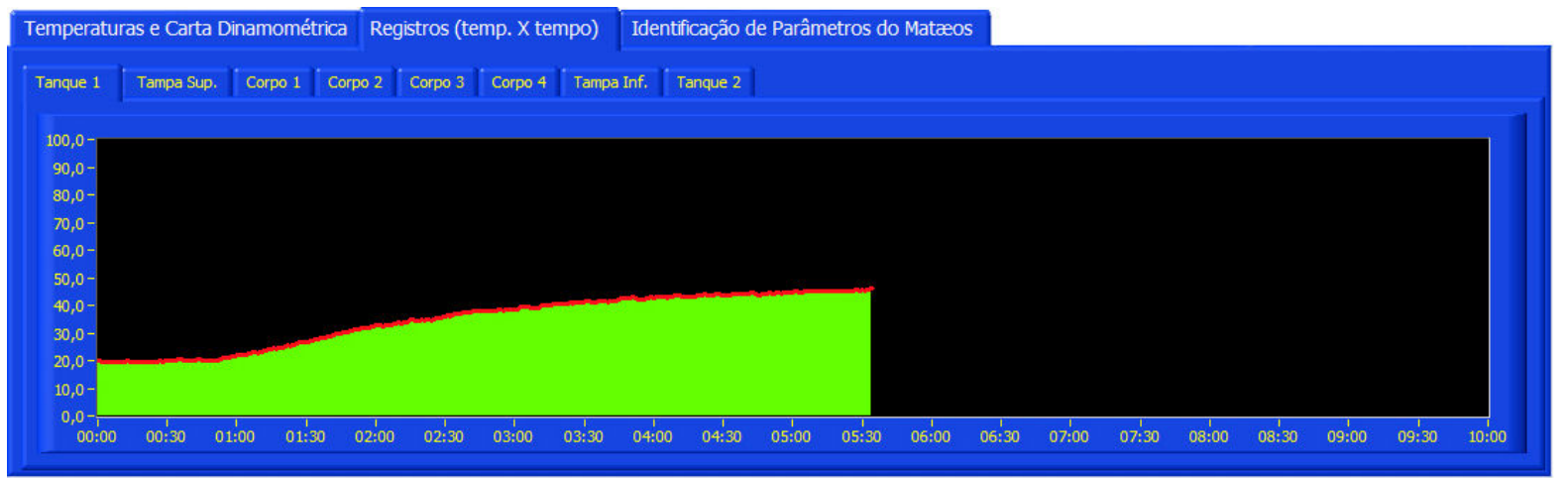

Fig. 3.5. Registro de uma das temperaturas monitoradas em tempo real (Tanque 1)

Outra informação também obtida é a carta dinamométrica, onde se representam graficamente os valores instantâneos da força e do deslocamento do motor. Este gráfico é de grande importância prática para a operação de sistemas reais de bombeamento de petróleo no campo. Na Fig. 3.4 à direita observa-se a carta dinamométrica em uma certa condição de operação.

O programa também possibilita a medição de algumas variáveis elétricas (Fig. 3.6), tais como: as correntes de fase de entrada, a potência ativa e reativa (grandezas estas medidas na entrada do inversor). O software também permite o cálculo dos valores médios das correntes de entrada durante a fase de subida, ou avanço do motor (calculados na metade do ciclo de movimento).

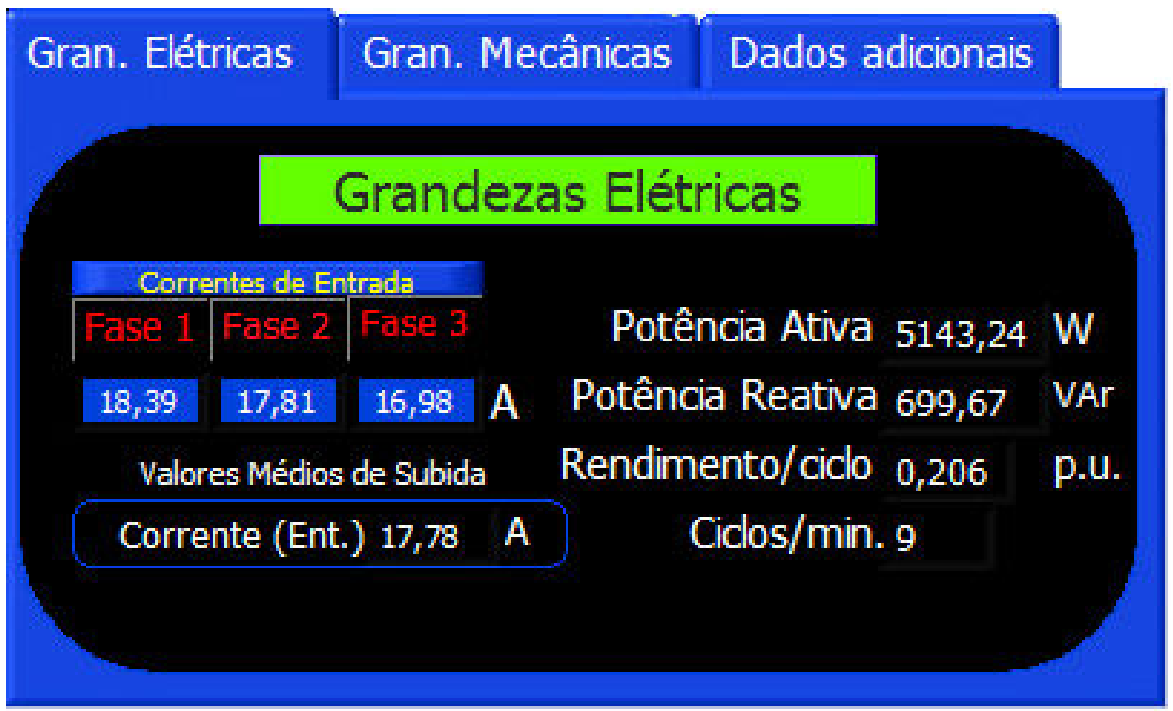

Fig. 3.6 Medidas das variáveis elétricas. 
Também são medidas variáveis mecânicas (Fig. 3.7), tais como: a força mecânica, a velocidade linear (sendo que as duas últimas permitem calcular a potência mecânica instantânea absorvida pela carga), a excursão e o escorregamento do motor. Outras variáveis são calculadas como valores médios durante a subida: a velocidade linear, a força mecânica e o escorregamento.

Define-se o rendimento como sendo a relação entre a potência média mecânica de saída e a potência média elétrica de entrada. Seu cálculo é efetuado desde a posição inicial (início do ciclo) até a posição final (ponto de desligamento da carga).

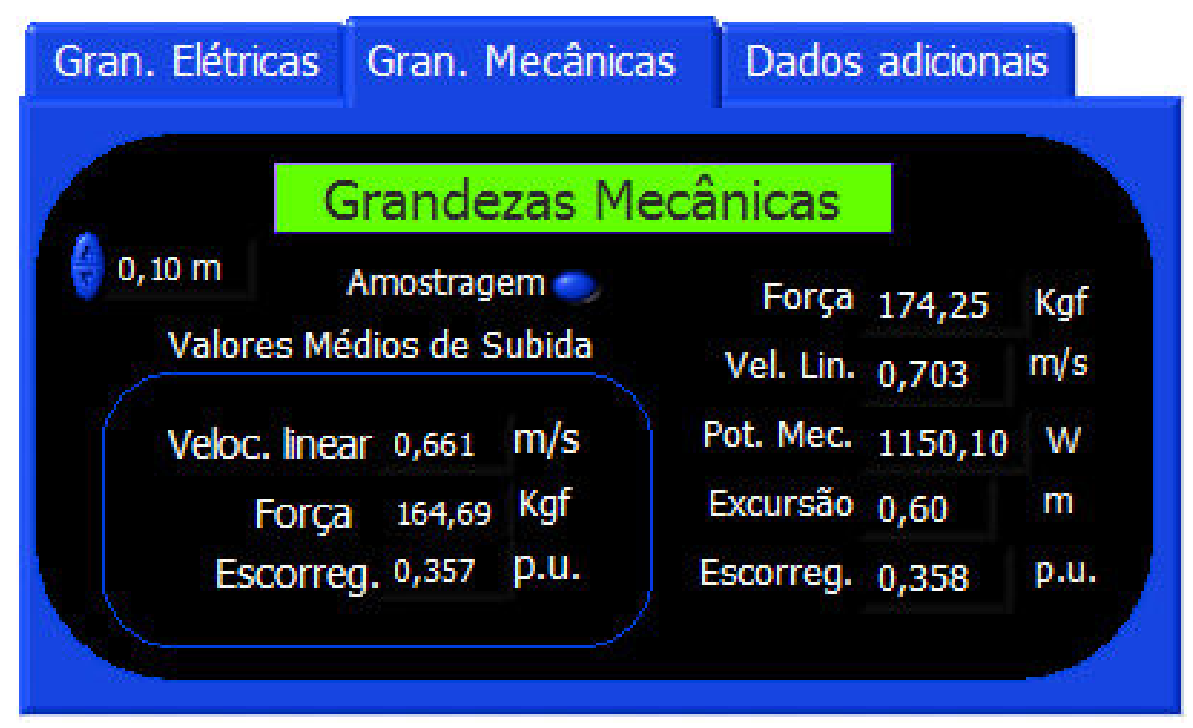

Fig. 3.7. Medidas das variáveis mecânicas.

Outras variáveis médias que também podem ser calculadas são: potência de entrada $\left(P_{\text {in }}\right)$, potência de saída $\left(P_{\text {out }}\right)$ e corrente do motor $\left(I_{s}\right)$. Podem ser observadas na Fig. 3.8. Todas essas variáveis calculadas são variáveis por módulo do motor e por fase (Ø). 


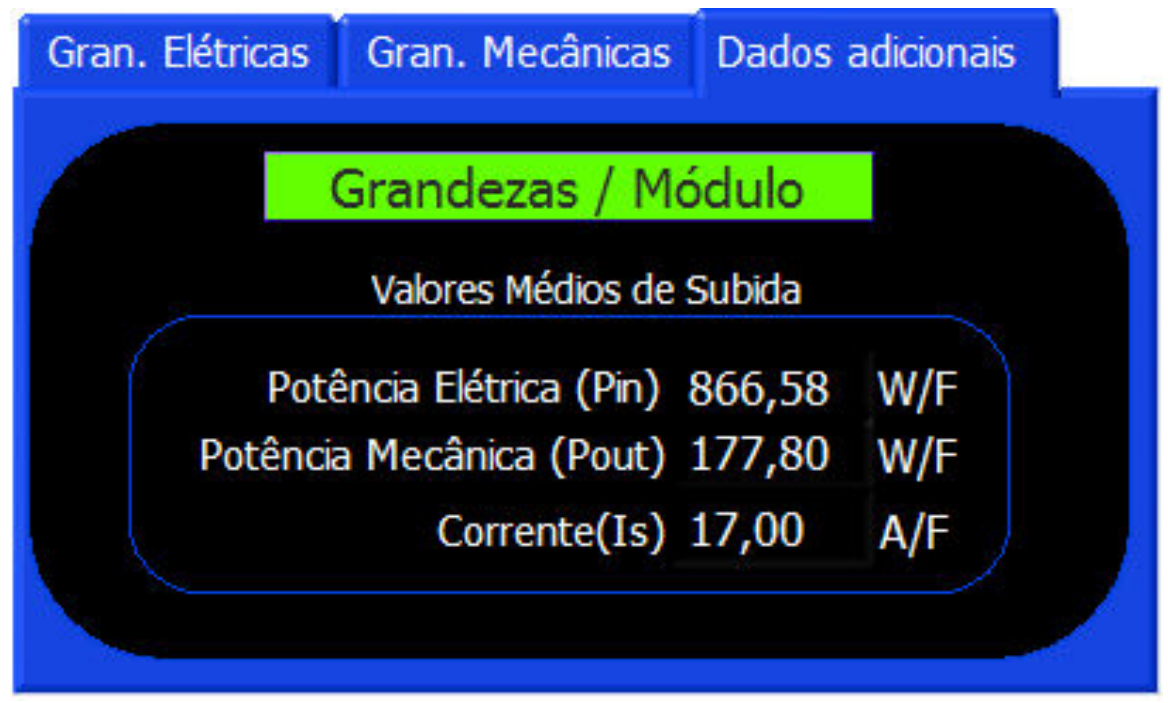

Fig. 3.8. Medidas das variáveis por módulo do motor.

Outra facilidade que o programa desenvolvido oferece é gerar gráficos no formato "Excel", tendo assim, boa flexibilidade na apresentação dos resultados, vide anexo B.

\subsection{A linguagem de programação gráfica}

Nesta seção é apresentada a linguagem de programação gráfica do sistema de controle, supervisório e aquisição de dados do MATÆEOS. São utilizados blocos chamados de Vl's "Virtual Instruments" com os quais estrutura-se a linguagem de programação (Mattnawrocki, 2002). São expostas as estruturas e a formulação utilizada no desenvolvimento do programa computacional descrito anteriormente.

\subsubsection{Estrutura de programação do sistema de controle}

Inicia-se a implementação do sistema de controle criando os canais de comunicação do hardware, através da placa de aquisição de dados $\mathrm{PCl}-6221$ utilizada no controle da máquina. 


\subsubsection{Partida do inversor}

A Fig. 3.9, mostra o canal de saída digital para o liga/desliga do inversor (Start/Forward).

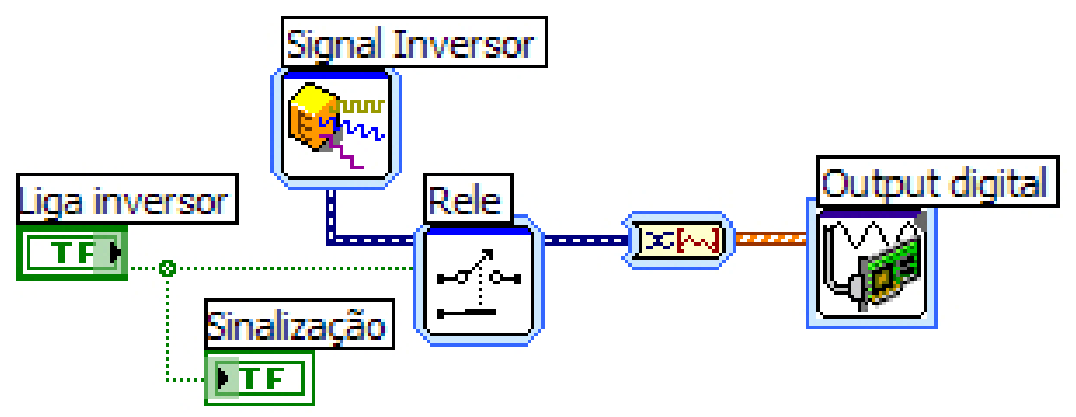

Fig. 3.9. Estrutura que liga o inversor.

A estrutura acima é implementada com o bloco VI DAQ Assistant definido como saída digital (output digital). O sinal de comando do inversor é enviado pelo software através do botão Liga Inversor ("1" ou "0"). Esse sinal é convertido aos níveis de tensão digital " 5 " V ou "0" V reconhecidos pela placa de aquisição de dados, através do bloco Sinal Inversor (gerador de sinais) e o bloco rele. O ligamento do inversor é realizado com um sinal em nível baixo "0" e o desligamento em nível alto "1".

\subsubsection{Medição da posição do secundário}

A estrutura da Fig. 3.10 executa a leitura da posição do motor ao longo do movimento.

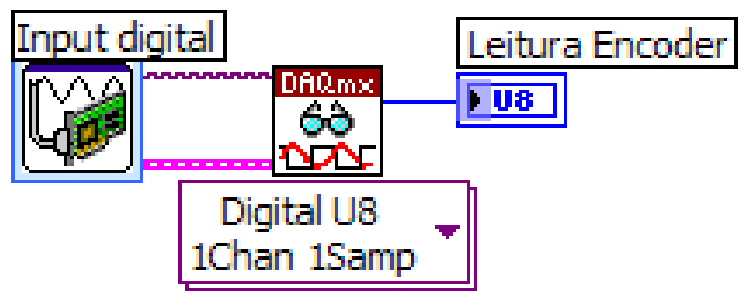

Fig. 3.10. Estrutura de leitura do encoder. 
Esta leitura é feita através de um encoder óptico do tipo incremental. Este encoder envia dois sinais em quadratura $(A$ e $B)$ na forma de pulsos para o contador de pulsos. Este contador de pulsos executa a contagem dos pulsos gerados pelo encoder incremental, obtendo uma informação absoluta da posição do motor no formato de numeração binária de tamanho 8 bits. Em seguida, esta informação é enviada para a placa de aquisição de dados, através do bloco VI DAQ Assistant configurado como entrada digital (input digital). Esta informação binária é lida pelo software através do canal virtual $D A Q m x$ Read e depois apresentada na caixa leitura encoder no formato de numeração decimal. A informação contida nesta caixa é usada como o sinal de realimentação para o sistema de controle, para a monitoração da excursão do motor e a construção da carta dinamométrica para o sistema supervisório.

\subsubsection{Acionamentos do motor e freio}

A próxima estrutura (Fig. 3.11) executa os acionamentos da velocidade síncrona do motor e do freio (carga do motor), através do bloco VI DAQ Assistant configurado como saída analógica para cada canal (output analógico 1 e output analógico 2) variando de 0 a $10 \mathrm{~V}$. Os acionamentos são gerados através do bloco (gerador de sinais) Sinal Vel. Sinc. e Sinal Freio. Cada gerador é parametrizado de forma diferente de acordo com os níveis de tensão exigidos por cada canal. Enquanto o sinal de velocidade síncrona é enviado para o inversor, o sinal de freio do motor é enviado ao Drive de acionamento do freio.

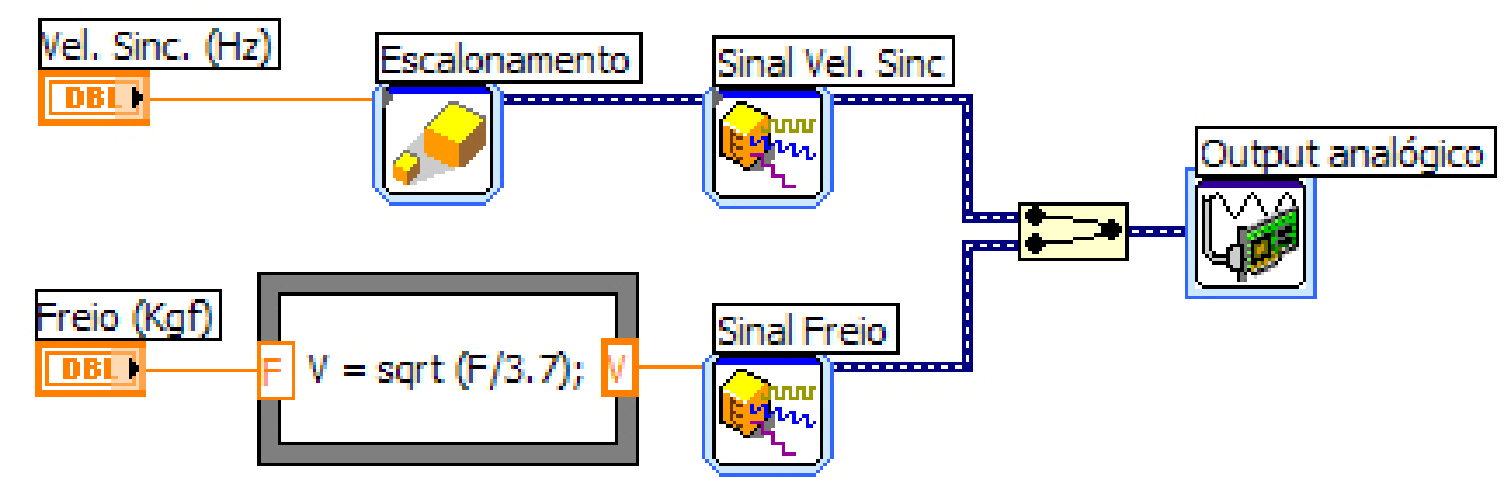

Fig. 3.11. Estrutura que aciona a velocidade do motor e freio (carga do motor). 
O cálculo da velocidade síncrona do motor é executado em função da rampa $\mathrm{V} / \mathrm{Hz}$ do hardware de acionamento do inversor vista na Fig. 3.12.

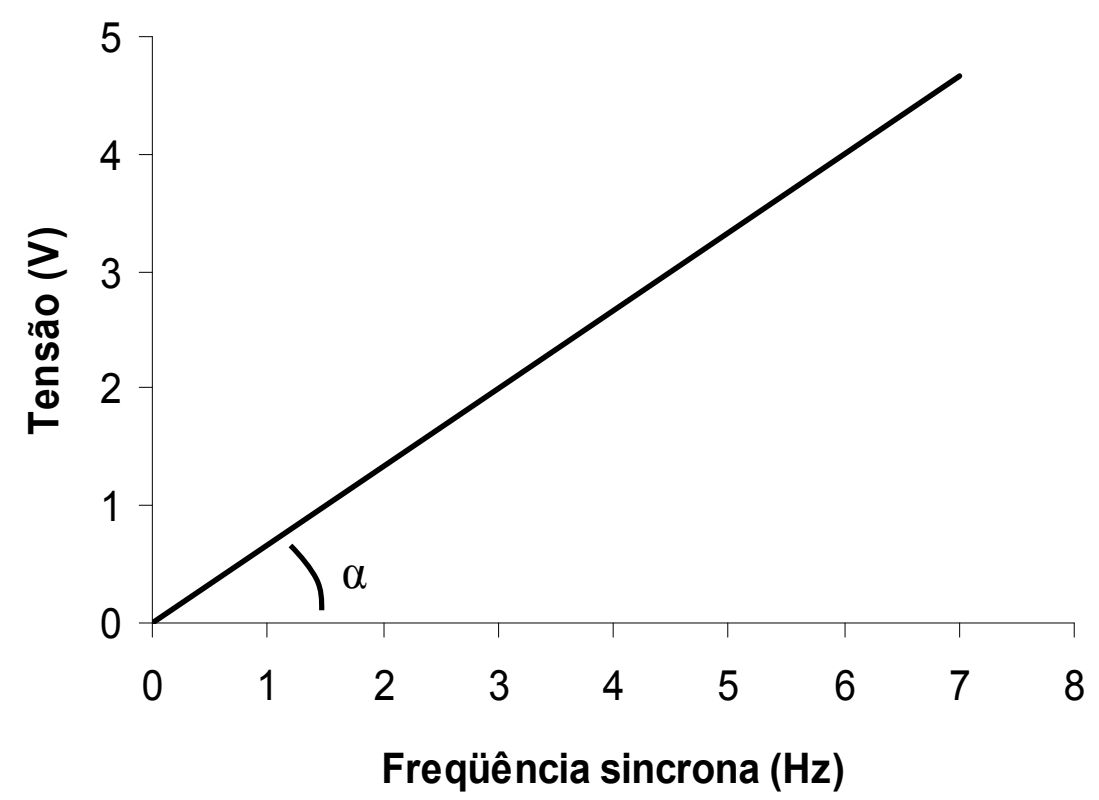

Fig. 3.12. Gráfico rampa $\mathbf{V} / \mathbf{H z}$ do hardware de acionamento do inversor.

O coeficiente angular da reta $\alpha$ é carregado no bloco Escalonamento e calculado pela expressão abaixo:

$$
F S=\alpha \cdot V_{V S}
$$

onde,

- FS é a freqüência síncrona (freqüência síncrona de controle de velocidade do motor). $F S$ varia de 0 à $7 \mathrm{~Hz}$;

- $V_{V S}$ é a tensão velocidade síncrona (tensão utilizada na entrada do canal do hardware do inversor para o controle da velocidade do motor). $V_{V S}$ varia de 0 à $4,6667 \mathrm{~V}$;

- $\alpha$ é o coeficiente angular da reta da relação $\mathrm{V} / \mathrm{Hz}$.

Resolvendo a equação (3.1) para $\alpha$, e definindo $F S=7$ e $V_{V S}=4,6667$ encontra-se $\alpha=0,667$, que é carregado no bloco Escalonamento. Com isso, obtémse a relação V/Hz e, através da caixa de entrada Vel. Sinc. (Fig. 3.11), configura-se 
a freqüência de operação do motor através de uma interface homem máquina. Essa interface pode ser vista na Fig. 3.1 no Painel de controle, na caixa Parâmetros. No sistema de controle são utilizadas duas freqüências síncronas de operação do motor: a freqüência de operação síncrona máxima e a mínima.

No sistema de freio, o atuador usado para o acionamento da carga é do tipo eletromecânico. Sua força desenvolvida é calculada pela expressão abaixo:

$$
F_{\text {FREIO }}=K_{F} \cdot V_{F}^{2}
$$

onde,

- $F_{F R E I O}$ é a força do freio (força desenvolvida pelo freio e aplicada diretamente no secundário do motor). $F_{F R E I O}$ varia de 0 a $300 \mathrm{Kgf}$;

- $V_{F}$ é a tensão do freio (tensão aplicada no controle do hardware do drive do acionamento do freio). $V_{F}$ varia de 0 a $9 \mathrm{~V}$;

- $K_{F}$ é a constante de proporcionalidade do freio.

Resolvendo a equação (3.2) para $K_{F}$, e definindo $F_{F R E I O}=300$ e $V_{F}=9$ encontra-se $K_{F}=3,7$. Com isso, implementa-se a equação acima no bloco formula visto na Fig. 3.11 e, através da caixa de entrada Freio, configura-se a carga do freio, através de uma interface homem-máquina. Essa interface também pode ser vista na Fig. 3.1 no Painel de controle, na caixa Parâmetros. No sistema de controle é usado o freio como carga imposta ao motor, permitindo o levantamento das características do motor.

\subsubsection{Sistema de controle}

A estrutura da Fig. 3.13 executa parte do sistema de controle do MAT/EOS. 


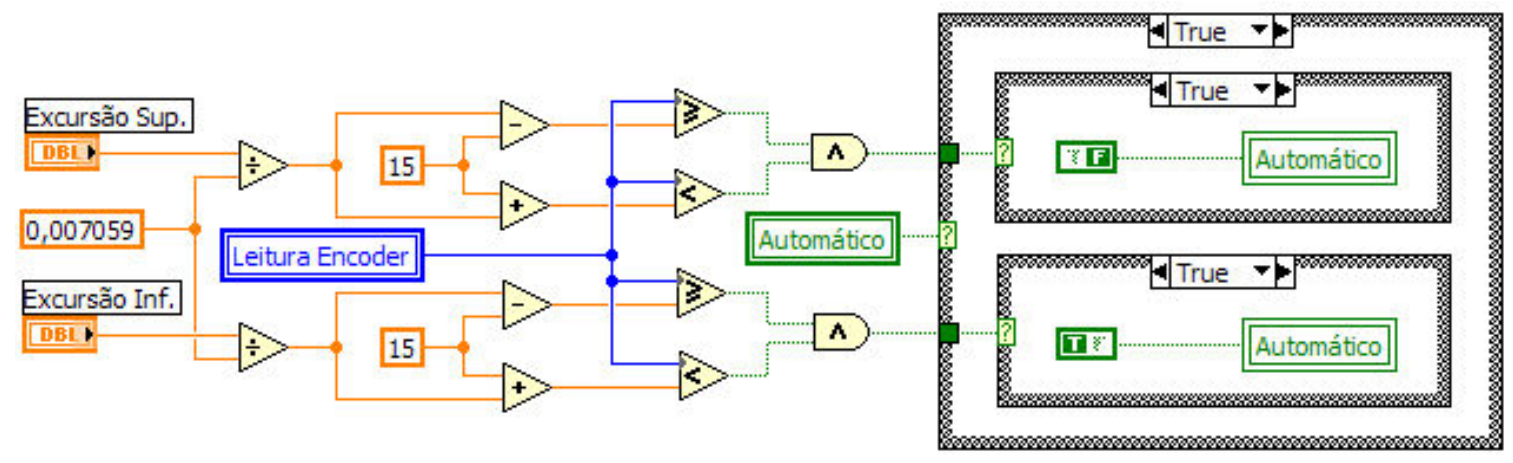

Fig. 3.13. Parte da estrutura do sistema de controle.

Como descrito na seção 3.1.1, o acionamento do motor tem características intermitentes, optando-se por um controle de final de curso por "Histerese", onde se fixa uma faixa de valores de posição. Essa faixa de valores é fixada por duas referências, uma superior e a outra inferior, através das caixas de entrada Excursão Sup. e Excursão Inf. vista na figura acima, obtendo assim, uma interface homemmáquina. Essa interface pode ser vista na Fig. 3.1 no Painel de controle.

Enquanto o valor da excursão superior varia de $E X S=1,1$ a $1,6 \mathrm{~m}$, o valor da excursão inferior varia de $E X I=0,2$ a 0,7 m. A informação real da excursão do motor pode ser vista na carta dinamométrica (eixo X). Em seguida, os limites das excursões (em metros) são convertidos nos padrões de leitura do encoder (na base decimal) usando-se a expressão:

$$
E X_{d}=\frac{E X_{m}}{K_{E}}
$$

onde,

- $E X_{d}$ é a excursão do motor (excursão do motor na base decimal). $E X_{d}$ (inferior) varia de 28 à $99 \mathrm{~m}$ e $E X_{d}$ (superior) varia de 156 a $226 \mathrm{~m}$;

- $E X_{m}$ é a excursão do motor (excursão do motor em metros). $E X_{m}$ (inferior) varia de 0,2 à $0,7 \mathrm{~m}$ e $E X_{m}$ (superior) varia de 1,1 a 1,6 m;

- $K_{E}$ é a constante de proporcionalidade do encoder.

Resolvendo a equação (3.3) para $K_{E}$, e definindo $E X_{m}=1,6$ e $E X_{d}=226$ encontra-se $K_{E}=0,007059$. Com isso, a equação (3.3) é implementada pela função 
"divide" carregando o valor da constante $K_{E}$. Após isso, essas duas referências (set points) são comparadas com a informação lida do encoder (sinal de realimentação) e enviadas ao sistema de controle, o qual comanda o acionamento dos dispositivos atuadores (motor e freio).

A estrutura de decisão que executa o controle é implementada por blocos Case, visto na Fig. 3.13 à direta. Esta estrutura implementa o sistema de controle por Histerese descrito na seção 3.1.1, o qual recebe as condições através de duas funções booleanas executadas pelo bloco And. As equações com as funções podem ser vistas abaixo:

$$
S_{S}=A_{S} \cdot B_{S} \quad \text { e } \quad S_{I}=A_{I} \cdot B_{I}
$$

sendo,

$$
\begin{aligned}
& A_{S}=L E \geq\left(E X S_{d}-15\right) \\
& B_{S}=L E<\left(E X S_{d}+15\right) \\
& A_{I}=L E \geq\left(E X I_{d}-15\right) \\
& B_{I}=L E<\left(E X I_{d}+15\right)
\end{aligned}
$$

onde,

- $S_{S}$ é a saída lógica superior para o controle (informação enviada ao bloco Case correspondente a parte superior do sistema de controle);

- $S_{I}$ é a saída lógica inferior para o controle (informação enviada ao bloco Case correspondente à parte inferior do sistema de controle);

- $E X S_{d}$ é a excursão superior do motor;

- $E X I_{d}$ é a excursão inferior do motor;

- $L E$ é a leitura do encoder.

Completando o sistema de controle descrito anteriormente, utiliza-se de uma outra estrutura auxiliar (Fig. 3.14). 


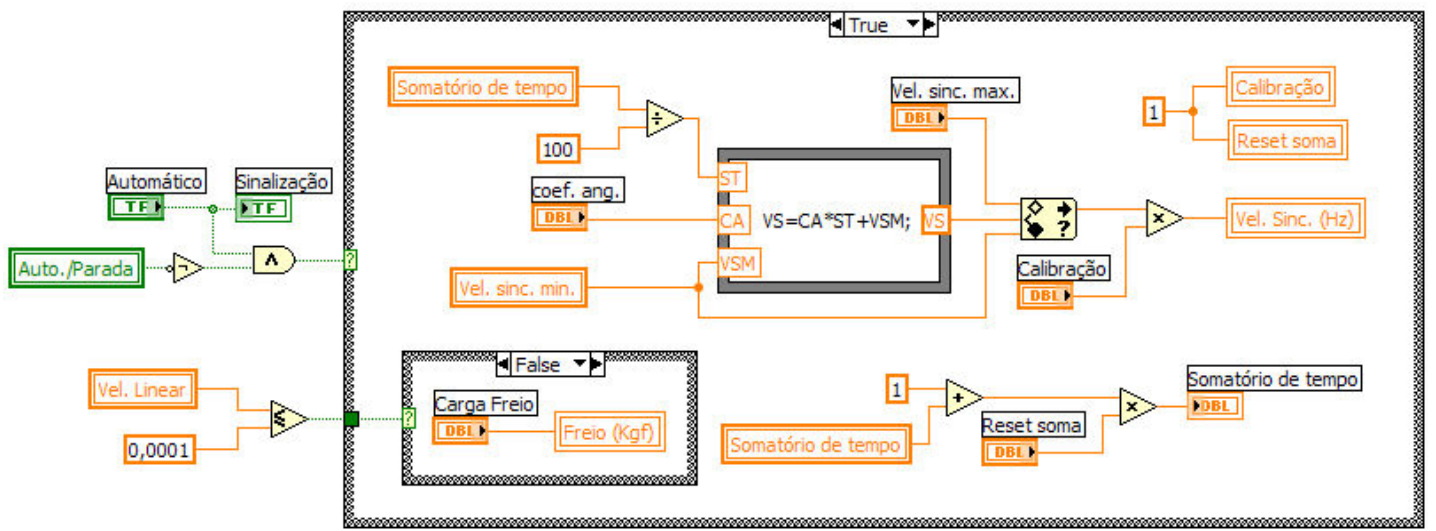

Fig. 3.14. Estrutura complementar do sistema de controle.

Esta estrutura atua em conjunto com a estrutura da Fig. 3.13. Nesta estrutura também utiliza-se o bloco Case para acionar os dispositivos atuadores (motor e freio). Esses dois acionamentos são realizados através de duas variáveis de alocação: as variáveis Vel. Sinc. e Freio. Estas duas variáveis estabelecem a comunicação com as variáveis de entrada Vel. Sinc e Freio da Fig. 3.11.

O acionamento do motor está condicionado através de uma rampa de velocidade síncrona VS (Fig. 3.15) onde, VS varia desde a velocidade síncrona mínima $V S_{m}$ até a velocidade síncrona máxima $V S_{M}$.

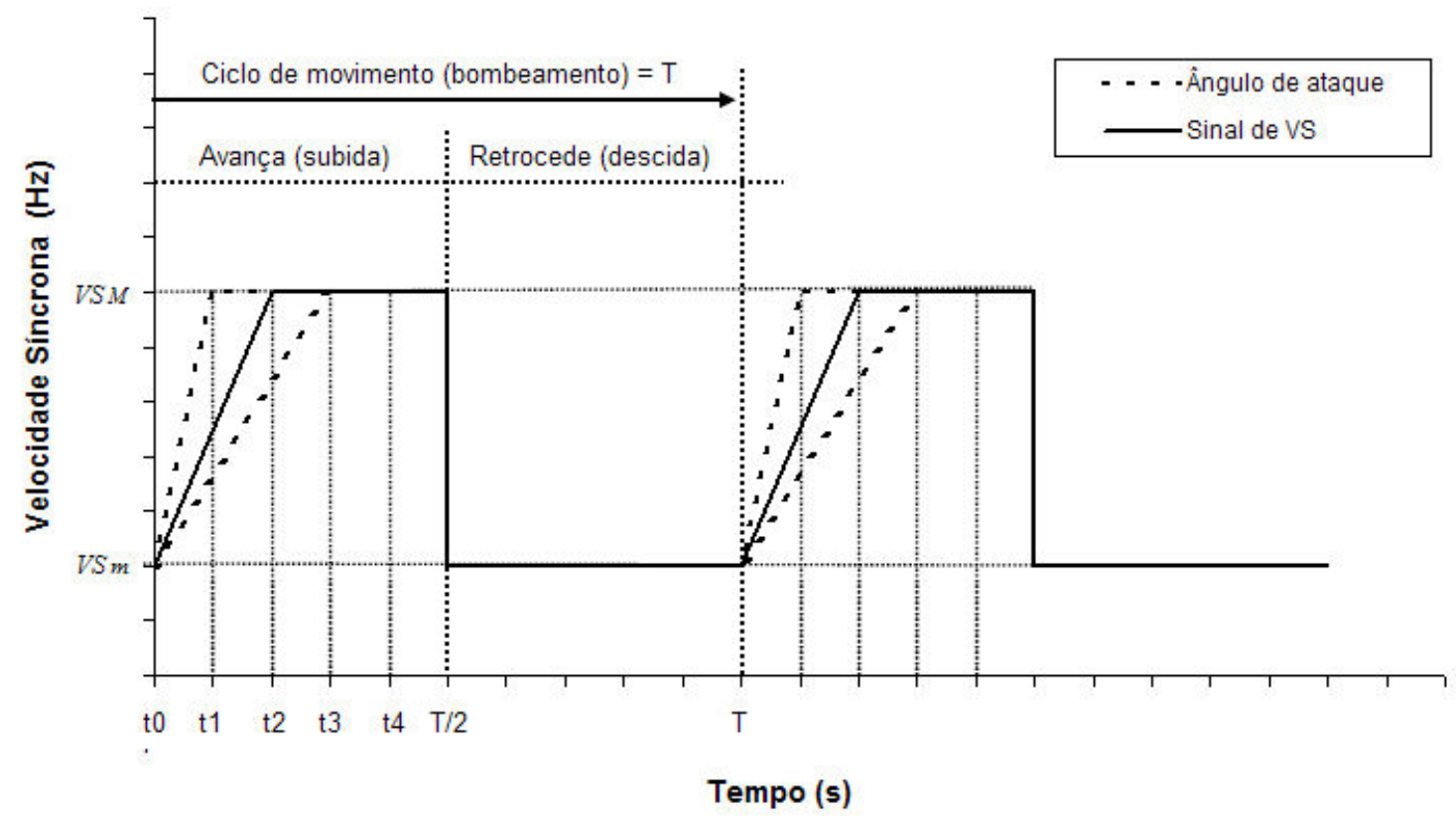

Fig. 3.15 Gráfico do sinal da velocidade síncrona. 
O gráfico acima representa o sinal da velocidade sincrona de acionamento do motor. Observa-se que no movimeto de subida é aplicada uma rampa de velocidade. Esta rampa evita solavancos causados no momento da inversão do movimento de descida para subida. A implementação da rampa foi realizada pelo bloco Fórmula, vide Fig. 3.14.

O ajuste da inclinação da rampa é feito pela caixa de entrada Coef. Ang., vide Fig. 3.14, através de uma interface homem-máquina. Essa interface também pode ser vista na Fig. 3.1 no Painel de controle na caixa Parâmetros.

Existe uma outra condição estabelecida pelo sistema de controle para que o sistema funcione corretamente. Essa condição é estabelecida durante a inversão do movimento para subida ou descida. Essa estrutura é implementada dentro da estrutura da Fig. 3.14. E pode ser vista com maiores detalhes nas Figs. 3.16 e 3.17, respectivamente.

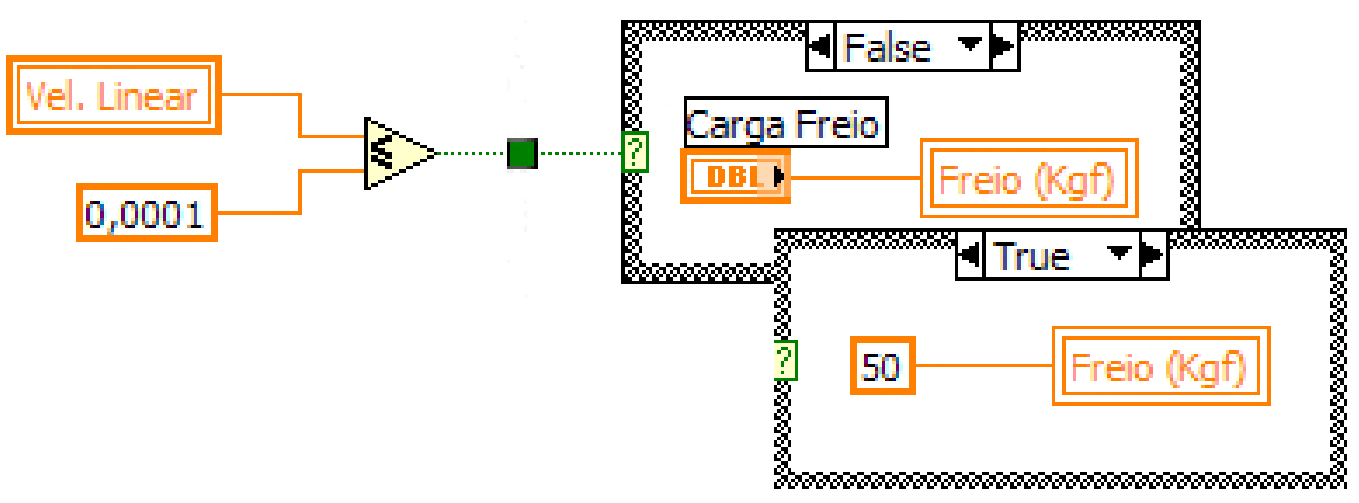

Fig. 3.16. Estrutura para evitar paradas durante a inversão do movimento para subida.

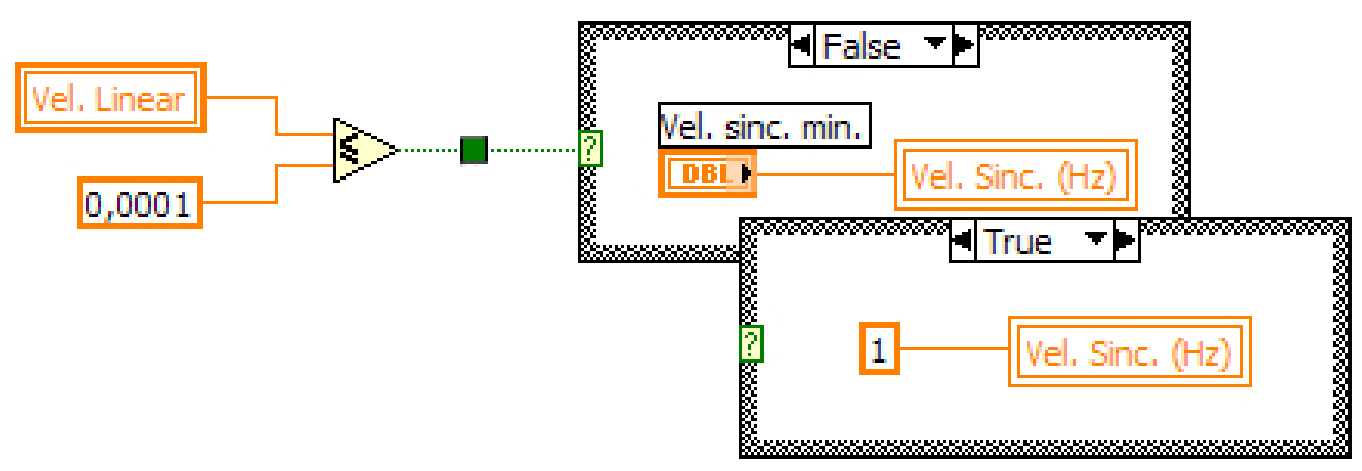

Fig. 3.17. Estrutura para evitar paradas durante a inversão do movimento para descida. 
Essa estrutura funciona da seguinte maneira: a inversão do movimento acontece sempre nos finais de curso do motor. É nos finais de curso que acontecem as paradas do motor. Essas paradas são ocasionadas devido às características do motor, que sofrem mudanças durante o ensaio em função da temperatura da mesma.

Para evitar essas paradas utilizam-se as estruturas das Figs. 3.16 e 3.17, sendo que uma atua no sistema do freio (parada que ocorre na inversão do movimento para subida devido ao freio) e a outra atua na velocidade síncrona da máquina (parada que ocorre na inversão do movimento para descida devido à velocidade síncrona).

Observe que, quando o motor funciona corretamente, sem paradas, o bloco False das estruturas atuam, não mudando as condições de operação do sistema. Enquanto que, se houver alguma parada, o bloco True das estruturas atua impedindo que o sistema pare. Essas estruturas estão condicionadas à variável de medida de alocação Vel. Linear. Essa variável informa ao sistema de controle se houve ou não parada.

Tomando-se como exemplo de que houve uma parada na inversão do movimento para subida (Fig. 3.16), a informação contida em Vel. Linear assume o valor "0" (zero). Com isso, o bloco True da estrutura atuará no sistema de freio, destravando-o. O mesmo ocorrerá se houver uma parada na inversão do movimento para descida (Fig. 3.17).

E por fim, toda a estrutura é condicionada ao comando da caixa de entrada Automático e à variável de alocação Auto./Parada através de uma lógica booleana, vide Fig. 3.14. A caixa de entrada Automático é comandada por uma interface homem-máquina. Essa interface pode ser vista na Fig. 3.1, no botão Automático do Painel de controle.

A estrutura que executa a parada do sistema pode ser vista na Fig. 3.18. 


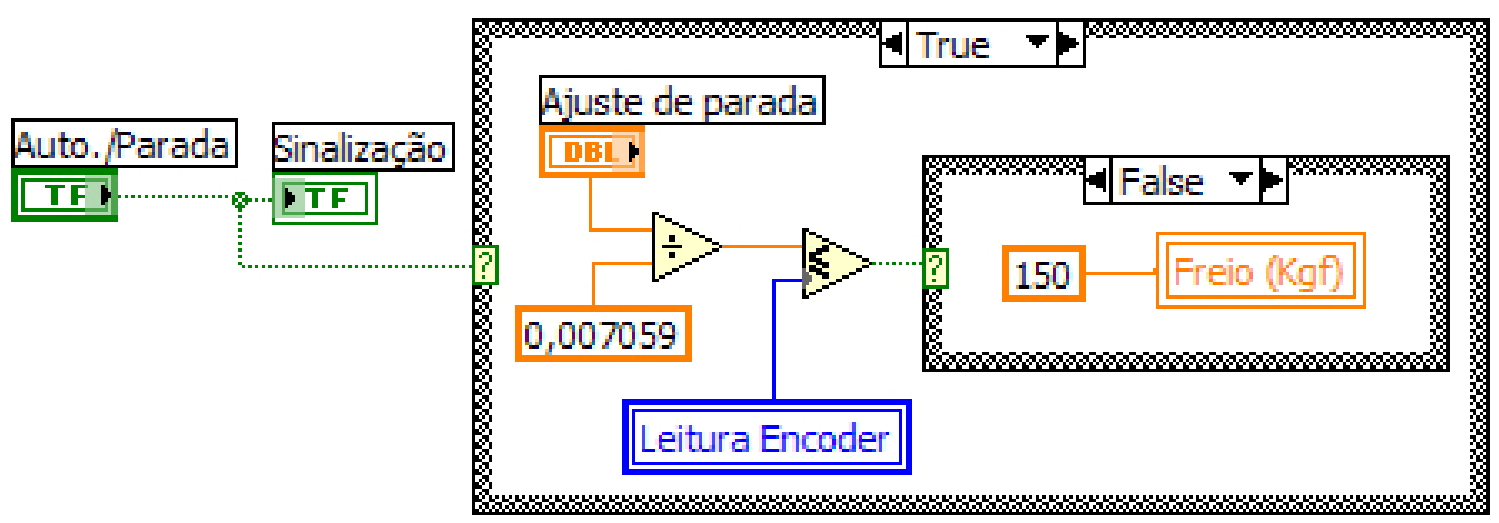

Fig. 3.18. Estrutura de parada da operação

A implementação desta estrutura é condicionada novamente por blocos Case, os quais atuam na parada definitiva do sistema em qualquer condição de operação. A parada do sistema é executada pela caixa de entrada Auto./Parada, através de uma interface homem-máquina. Essa interface pode ser vista na Fig. 3.1, no Painel de controle, no botão Auto./Parada.

Atuando no botão Auto./Parada, inicia-se a parada do sistema através de dois blocos Case, um na condição False (Fig. 3.14) e o outro na condição True (Fig. 3.18) sob a leitura do encoder $L E$, até atingir a posição inicial "0" (zero). Atingida a posição inicial, o sistema pára em definitivo.

A seguir, através do exemplo ilustrativo da Fig. 3.19, é detalhado o funcionamento do sistema de controle do MATÆES, descrito anteriormente. Essa demonstração é feita passo a passo, exibindo a excursão do motor ao longo do movimento. Esse movimento é descrito pelo ciclo de Histerese implementado pela estrutura à direita na Fig. 3.13 e visto em detalhes na Fig. 3.20. A Tabela 3.1 exemplifica de forma didática, passo a passo, o funcionamento do sistema de controle, do início ao término. 


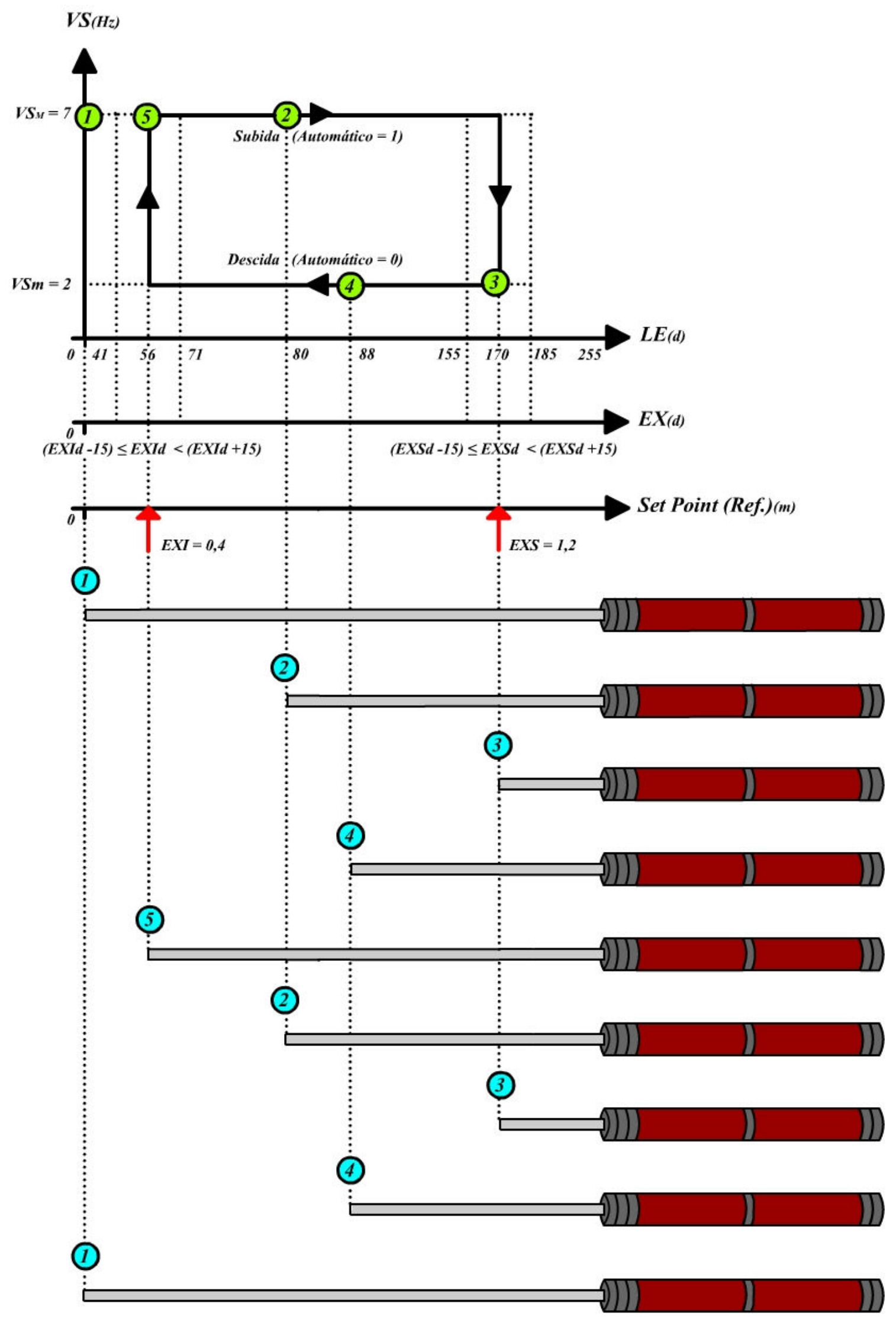

Fig. 3.19. Exemplo ilustrativo da operação do motor. 
Tabela 3.1. Operacionalização do sistema de controle.

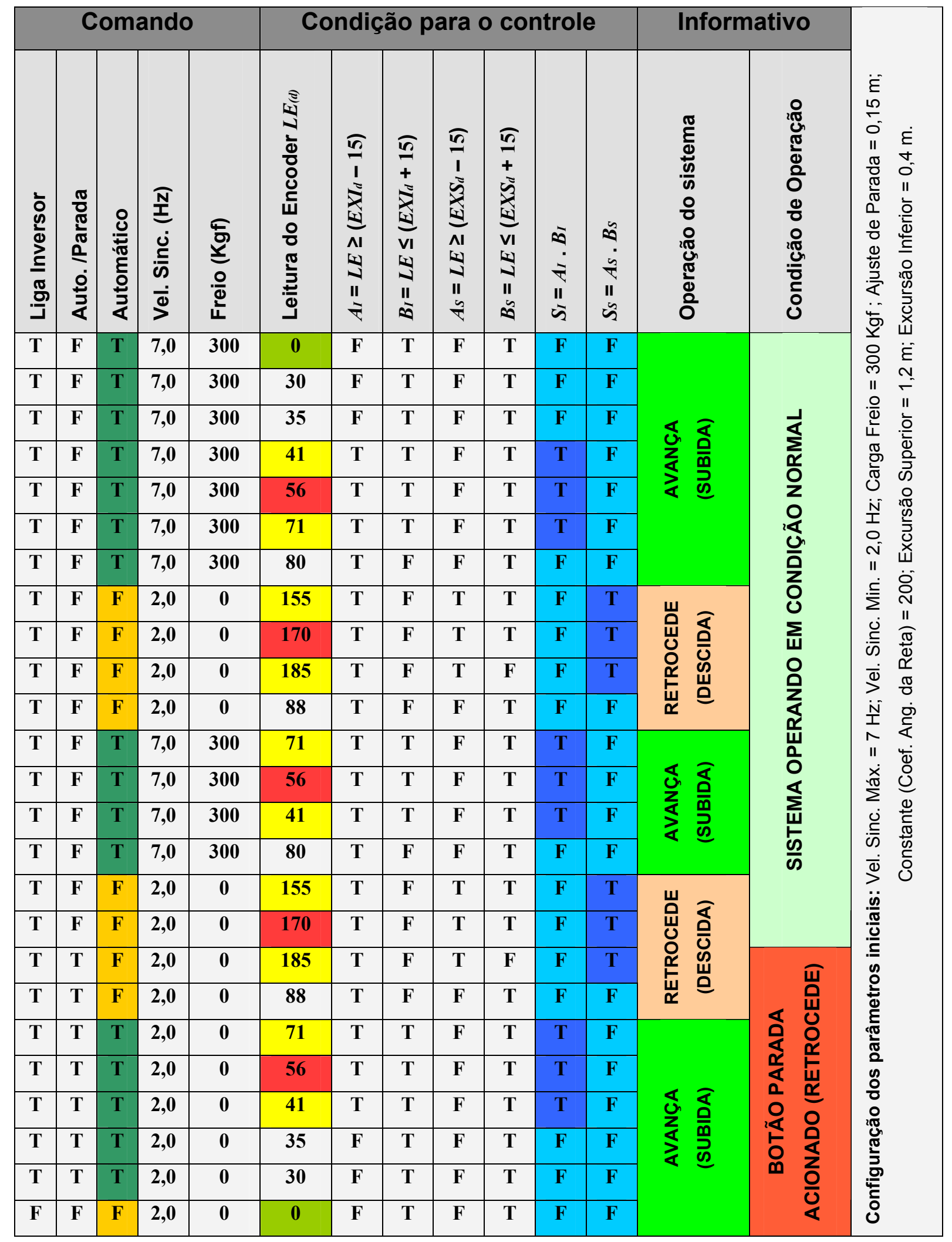



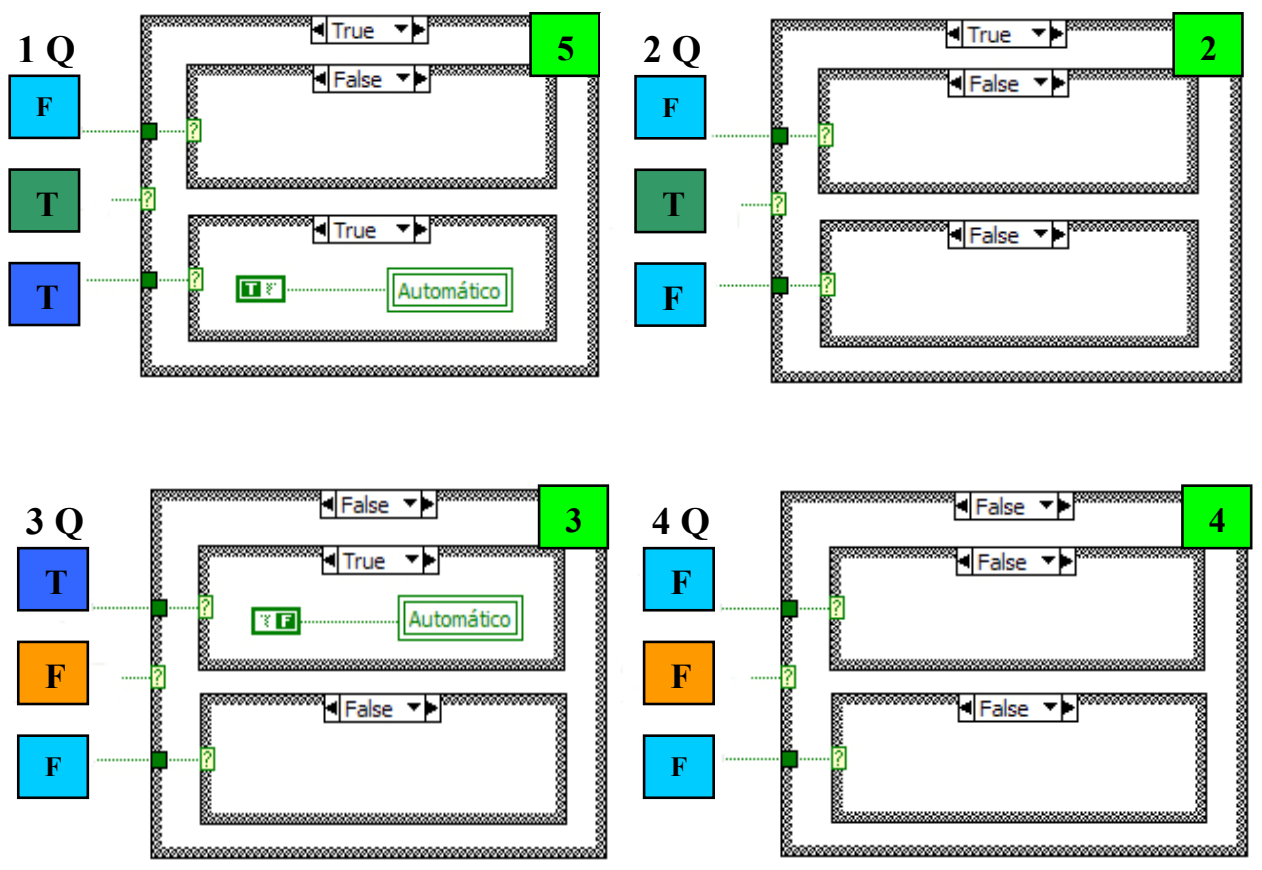

Fig. 3.20. Estruturas que representam a seqüência do ciclo de Histerese.

De acordo com a Fig. 3.19, a operação do motor obedece o ciclo de Histerese. Antes do início do funcionamento do sistema é necessário ajustar os parâmetros iniciais da máquina, o que é feito manualmente pelo operador, através da interfacehomem máquina do painel de controle. Esses parâmetros podem ser vistos na Tabela 3.1 (em configuração dos parâmetros iniciais).

Após isso, o ciclo se inicia comandando o Liga inversor em "T" (true) e, em seguida, o Automatico em "T" (true). Ao fazer isso, o motor executa o movimento de avanço (ou subida) com Vel. Sinc. Máx em $7 \mathrm{~Hz}$ "1" (passo 1). O movimento de avanço segue por "2" (passo 2) até atingir o final de curso referente à excursão superior (set point). Atingida a excursão superior "3" (passo 3), o motor executa o movimento de retroceder (ou descida) com Vel. Sinc. Min. em $2 \mathrm{~Hz}$. O movimento de retroceder segue por "4" (passo 4) até atingir o outro final de curso referente à excursão inferior (set point).

No entanto, atingida a excursão inferior "5" (passo 5), o motor executa o movimento de avanço novamente, entrando em loop num ciclo estabelecido por " 5 ", "2", “3", "4" e "5", em torno das duas referências (set points). Esse loop é rompido comandando Auto./Parada em "T" (true), estabelecendo o retorno do motor para a posição “0” (zero). 
Isso pode ser visto na Tabela 3.1, quando é comandado o Auto./Parada num determinado momento de operação. Em qualquer ponto do ciclo de operação em que for comandado Auto./Parada, o mesmo ocasiona o retorno do motor para o ponto de partida.

Observa-se que, nas bordas de transição do ciclo de Histerese, relacionados às referências (set. points), existe uma pequena diferença para mais $(+15)$ e para menos (-15) para a cada uma delas. Essa diferença existe para que o sistema de controle implementado em "LABVIEW" (Fig. 3.20) possa detectar e atuar na inversão do movimento. Isso pode ser observado na Tabela 3.1 durante a operação do motor.

Na Fig. 3.20 é exibida a estrutura da seqüência do ciclo de Histerese do sistema de controle. O ciclo se inicia em "1" (passo 1), representado pelo "2 Q" (quadrante), em seguida executa o loop estabecido por "5", "2", "3", "4" e "5" como descrito ateriormente e representado pela seqüência "1 Q", "2 Q", "3 Q", "4 Q" e "1 Q”. Essa seqüência também pode ser vista na Tabela 3.1, nas colunas 3,11 e 12, sendo as condições estabelecidas para o sistema de controle.

\subsubsection{Estrutura de programação do sistema supervisório}

Inicia-se a implementação do sistema supervisório criando os canais de comunicação do hardware, através da placa de aquisição de dados $\mathrm{PCl}-6221$ e $\mathrm{PCl}$ - 4351, utilizadas para o controle do motor e monitoramento das variáveis elétricas e mecânicas do mesmo.

\subsubsection{Monitoração da velocidade linear}

A Fig. 3.21 mostra a excursão do motor, ilustrando o cálculo da velocidade linear do mesmo. Este cálculo é feito através da leitura do canal "A" do encoder. A velocidade linear no secundário do motor é obitida em função da velocidade angular do encoder representada pela equação a seguir,

$$
V_{L}=W_{E} \cdot R_{P}
$$

onde 
- $V_{L}$ é a velocidade linear do secundário do motor;

- $W_{E}$ é a velocidade angular do encoder por ranhura (velocidade angular encoder e acoplamento polia dentada e encoder);

- $R_{P}$ é o raio da polia dentada.

O cálculo da velocidade angular do encoder é dependente da freqüência de operação do mesmo. Essa freqüência é gerada de acordo com o número de ranhuras do encoder. A equação abaixo mostra o cálculo da velocidade angular do encoder,

$$
W_{E}=\frac{2 \cdot \pi \cdot f_{E}}{N_{R}}
$$

onde

- $f_{E}$ é a freqüência do encoder (freqüência gerada por cada ranhura do encoder);

- $N_{R}$ é o número de ranhuras do encoder.

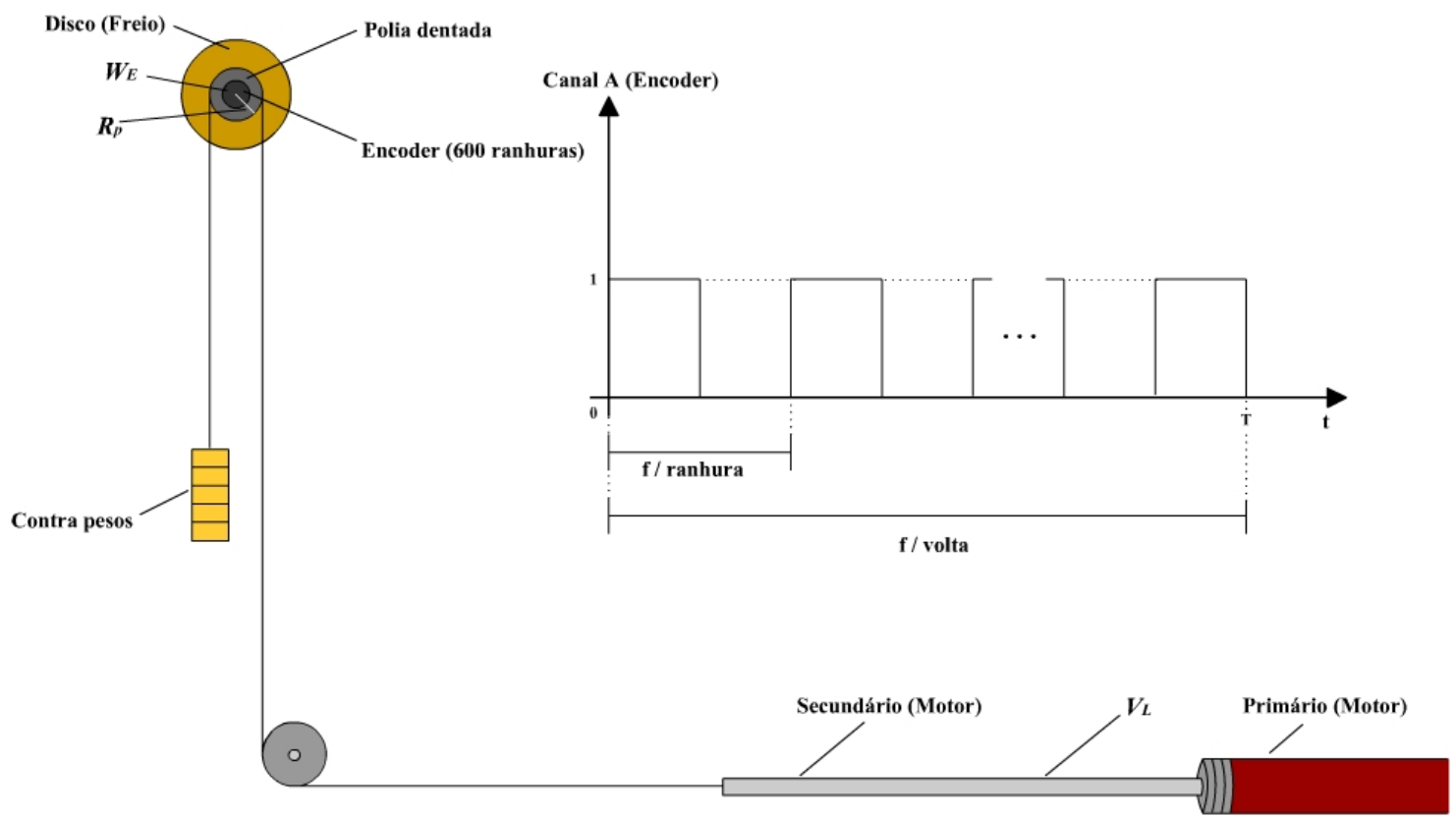

Fig. 3.21. Layout da velocidade linear obtida pelo encoder.

Substituindo a equação (3.10) em (3.9) obtém-se, 


$$
V_{L}=\frac{2 \cdot \pi \cdot R_{p}}{N_{R}} \cdot f_{E}
$$

Como $R_{P}$ e $N_{R}$ são constantes, então $\frac{2 \cdot \pi \cdot R_{p}}{N_{R}}$ define uma constante chamada de $K_{V L}$, que é utilizada para o cálculo da velocidade linear do secundário do motor $V_{L}$ :

$$
V_{L}=K_{V L} \cdot f_{E}
$$

Adotando, $R_{P}=0,0611 \mathrm{~m}$ e $N_{R}=600$ ranhuras calcula-se $K_{V L}$ como sendo

$$
K_{V L}=\frac{2 \cdot \pi \cdot 0,0611}{600}
$$

A velocidade linear da máquina $V_{L}$ varia de 0 a $1,05 \mathrm{~m} / \mathrm{s}$. $O$ sinal de $f_{E}$ é medido em função da velocidade linear desenvolvida. Como exemplo, tomando a velocidade linear máxima da máquina $V_{L}=1,05 \mathrm{~m} / \mathrm{s}$, substituindo-a na equação (3.12) e resolvendo-a, obtém-se $f_{E}=1.642 \mathrm{~Hz}$, que é a freqüência máxima obtida na leitura do canal "A" do encoder.

A estrutura da Fig. 3.22 exibe a implementação do cálculo da velocidade linear do motor através de blocos.

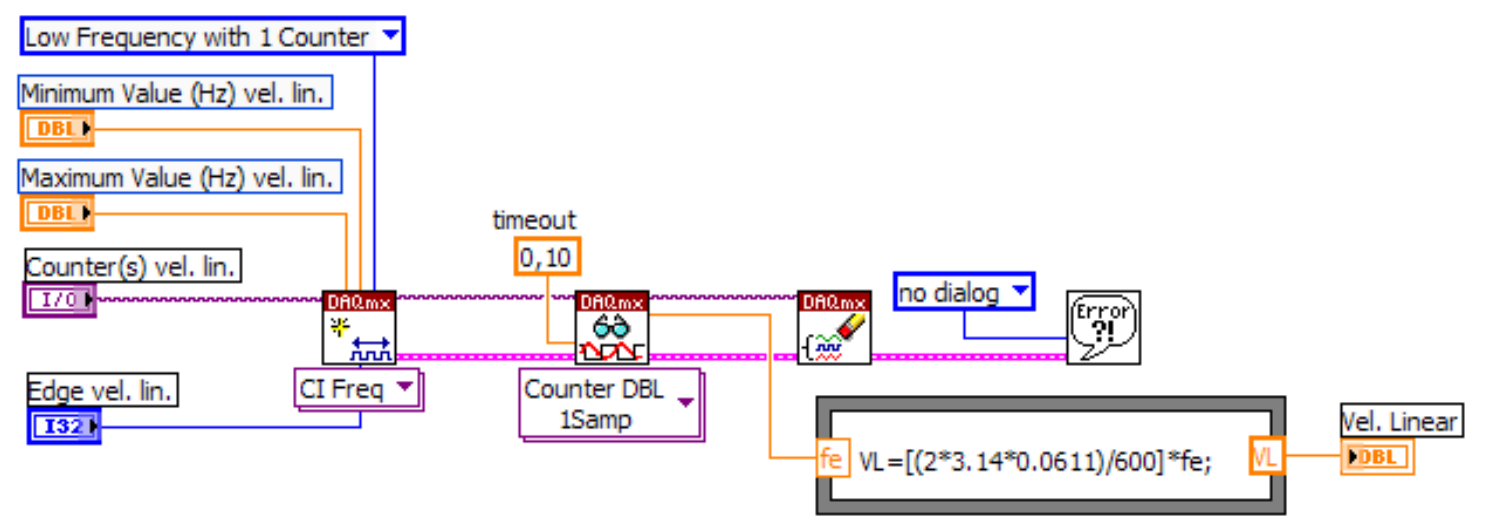

Fig. 3.22. Estrutura que implementa o cálculo da velocidade linear do motor. 


\subsubsection{Monitoração da posição e curva dinamométrica}

O sinal do encoder gerado pelo canal "A" é enviado para a placa de aquisição de dados e lido através do bloco VI DAQ Assistant, configurado como entrada para a medição de freqüência. Em seguida, esta informação passa por outro bloco VI para a amostragem, seguindo para o bloco fórmula. A informação da velocidade linear do motor pode ser vista na Fig. 3.1, na tela principal do controle e supervisório do MATÆEOS.

$\mathrm{Na}$ estrutura anterior, a equação (3.12) é implementa pelo bloco formula, o qual converte a informação (freqüência gerada pelo encoder) na velocidade linear.

A Fig. 3.23 exibe a estrutura que supervisiona em tempo real a excursão e a carta dinamométrica do motor. Esta estrutura recebe a informação dos blocos Leitura encoder e Carga do motor (medida feita pela célula de carga). Após isso, essa informação é convertida na distância percorrida pelo motor, através do bloco escalonamento. $\mathrm{O}$ valor da constante de escalonamento é calculada pela expressão:

$$
P M=K_{E} \cdot L E
$$

onde

- $P M$ é a posição do motor (distância percorrida pelo secundário do motor em metros). $P M$ varia de 0 a $1,8 \mathrm{~m}$;

- $L E$ é a leitura do encoder (valor lido do encoder e apresentado na forma decimal intero pelo software). $L E$ varia de 0 a 255;

- $K_{E}$ é a constante de proporcionalidade do encoder.

Resolvendo a equação (3.14) para $K_{E}$, e definindo $P M=1,8$ e $L E=255$, encontra-se $K_{E}=0,007059$, valor esse que é carregado no bloco escalonamento. Observa-se que $K_{E}$ é o mesmo calculado na equação (3.3) porque as grandezas utilizadas para os cálculos são as mesmas, sendo $P M=E X_{m}$ e $L E=E X_{d}$. Com isso, obtém-se a informação da posição do motor apresentada na caixa Posição do motor e Excursão. Essa informação serve para a monitoração em tempo real da excursão do motor, como é apresentada (Fig. 3.1) na tela principal do controle e supervisório do MATÆEOS e também como uma das informações para a plotagem da carta dinamométrica. 


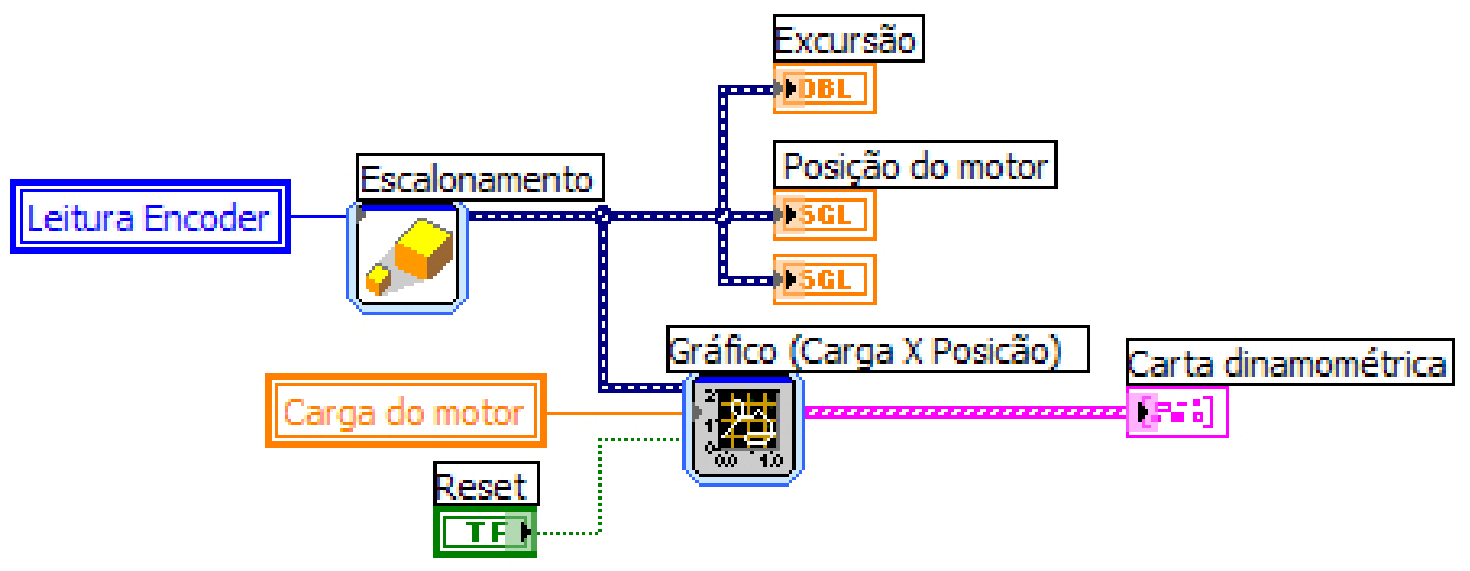

Fig. 3.23. Estrutura que supervisiona a excursão e plota a carta dinamométrica do motor

Na estrutura da Fig. 3.23 é apresentado também o bloco que plota a carta dinamométrica representada pelo bloco Gráfico (carga $x$ posição). Este bloco apresenta as informações de posição do motor no eixo $\mathrm{X}$ e de carga do motor no eixo Y. Existe também o botão de Reset que executa a limpeza de tela gráfica da carta dinamométrica.

\subsubsection{Monitoração das variéveis eletromecânicas}

Na Fig. 3.24 é exibido o layout estrutural da leitura das variáveis elétricas e mecânicas do motor. As variáveis elétricas lidas referem-se à entrada do inversor (saída do painel de energia) e as variáveis mecânicas, ao secundário do motor.

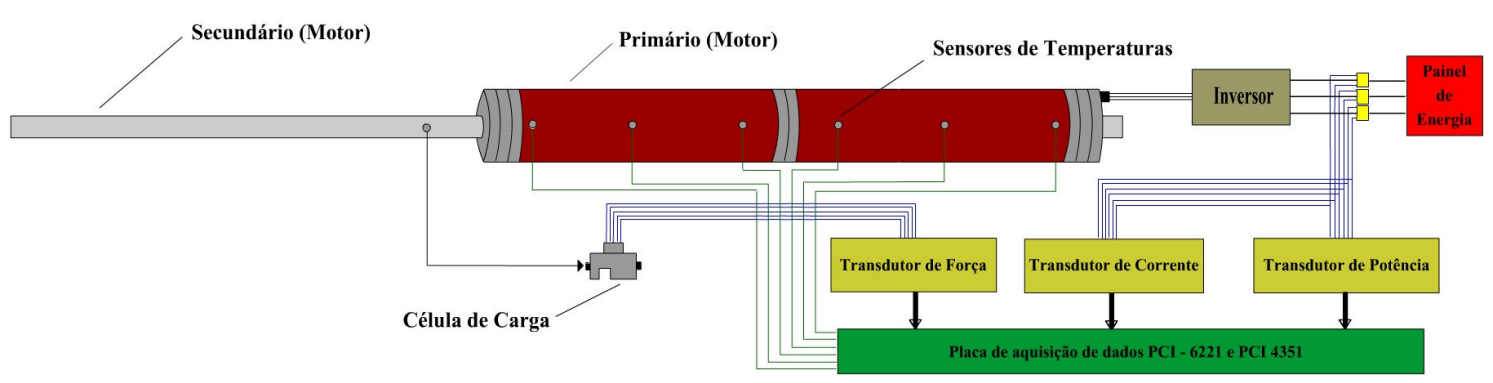

Fig. 3.24. Layout estrutural das variáveis do motor.

A Fig. 3.25 expõe a estrutura de programação que realiza a leitura das variáveis do motor, através do bloco VI DAQ Assistant configurado como entrada 
analógica (input analógico 1, 2, 3, 4, 5 e 6), criando um canal para cada variável medida.

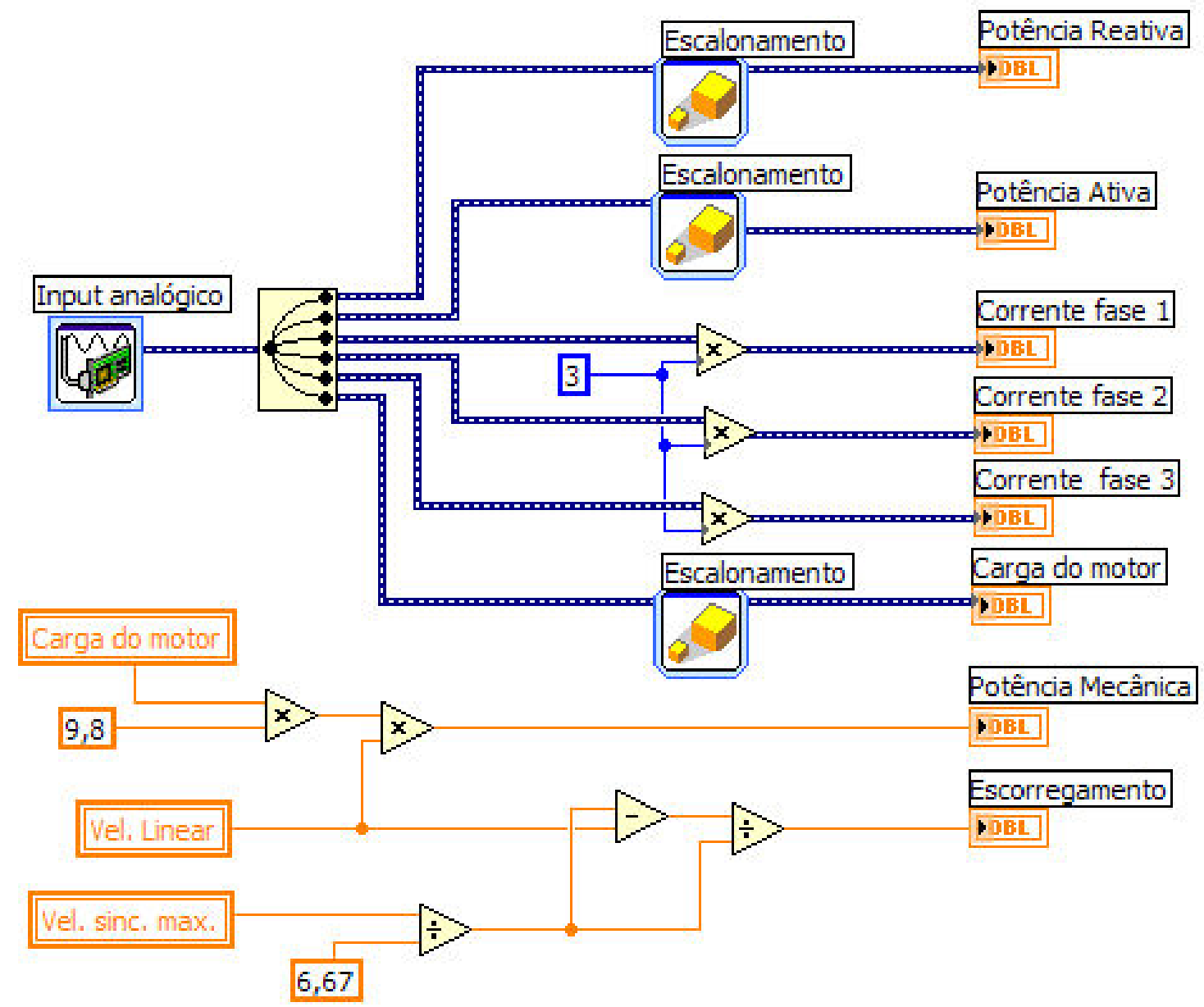

Fig. 3.25. Estrutura que implementa a leitura das variáveis elétricas e mecânicas.

As variáveis medidas (Fig. 3.25) são amostradas em tempo real. Os instrumentos transdutores fornecem em suas saídas tensões que variam de 0 a $10 \mathrm{~V}$. Descrevendo cada parte da estrutura de programação, a informação da potência reativa é caculada pela expressão abaixo,

$$
P_{R}=K_{P R} \cdot V_{P R}
$$

onde

- $P_{R}$ é a potência reativa; 
- $V_{P R}$ é a tensão associada á potência reativa (tensão utilizada na saída do canal do hardware do instrumento proporcional a potência reativa);

- $K_{P R}$ é a constante de proporcionalidade da potência reativa.

De acordo com os dados do fabricante do instrumento, a constante $K_{P R}$ vale 1143. Substituindo $K_{P R}=1143$ e $V_{P R}=10 \mathrm{~V}$ em (3.15) obtém-se $P_{R}=11430 \mathrm{Var}$, sendo este o valor máximo medido pelo instrumento. $O$ valor de $K_{P R}$ é carregado no bloco Escalonamento, vide Fig. 3.25.

Prosseguindo na Fig. 3.25, a potência ativa é caculada pela expressão abaixo,

$$
P_{A}=K_{P A} \cdot V_{P A}
$$

onde

- $P_{A}$ é a potência ativa;

- $V_{P A}$ é a tensão associada à potência ativa (tensão utilizada na saída do canal do hardware do instrumento proporcional a potência ativa);

- $K_{P A}$ é a constante de proporcionalidade da potência ativa.

De acordo com os dados do fabricante do instrumento, a constante $K_{P A}$ também vale 1143. Substituindo $K_{P A}=1143$ e $V_{P A}=10 \mathrm{~V}$ em (3.16) obtém-se $P_{A}=$ $11430 \mathrm{~W}$, sendo este o valor máximo medido pelo instrumento. O valor de $K_{P A}$ é carregado no bloco Escalonamento, vide figura 3.25.

Dando continuidade à Fig. 3.25, o valor da corrente por fase é calculado pela expressão abaixo,

$$
I_{F}=K_{I F} \cdot V_{I F}
$$

onde

- $I_{F}$ é a corrente de linha 
- $V_{I F}$ é a tensão associada à corrente por fase (tensão utilizada na saída do canal do hardware do instrumento proporcional à corrente de fase);

- $K_{I F}$ é a constante de proporcionalidade da corrente por fase.

De acordo com os dados do fabricante do instrumento, a constante $K_{I F}$ vale 3 . Substituindo $K_{I F}=3$ e $V_{I F}=10 \mathrm{~V}$ em (3.17), obtém-se $I_{F}=30 \mathrm{~A}$, sendo este o valor máximo medido pelo instrumento. $O$ valor de $K_{I F}$ é carregado como uma constante através da função Multiplica, vide Fig. 3.25.

Continuando na Fig. 3.25, o valor da carga do motor é caculado pela expressão abaixo,

$$
C_{M}=K_{C M} \cdot V_{C M}
$$

onde

- $C_{M}$ é a carga do motor;

- $V_{C M}$ é a tensão associada à carga do motor (tensão utilizada na saída do canal do hardware do instrumento proporcional à carga do motor);

- $K_{C M}$ é a constante de proporcionalidade da carga do motor.

De acordo com os dados do fabricante do instrumento, o transdutor de força possui fundo de escala de $500 \mathrm{Kgf}$, sendo que a variação da tensão de saída é de 0 a $10 \mathrm{~V}$. Resolvendo a equação (3.18) para $K_{C M}$ e definindo $C_{M}=500$ e $V_{C M}=10$, encontra-se $K_{C M}=50$. O valor de $K_{C M}$ é carregado no bloco Escalonamento, vide Fig. 3.25. O valor máximo medido pelo instrumento é de $500 \mathrm{Kgf}$.

Outras grandezas podem ser extraídas em função das variáveis medidas como a potência mecânica e o escorregamento. Obeserva-se na Fig. 3.25 as duas estruturas de programação implementadas para o cálculo das variáveis citadas.

A potência mecânica é caculada pela expressão abaixo,

$$
P_{M}=C_{M} \cdot V_{L} \cdot g
$$

onde 
- $P_{M}$ é a potência mecânica;

- $g$ é a aceleração da gravidade $(\mathrm{g}=9,8 \mathrm{~m} / \mathrm{s})$.

Como as grandezas $C_{M}$ e $V_{L}$ são medidas, então $P_{M}$ é obtido diretamente. A equação (3.19) é implementada por dois blocos multiplica como pode ser visto na Fig. 3.25.

E por fim, a informação do escorregamento é calculada pela expressão abaixo,

$$
s=\frac{\frac{V S_{M}}{6,67}-V_{L}}{\frac{V S_{M}}{6,67}}
$$

onde,

- $s$ é o escorregamento do motor (escorregamento varia de 0 a 1).

Adotando $V S_{M}=7 \mathrm{~Hz}$ e $V_{L}$ assume um valor no intervalo de 0 à $1,05 \mathrm{~m} / \mathrm{s}$. A equação (3.20) é também implementada por blocos de funções matemáticas como pode ser visto na Fig. 3.25.

Todas as variáveis elétricas e mecânicas podem ser monitoradas através de uma interface homem-máquina. Essa interface pode ser vista na Fig. 3.1 e, com mais detalhes, nas Figs. 3.6 e 3.7 .

\subsubsection{Monitoração das temperaturas}

A Fig. 3.26 implementa a estrutura que executa a leitura das temperaturas da máquina e dos dois reservatórios da bancada. Como mencionado na seção 2.2.4, os sensores utilizados são do tipo RTD's. A seguir é apresentada a equação que rege o seu funcionamento:

$$
t_{e}=\frac{\frac{R_{0}-V_{0}}{I_{e}}}{\left.-0,5 \cdot\left(R_{0} \cdot A+\sqrt{(} R_{0} \cdot R_{0} \cdot A \cdot A-4 \cdot R_{0} \cdot B \cdot\left(\frac{R_{0}-V_{0}}{I_{e}}\right)\right)\right)}
$$


onde

- $t_{e}$ é a temperatura do RTD (temperatura em ${ }^{\circ} \mathrm{C}$ );

- $R_{0}$ é a resistência do RTD (resistência medida a $0^{\circ} \mathrm{C}, R_{0}=100 \Omega$ );

- $V_{0}$ é a voltage do RTD;

- $I_{e}$ é a corrente de excitação do RTD (corrente de excitação, padrão $150 \mu \mathrm{A}$ );

- $A, B$ são os coeficientes do RTD (os coeficientes assumem valores de acordo com a tabela Van Dusen: $A=3,90802$ e-3 e $B=-5,9019$ e-7.

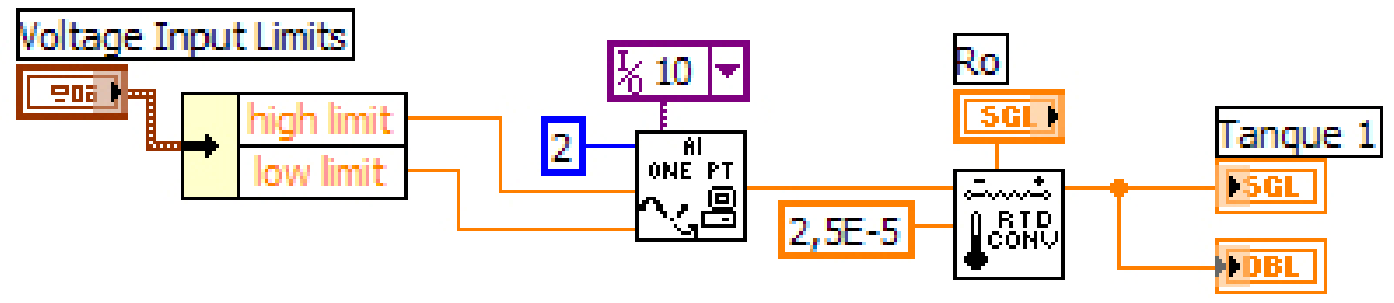

Fig. 3.26. Estrutura que implementa a leitura das temperaturas.

A equação (3.21) é implementada pelo bloco RTD conv (Fig. 3.26). Observase que a corrente de excitação utilizada é de $25 \mu \mathrm{A}$ e não de $150 \mu \mathrm{A}$ (corrente padrão). O tipo de RTD's utilizados no projeto possui uma configuração com padrões diferentes, mas apresentam os mesmos coeficientes $A, B$ e $R_{0}$.

A estrutura funciona da seguinte maneira: através do bloco Al ONE PT cria-se o canal analógico de comunicação com hardware da placa PCl 4351. Neste bloco é configurado o canal e o hardware utilizado. Como exemplo, na estrutura da Fig. 3.26, o canal é de número 10 e o hardware de número 2 é que implementa a medição da temperatura do tanque 1. Na saída deste bloco é obtida a tensão medida $V_{0}$ do RTD. Em seguida, essa tensão é enviada ao bloco RTD conv que executa a conversão da tensão para graus Celsius $\left({ }^{\circ} \mathrm{C}\right)$. Depois a temperatura pode ser monitorada através de uma interface homem-máquina e atualizada de segundo em segundo. Essa interface pode ser vista na Fig. 3.1, na tela principal do MATÆEOS e, na Fig. 3, com mais detalhes.

Para cada sensor RTD foi implementada uma estrutura de programação igual à da estrutura da Fig. 3.26, mudando apenas a configuração do canal. 


\subsubsection{Estrutura de programação dos valores médios medidos}

\subsubsection{O sistema de amostragem}

A estrutura (Fig. 3.27) exibe uma lógica que servirá para habilitar a amostragem para o cálculo da excursão do motor e também para o cálculo dos valores médios das variáveis elétricas e mecânicas.

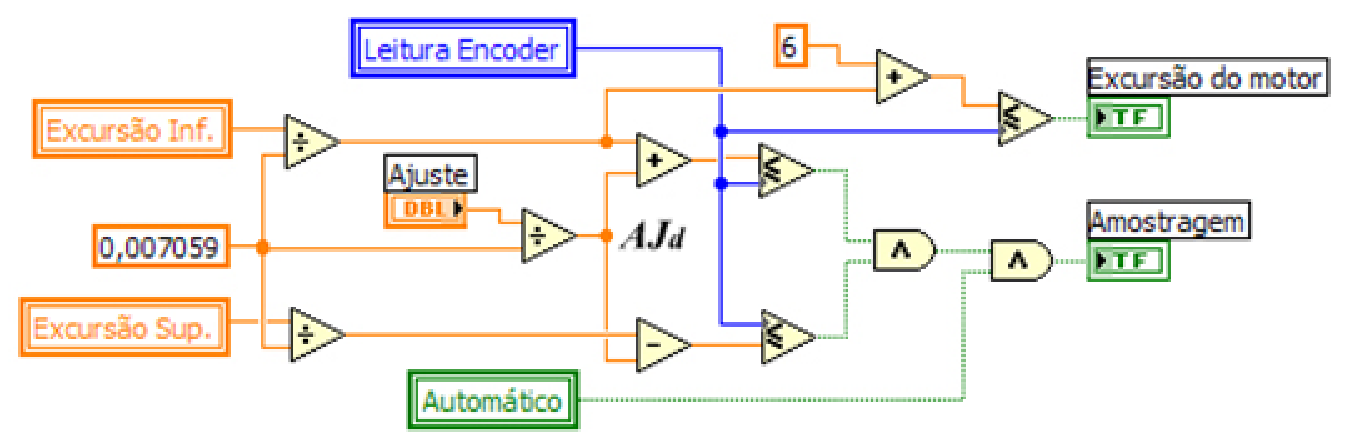

Fig. 3.27. Estrutura que implementa a lógica para amostragem.

O cálculo da excursão do motor é dado pela expressão abaixo,

$$
E M=\left(E X I_{d}+6\right) \leq L E
$$

onde

- EM é a excursão do motor (sinal de amostragem para o cálculo da excursão do motor).

A equação (3.22) mostra que $E M=1$ (início de contagem do tempo para o cálculo da excursão do motor), quando $L E$ for maior ou igual $\left(E X I_{d}+6\right)$. A utilização desse incremento de 6 (seis) em $E X I_{d}$ é usado para que a lógica funcione corretamente.

Seguindo na estrutura da Fig. 3.27, a amostragem para os cálculos dos valores médios das variáveis elétricas e mecânicas, é dada pela expressão abaixo, 


$$
A M=A U T O M \cdot \cdot\left(A_{I} \cdot A_{S}\right)
$$

sendo,

$$
\begin{aligned}
& A_{I}=\left(E X I_{d}+A J_{d}\right) \leq L E \\
& A_{S}=L E \leq\left(E X S_{d}-A J_{d}\right)
\end{aligned}
$$

onde

- $A M$ é a amostragem (sinal de amostragem para o cálculo das variáveis médias);

- AUTOM. é o automático (sinal de comando de controle do motor );

- $A_{I}$ é o ajuste inferior;

- $A_{S}$ é o ajuste superior;

- $A J_{d}$ é o ajuste (ajuste na base decimal).

A equação (3.23) mostra que $A M=1$ (início de contagem do tempo para o cálculo dos valores médios), quando todas as condições forem satisfeitas, ou seja, $A U T O M=A I=A S=1$. Para que $A I=A S=1$ deva obedecer as condições impostas pelas equações (3.24) e (3.25).

Essa estrutura de programação é utilizada para que o cálculo das grandezas médias e do rendimento do motor aconteçam apenas durante o movimento de avanço (ou subida).

$\mathrm{Na}$ Fig. 3.28, para um melhor entendimento, segue-se uma pequena ilustração de como funciona o processo de amostragem para o cálculo dos valores médios.

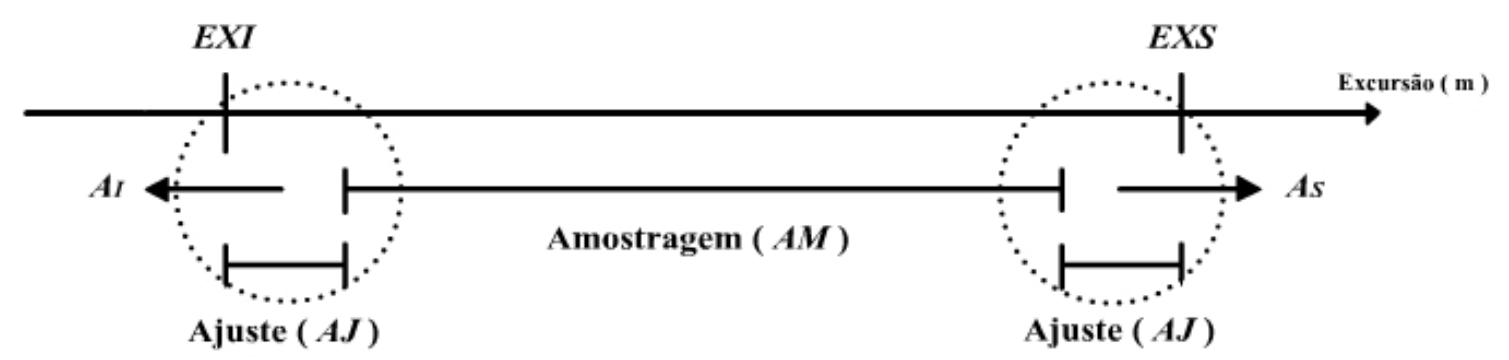

Fig. 3.28. Ilustração da amostragem para o cálculo dos valores médios. 
Como descrito anteriormente, através de uma interface homem-máquina podem-se ajustar os limites de amostragem para os cálculos. Essa interface pode ser vista na Fig. 3.7 da seção 3.1 .

\subsubsection{Cálculo do ciclos por minuto}

A Fig. 3.29 mostra a estrutura de programação que executa o cáculo dos ciclos por minuto do motor ao longo do movimento. $\mathrm{O}$ cáculo é executado apenas quando o motor está excursionando, obedecendo o intervado de excursão imposto por $E M$, visto na Fig. 3.27. O comando é realizado através do bloco True, False, comandado pela variável de alocação de EM Excursão do motor. Essa variável comanda o bloco durante o intervalo de excursão de acordo com a freqüência de amostragrem do subsistema.

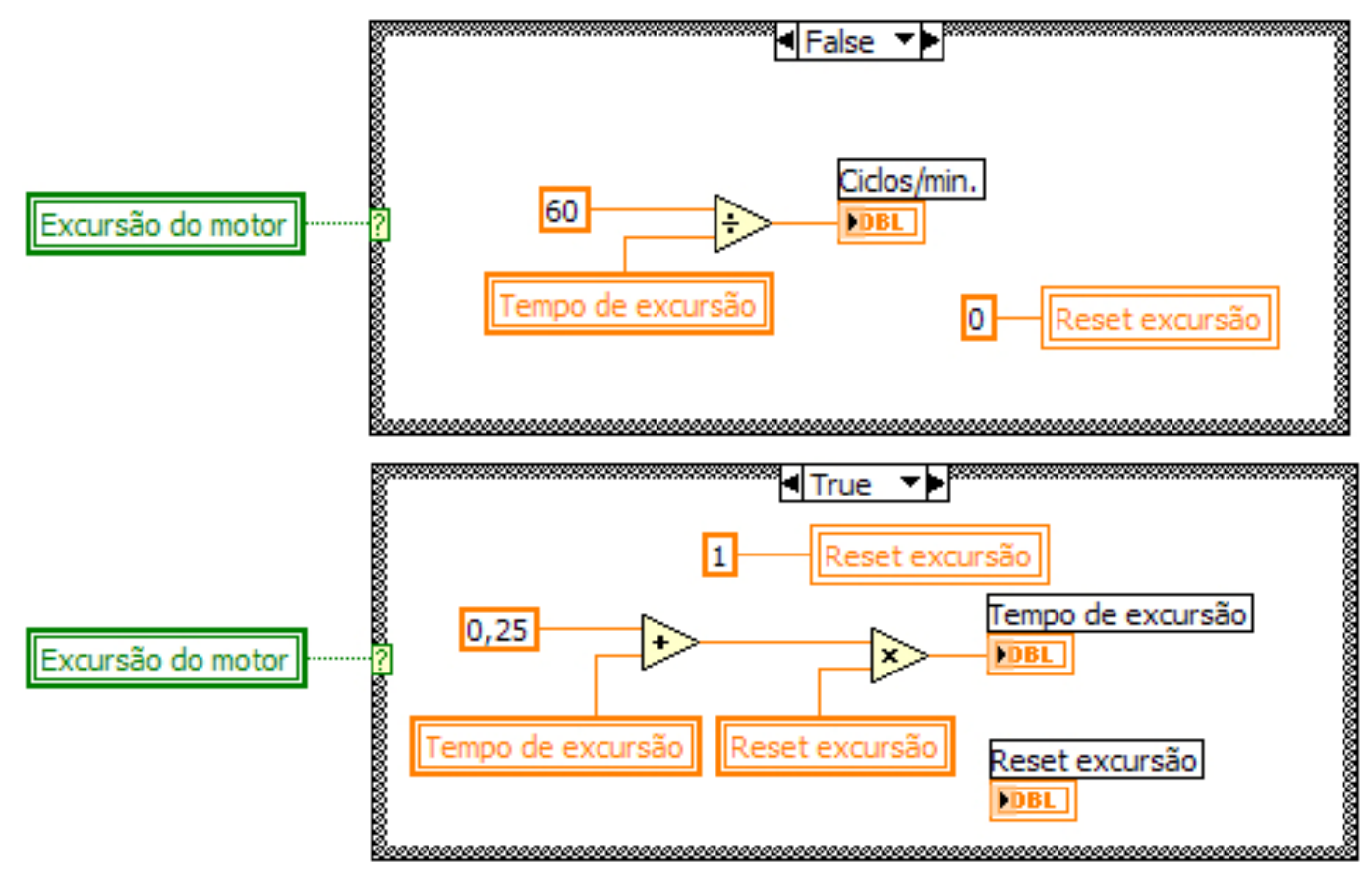

Fig. 3.29. Estrutura de programação utilizada para o cálculo dos ciclos por minuto do motor.

O cálculo da freqüência do movimento do motor (em ciclos por minuto) é dado pela expressão abaixo, 


$$
C / M=\frac{60}{T E}
$$

onde

- $C / M$ é o valor da freqüência do motor (em ciclos por minuto);

- $T E$ é o tempo de excursão (tempo equivalente a um ciclo).

sendo

$$
T E=R E S E T_{T E} \cdot(0,25+T E)
$$

onde

- $\operatorname{RESET}_{T E}$ é o reset do tempo de excursão (lógica utilizada nos blocos para limpar o conteúdo em $T E$ a cada novo ciclo do motor). RESET $T_{T E}$ assume valores de "1" ou "0".

As equações (3.26) e (3.27) são implementadas pelas funções matemáticas vistas na Fig. 3.29.

A estrutura de programação da Fig. 3.29, funciona da seguinte maneira: quando $E M=1$, é iniciada a contagem do tempo executado pelo bloco True, salvando essa contagem na variável TE. Após o motor realizar uma excursão completa (um ciclo), $E M=0$ e a contagem termina. Então, o bloco False é executado realizando o cálculo da freqüência do movimento através da equação (3.26). Este valor é atualizado a cada ciclo do motor e pode ser monitorado através de uma interface homem-máquina, vide Fig. 3.6.

\subsubsection{Cálculo do rendimento}

A estrutura de programação da Fig. 3.30 apresenta o cáculo do rendimento do motor. Esse cálculo é executado ao longo da excursão do motor no movimento de avanço (ou subida). O cálculo é executado apenas quando o motor está excursionando, obedecendo o intervado de excursão imposto por $A M$, visto na Fig. 3.27 e ilustrado na Fig. 3.28. O comando é feito através do bloco True, False, comandado pela variável de alocação de $A M$ Amostragem. Essa variável comanda o 
bloco durante o intervalo de excursão de acordo com a freqüência de amostragrem do subsistema.

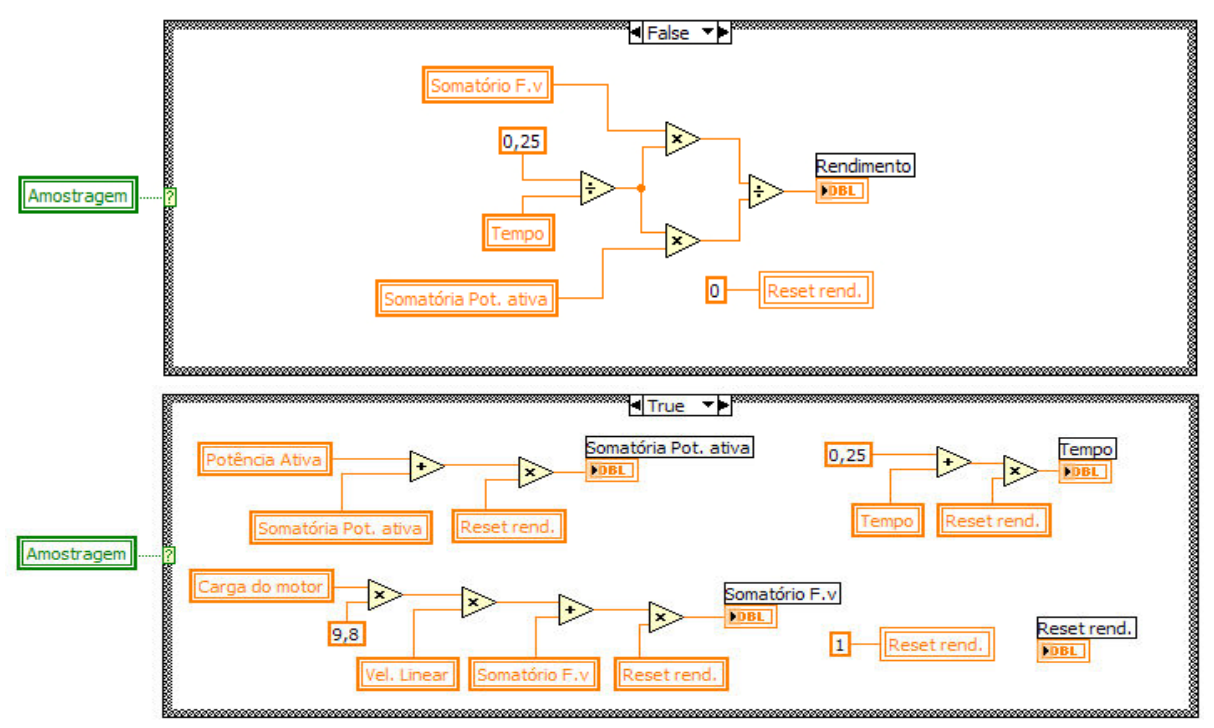

Fig. 3.30. Estrutura de programação utilizada para o cálculo do rendimento do motor.

O cálculo do rendimento do motor é dado pela expressão abaixo,

$$
\eta=\frac{\frac{0.25}{S_{T R}} \cdot S_{F V}}{\frac{0.25}{S_{T R}} \cdot S_{P A}}
$$

onde,

- $\eta$ é o rendimento do motor;

- $S_{F V}$ é o somatório das variáveis mecânicas (potência mecânica desenvolvida pelo motor);

- $S_{P A}$ é o somatório das variáveis elétricas (potência ativa desenvolvida pelo motor);

- $S_{T R}$ é o somatório de tempo para o cálculo do rendimento.

sendo,

$$
T_{R}=\operatorname{RESET}_{\eta} \cdot\left(0,25+T_{R}\right)
$$


e,

$$
\begin{gathered}
S_{F V}=\operatorname{RESET}_{\eta} \cdot\left[\left(C_{M} \cdot V_{L} \cdot 9,8\right)+S_{F V}\right], \\
S_{P A}=\operatorname{RESET}_{\eta} \cdot\left(P_{A}+S_{P A}\right)
\end{gathered}
$$

onde

- RESET $T_{\eta}$ é reset do rendimento (lógica utilizada nos blocos para limpar o conteúdo em $S_{F V}, S_{P A}$ e $T_{R}$ a cada novo meio ciclo do motor). RESET Rend assume valores de " 1 " ou " 0 ".

As equações (3.28), (3.29), (3.30) e (3.31) são implementadas por funções matemáticas vistas na Fig. 3.30.

A estrutura de programação da Fig. 3.30 funciona da seguinte maneira: quando $A M=1$, é iniciada a contagem do tempo, o somátorio das variávies mecânicas (potência mecânica) e das variáveis elétricas (potência ativa), executado pelo bloco True, salvando essa contagem nas três variáveis $T_{R}, S_{F V}$ e $S_{P A}$,

respectivamente. Após o motor completar meia excursão ou meio ciclo (no movimento de avanço, ou subida), $A M=0$ e a contagem termina. Então, o bloco False é executado realizando o cálculo do rendimento, através da equação (3.28). O valor do rendimento é atualizado a cada meio ciclo do motor e pode ser monitorado através de uma interface homem-máquina, vide Fig. 3.7.

\subsubsection{Cálculo das variáveis médias}

As próximas estruturas de programação a seguir apresentam os cálculos das variáveis médias do motor, vide Fig. 3.31 e 3.32. Esses cálculos também são executados ao longo da excursão do motor no movimento de avanço (ou subida) como descrito anteriormente. O comando também é realizado através do bloco True, False, comandado pela variável de alocação de AM Amostragem. Essa variável comanda o bloco durante o intervalo de excursão de acordo com a freqüência de amostragrem do subsistema. 


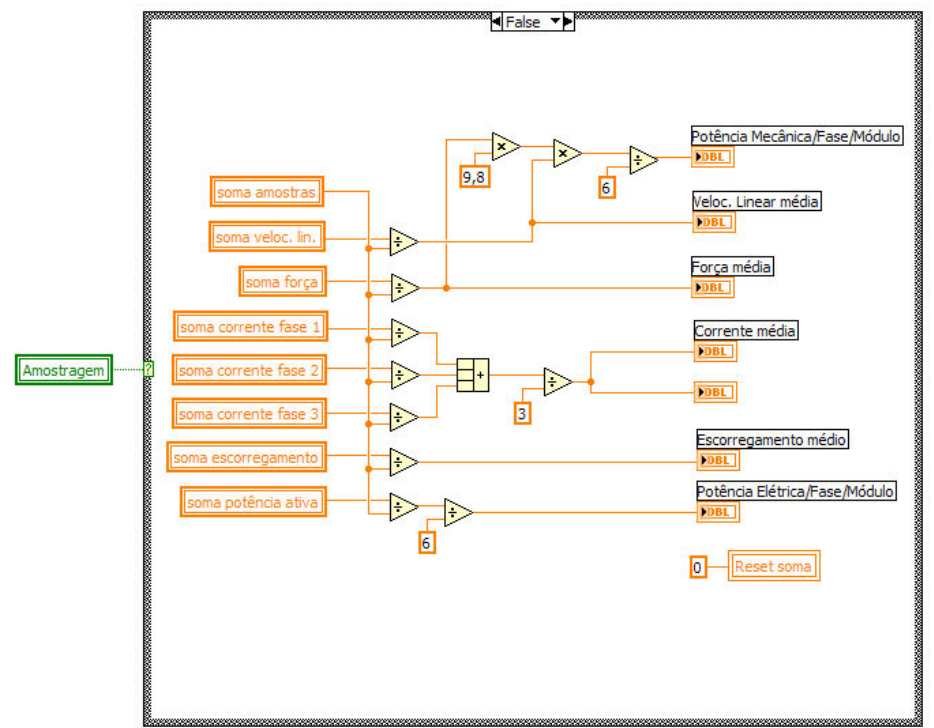

Fig. 3.31. Estrutura de programação utilizada para o cálculo das variáveis médias do motor.

O cálculo da média das variáveis é dado pelas expressões a seguir, na ordem,

$$
\begin{gathered}
P_{M_{F / M}}=\frac{F_{M} \cdot 9,8 \cdot V_{L_{M}}}{6}, \\
V_{L_{M}}=\frac{S_{V_{L}}}{S_{A}}, \\
\frac{F_{M}=\frac{S_{F}}{S_{A}},}{S_{I_{F 1}}}+\frac{S_{I_{F 2}}}{S_{A}}+\frac{S_{I_{F 3}}}{S_{A}} \\
\frac{S_{A}}{I_{F_{M}}}, \\
P_{E_{F / M}}=\frac{S_{P_{A}}}{6} \\
S_{M}=\frac{S_{S}}{S_{A}},
\end{gathered}
$$

onde 
- $P_{M_{F / M}}$ é a potência mecânica média (potência mecânica média por fase e por módulo, número de módulos);

- $V_{L_{M}}$ é a velocidade média;

- $F_{M}$ é a força média;

- $I_{F_{M}}$ é a corrente média;

- $s_{M}$ é o escorregamento médio;

- $P_{E_{F / M}}$ é a potência elétrica média (potência elétrica média por fase e por número de módulos);

- $S_{V_{L}}$ é o somatório de velocidade linear;

- $S_{F}$ é o somatório de força;

- $S_{I_{F 1}}$ é o somatório de corrente da fase 1;

- $S_{I_{F 2}}$ é o somatório de corrente da fase 2;

- $S_{I_{F 3}}$ é o somatório de corrente da fase 3;

- $S_{s}$ é o somatório de escorregamento;

- $S_{P_{A}}$ é o somatório de potência ativa;

- $S_{A}$ é o somatório de amostra.

As equações (3.32), (3.33), (3.34), (3.35), (3.36) e (3.37) são implementadas por funções matemáticas, vide Fig. 3.31.

Segue-se na Fig. 3.32 a estrutura de programação complementar para o cálculo das variáveis médias. 


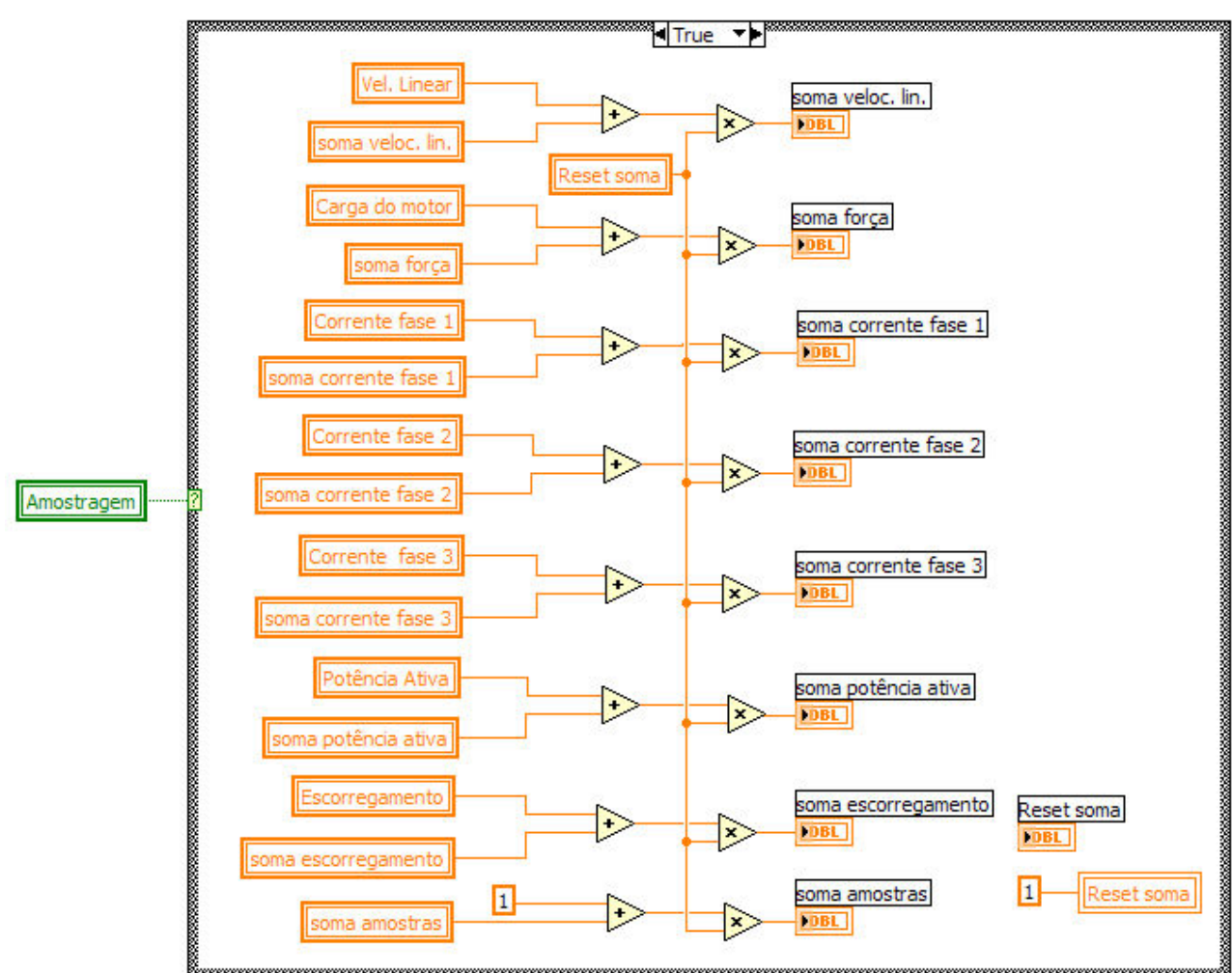

Fig. 3.32. Estrutura de programação complementar utilizada no cálculo das variáveis médias. sendo

$$
\begin{gathered}
S_{V_{L}}=\operatorname{RESET}_{\text {SOMA }} \cdot\left(V_{L}+S_{V_{L}}\right), \\
S_{F}=\operatorname{RESET}_{\text {SOMA }} \cdot\left(C_{M}+S_{F}\right), \\
S_{I_{F 1}}=\operatorname{RESET}_{\text {SOMA }} \cdot\left(I_{F 1}+S_{I_{F 1}}\right), \\
S_{I_{F 2}}=\operatorname{RESET}_{\text {SOMA }} \cdot\left(I_{F 2}+S_{I_{F 2}}\right), \\
S_{I_{F 3}}=\operatorname{RESET}_{S O M A} \cdot\left(I_{F 3}+S_{I_{F 3}}\right), \\
S_{P_{A}}=\operatorname{RESET}_{S O M A} \cdot\left(P_{A}+S_{P_{A}}\right), \\
S_{s}=\operatorname{RESET}_{\text {SOMA }} \cdot\left(s+S_{s}\right),
\end{gathered}
$$




$$
S_{A}=\operatorname{RESET}_{\text {SOMA }} \cdot\left(1+S_{A}\right)
$$

onde

- $\operatorname{RESET}_{S O M A}$ é o reset da soma (lógica utilizada nos blocos para limpar o conteúdo em $S_{V_{L}}, S_{F}, S_{I_{F 1}}, S_{I_{F 2}}, S_{I_{F 3}}, S_{s}, S_{P_{A}}$ e $S_{A}$ a cada novo meio ciclo do motor). RESET $T_{\text {SOMA }}$ assume valores de "1" ou "0".

As equações (3.38), (3.39), (3.40), (3.41), (3.42), (3.43), (3.44) e (3.45) são implementadas por funções matemáticas vistas na Fig. 3.32.

A estrutura de programação da Fig. 3.32 funciona da seguinte maneira: quando $A M=1$, é iniciada a contagem do somátorio das variáveis mecânicas $\left(V_{L}\right.$, $C_{M}$ e $\left.s\right)$, das variáveis elétricas $\left(I_{F 1}, I_{F 2}, I_{F 3}\right.$ e $\left.P_{A}\right)$ e das amostras, executado pelo bloco True, salvando essa contagem nas variáveis $S_{V_{L}}, S_{F}, S_{I_{F 1}}, S_{I_{F 2}}, S_{I_{F 3}}, S_{s}, S_{P_{A}}$ e $S_{A}$, respectivamente. Após o motor completar meia excursão ou, meio ciclo (no movimento de avanço, ou de subida ), $A M=0$ e a contagem termina. Então, o bloco False é executado realizando o cálculo das variáveis médias envolvidas através das equações (3.32), (3.33), (3.34), (3.35), (3.36) e (3.37). Os valores das variáveis médias são atualizados a cada meio ciclo do moto e, podem ser monitorados através de uma interface homem-máquina, vide Figs. 3.7 e 3.8.

\subsubsection{Estrutura de programação do sistema de aquisição de dados}

\subsubsection{Aquisição das temperaturas}

A Fig. 3.33, apresenta a estrutura de programação que monitora graficamente as temperaturas do motor e também salva-as para análises. 


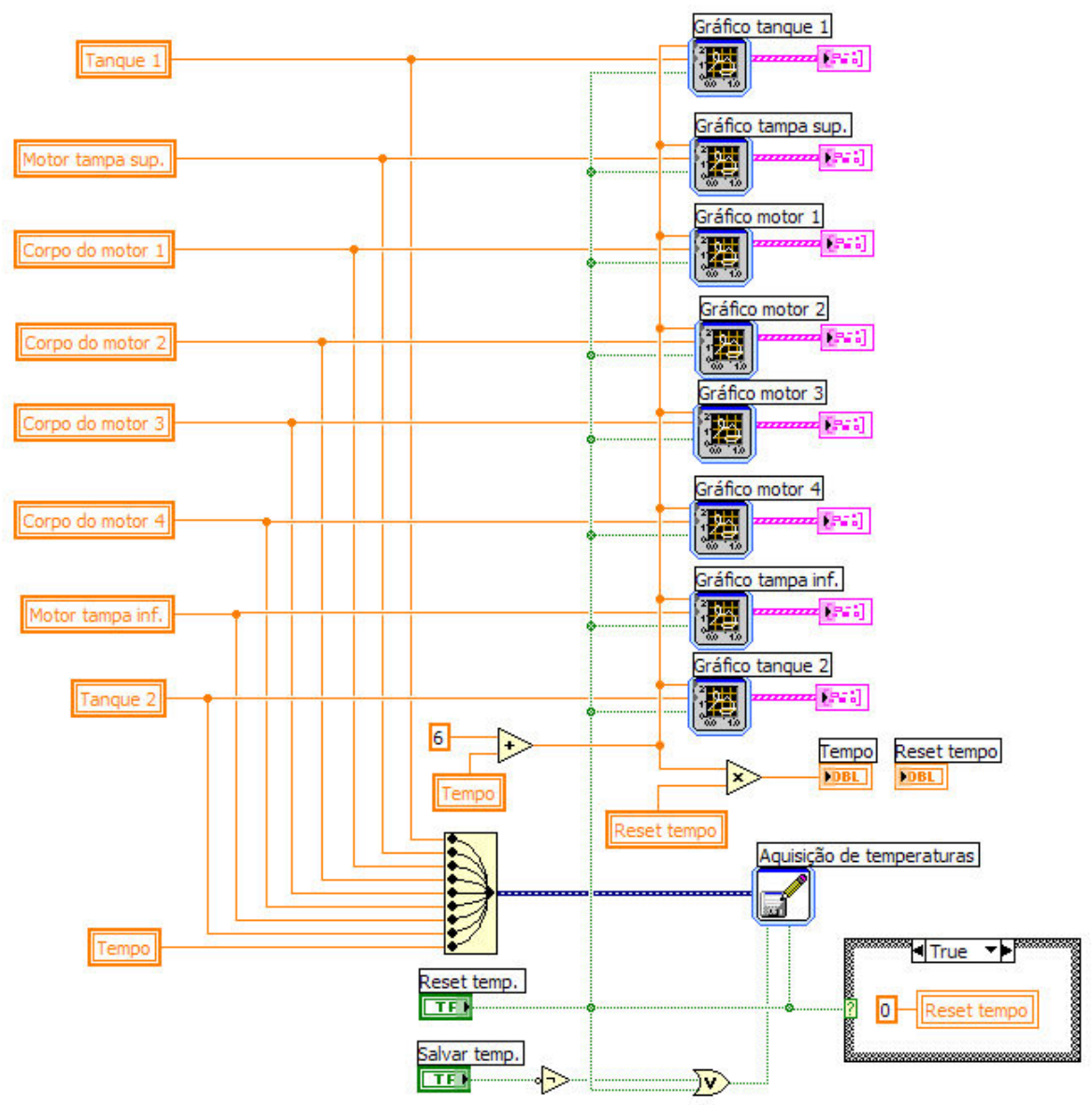

Fig. 3.33. Estrutura de programação de monitoração gráfica e aquisição das temperaturas.

Descrevendo a estrutura acima, a monitoração das temperaturas é feita ao longo do tempo e implementada pelos blocos $X Y$ Graph. $O$ eixo $Y$ corresponde às entradas das temperaturas, lidas através da estrutura de programação exibida anteriormente, (Fig. 3.26); no eixo $X$ tem-se a entrada do tempo, calculado pela expressão abaixo,

$$
T_{\text {Temp }}=\operatorname{RESET}_{T} \cdot\left(6+T_{\text {Tempo }}\right)
$$

onde

- $T_{\text {Tempo }}$ é a contagem do tempo (contagem do tempo de amostragem para as temperaturas);

- $R E S E T_{T}$ é o reset do tempo (limpa o valor do conteúdo variável tempo). $\operatorname{RESET}_{T}$, assumem valores de " 1 " ou "0". 
A equação (3.46) é implementada por funções matemáticas vistas na Fig. 3.33. O sistema de contagem de tempo é atualizado a cada minuto, sendo que a parcela 6 (seis) colocada na expressão (3.46) serve de referência para amostragem de minuto a minuto.

O $\operatorname{RESET}_{T}$ depende de uma lógica para atuar na estrutura de contagem do tempo. Essa lógica e realizada pelo bloco True, False e comandado pela caixa de entrada Reset temp. Quando Reset temp. =1, RESET $T_{T}=0$ e limpa-se o conteúdo em $T_{T E M P}$. Reset temp. também limpa todas as telas gráficas das temperaturas. Reset temp. é comandado por uma interface homem-máquina e, pode ser visto na Fig. 3.1, na tela principal de controle, e na Fig. 3.4 em mais detalhes através do botão nomeado como Reset.

Dando continuidade à descrição da estrutura de programação da Fig. 3.33, as temperaturas, além de serem monitoradas graficamente, podem ser salvas para análises. Os registros são feitos através do bloco Write LVM. Este bloco gera um arquivo do tipo .Ivm que pode ser lido no próprio ambiente de programação do "LABVIEW" (vide anexo B). Na fig. 3.33 pode ser visto nomeado como Aquisição de temperaturas. Este bloco salva todas as temperaturas ao longo do tempo. Todos os valores de temperaturas lidos são multiplexados através da função Merge signals e depois salvos.

O controle do bloco Aquisição de temperaturas é comandado por duas caixas de entrada, Salvar temp. e Reset temp. descritas anteriormente, os quais, comanda a entrada de Enable e Reset do bloco. O comando Enable é executado através da expressão

$$
S_{S_{T}}=\left(\bar{S}_{T}+R_{T}\right)
$$

onde

- $S_{S_{T}}$ é a saída salvar temperaturas. (saída da lógica que habilita o bloco que salva as temperaturas);

- $\bar{S}_{T}$ é salvar temperaturas.;

- $R_{T}$ é reset temperaturas. 
A equação (3.47) é implementada por funções booleanas vistas na Fig. 3.33. Salvar temp. e Reset temp. são comandadas por uma interface homem- máquina que pode ser vista da Fig. 3.1, nomeadas pelos botões Salvar dados e Reset, respectivamente.

O bloco aquisição de temperaturas funciona da seguinte maneira: comandando o botão Salvar, sendo $\bar{S}_{T}=0$, automaticamente $S_{S_{T}}=1$, habilita o bloco e se inicia a aquisição das temperaturas. Com $\bar{S}_{T}=1$ para a aquisição. Para limpar o arquivo, basta comandar o botão Reset.

\subsubsection{Aquisição de dados}

A próxima estrutura de programação da Fig. 3.34, apresenta o bloco que executa a aquisição de dados. O bloco utilizado para aquisição de dados é o mesmo utilizado na aquisição das temperaturas, nomeado como Aquisição de dados.

Observe que todas as variáveis do sistema são monitoradas pelo software e salvas para análises. O seu funcionamento é parecido com o da aquisição de temperaturas. Os registros são feitos através do bloco Write LVM. Esse bloco salva todas as variáveis ao longo do tempo. Todos as variáveis lidas são multiplexadas através da função Merge signals e depois salvas. 


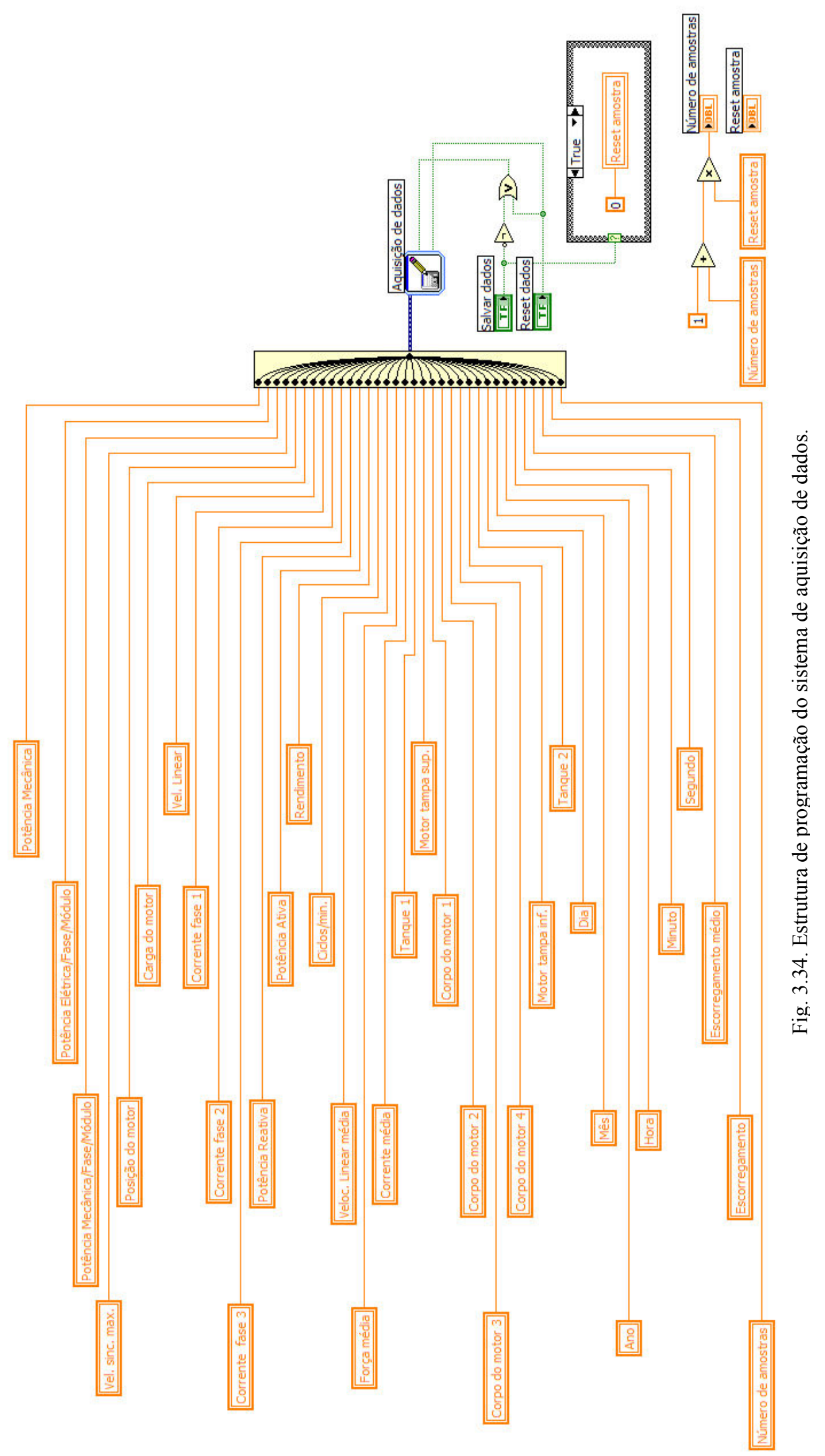


A freqüência de amostragem do sistema para aquisição de dados é mesma freqüência de amostragem geral do sistema. Existe um contador de amostras para facilitar depois as análises (vide anexo B), dado pela expressão abaixo,

$$
C_{N_{A}}=\operatorname{RESET}_{A} \cdot\left(1+C_{N_{A}}\right)
$$

onde

- $C_{N_{A}}$ é o contador do número de amostras;

- $\operatorname{RESET}_{A}$ é o reset amostras (limpa o valor do conteúdo da variável número de amostras). RESET $T_{A}$, assume valores "1" ou "0".

A equação (3.48) é implementada por funções matemáticas, vista na Fig. 3.34. O sistema de contagem do número de amostras é atualizado de acordo com a amostragem geral do sistema.

O $\operatorname{RESET}_{A}$ depende de uma lógica para atuar na estrutura de contagem do número de amostras. Essa lógica é a mesma utilizada na aquisição das temperaturas e feita pelo bloco True, False, que é comandado pela caixa de entrada Reset dados. Quando Reset dados. $=1, R_{E S E T}=0$ e limpa-se o conteúdo de $C_{N_{A}}$. Reset dados é comandado por uma interface-homem máquina e pode ser visto na Fig. 3.1, na tela principal de controle, e na Fig. 3.3 em mais detalhes, através do botão nomeado como Reset.

O controle do bloco Aquisição de dados é comandado por duas caixas de entrada Salvar dados. e Reset dados. descrita anteriormente, os quais, comandam a entrada de Enable e Reset do bloco. O comando Enable é executado através da expressão,

$$
S_{S_{D}}=\left(\bar{S}_{D}+R_{D}\right)
$$

onde,

- $S_{S_{D}}$ é a saída salvar dados ( saída da lógica que habilita o bloco que salva os dados );

- $\bar{S}_{D}$ é salvar dados;

- $R_{D}$ é o reset dados. 
A equação (3.49) é implementada por funções booleanas vistas na Fig. 3.34. Salvar dados. e Reset dados. são comandadas por uma interface homem-máquina que pode ser vista da Fig. 3.1, nomeadas pelos botões Salvar e Reset, respectivamente.

O bloco aquisição de dados funciona da seguinte maneira: comandando o botão Salvar, sendo $\bar{S}_{D}=0$, automaticamente $S_{S_{D}}=1$, habilita-se o bloco e inicia-se a aquisição de dados. Com $\bar{S}_{D}=1$ para a aquisição. Para limpar o arquivo basta comandar o botão Reset.

No anexo B, são apresentados os softwares de monitoração em "off" do MATÆEOS, que utilizam os arquivos .Ivm apresentados nesta seção. Esses softwares permitirão monitorar o motor e apresentar os resultados de uma útil para análises posteriores. 


\section{Os ensaios com o MAT/EOS}

Esta seção apresenta os ensaios realizados com o MATÆEOS e seus resultados e análises.

\subsection{Parametrização do inversor}

Foram realizados três ensaios, parametrizando o inversor em três freqüências nominais diferentes como,

$$
\begin{aligned}
& \cdot 230 \mathrm{~V} / 7 \mathrm{~Hz} \\
& \cdot 230 \mathrm{~V} / 6 \mathrm{~Hz} \\
& \cdot 230 \mathrm{~V} / 5 \mathrm{~Hz}
\end{aligned}
$$

Estes ajustes estabelecem o "fluxo nominal" para cada ensaio, pois o MATÆEOS é um motor de indução.

O objetivo deste procedimento é determinar o melhor ajuste para a parametrização do inversor.

As medições das correntes e potências elétricas do motor são realizadas na entrada do inversor. Então, o rendimento estimado foi obtido considerando um rendimento do inversor de $98 \%$.

\subsection{Ajuste da freqüência de operação}

Dada a relação $\mathrm{V} / \mathrm{Hz}$ do inversor, são realizados testes em diferentes freqüências de operação. As freqüências escolhidas para cada caso são dadas a seguir. 
- $230 \mathrm{~V} / 7 \mathrm{~Hz}$ - freqüências de operação:

- $7,0 \mathrm{~Hz}$

- $6,5 \mathrm{~Hz}$

- $6,0 \mathrm{~Hz}$

- $230 \mathrm{~V} / 6 \mathrm{~Hz}$ - freqüências de operação:

- $6,5 \mathrm{~Hz}$

- $6,0 \mathrm{~Hz}$

- $5,5 \mathrm{~Hz}$

- 230 V/5 Hz - freqüências de operação:

- $5,5 \mathrm{~Hz}$

- $5,0 \mathrm{~Hz}$

- $4,5 \mathrm{~Hz}$

Com estes testes, é possível determinar a influência do "enfraquecimento" ou do "fortalecimento" do fluxo do motor no desempenho do mesmo.

\subsection{Ensaios com inversor parametrizado em $230 \mathrm{~V} / 7 \mathrm{~Hz}$}

Dentre todos os testes realizados, o ajuste da relação $230 \mathrm{~V} / 7 \mathrm{~Hz}$ estabelece a mais "fraca" configuração de fluxo nas partes magnéticas do motor. Ao ajustar a freqüência de saída do inversor em 7,0, 6,5 e 6,0 Hz, realiza-se uma redução proporcional na tensão de alimentação do motor, o que mantém a configuração de fluxo magnético. Em tese, a conseqüência direta deste fato é a manutenção da capacidade de "produção de força" do motor em freqüências abaixo da nominal, embora isso não represente necessariamente piora ou melhora no desempenho como um todo. 


\subsubsection{Resultados obtidos com freqüência de operação em $7,0 \mathrm{~Hz}$}

A Tabela 4.1 apresenta os resultados obtidos no ensaio, com a freqüência de operação ajustada em $7,0 \mathrm{~Hz}$.

Tabela 4.1. Parametrização 230 V/7 Hz. Freqüência de operação $7,0 \mathrm{~Hz}$.

\begin{tabular}{|r|c|c|}
\hline Força média medida na subida $F_{M}(\mathrm{Kgf})$ & 180,5 & 159,0 \\
\hline Rendimento $(\%)$ & 8,0 & 18,0 \\
\hline Ciclos por minuto & 8 & 9 \\
\hline Corrente de acionamento $I_{s}(\mathrm{~A})$ & 19,0 & 18,2 \\
\hline Velocidade linear $V_{L}(\mathrm{~m} / \mathrm{s})$ & 0,29 & 0,60 \\
\hline Excursão média $(\mathrm{m})$ & 1,17 & 1,15 \\
\hline Temperatura média da carcaça $\left({ }^{\circ} \mathrm{C}\right)$ & 66,9 & \multicolumn{1}{|c}{} \\
\cline { 1 - 2 } Temperatura média reservatório $\left({ }^{\circ} \mathrm{C}\right)$ & 48,8 & \multicolumn{1}{|c}{}
\end{tabular}

Observam-se nas Figs. 4.1 e 4.2 a seguir as curvas dinamométricas do motor para as cargas aproximadas de $190 \mathrm{Kgf} \mathrm{e} 160 \mathrm{Kgf}$, respectivamente.

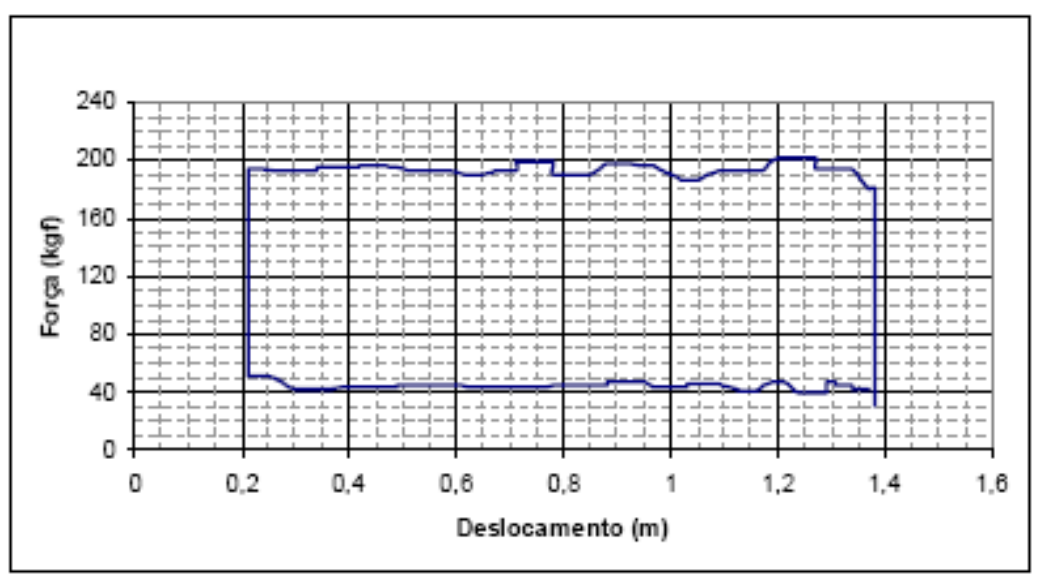

Fig. 4.1. Curva dinamométrica. Parametrização em 230 V/7 Hz. Freqüência de operação $7 \mathrm{~Hz}$; Carga: $190 \mathrm{Kgf}$. 


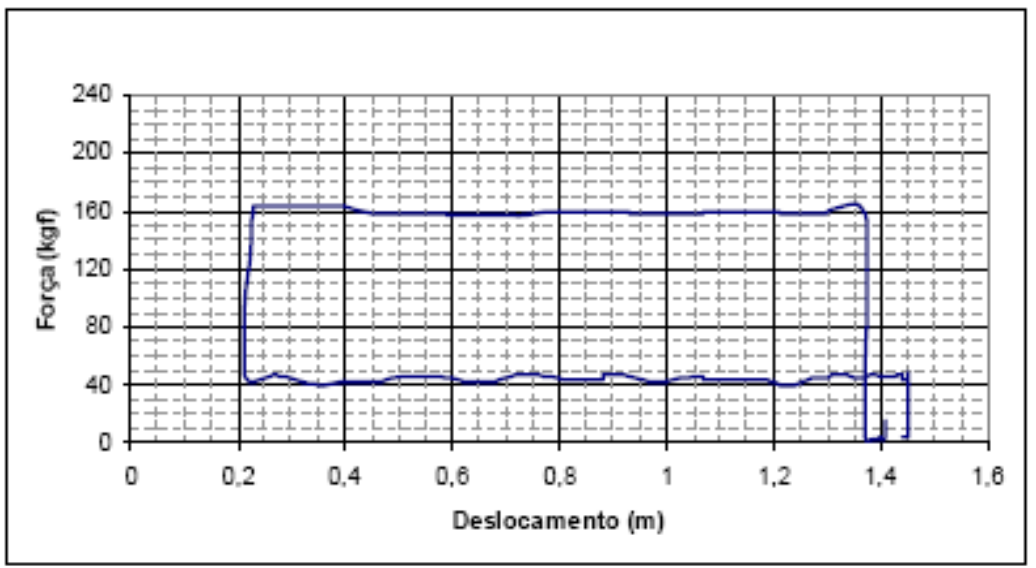

Fig. 4.2. Curva dinamométrica. Parametrização em 230 V/7 Hz. Freqüência de operação 7 Hz; Carga: $160 \mathrm{Kgf}$.

\subsubsection{Resultados obtidos com freqüência de operação em $6,5 \mathrm{~Hz}$}

A Tabela 4.2 mostra os resultados obtidos no ensaio com freqüência de operação em $6,5 \mathrm{~Hz}$.

Tabela 4.2. Parametrização $230 \mathrm{~V} / 7 \mathrm{~Hz}$. Freqüência de operação $6,5 \mathrm{~Hz}$.

\begin{tabular}{|r|c|c|}
\hline Força média medida na subida $F_{M}(\mathrm{Kgf})$ & 191,3 & 162,4 \\
\hline Rendimento $(\%)$ & 11,0 & 17,0 \\
\hline Ciclos por minuto & 9 & 9 \\
\hline Corrente de acionamento $I_{s}(\mathrm{~A})$ & 19,9 & 17,8 \\
\hline Velocidade linear $V_{L}(\mathrm{~m} / \mathrm{s})$ & 0,33 & 0,55 \\
\hline Excursão média $(\mathrm{m})$ & 1,21 & 1,22 \\
\hline Temperatura média da carcaça $\left({ }^{\circ} \mathrm{C}\right)$ & 66,7 & \multicolumn{1}{|c}{} \\
\cline { 1 - 2 } Temperatura média reservatório $\left({ }^{\circ} \mathrm{C}\right)$ & 49,2 & \multicolumn{1}{|c}{} \\
\cline { 1 - 2 } &
\end{tabular}

As curvas dinamométricas do motor com a freqüência do inversor ajustada em $6,5 \mathrm{~Hz}$ são mostradas nas Figs. 4.3 e 4.4, para cargas aproximadas de 190 e 160 Kgf, respectivamente. 


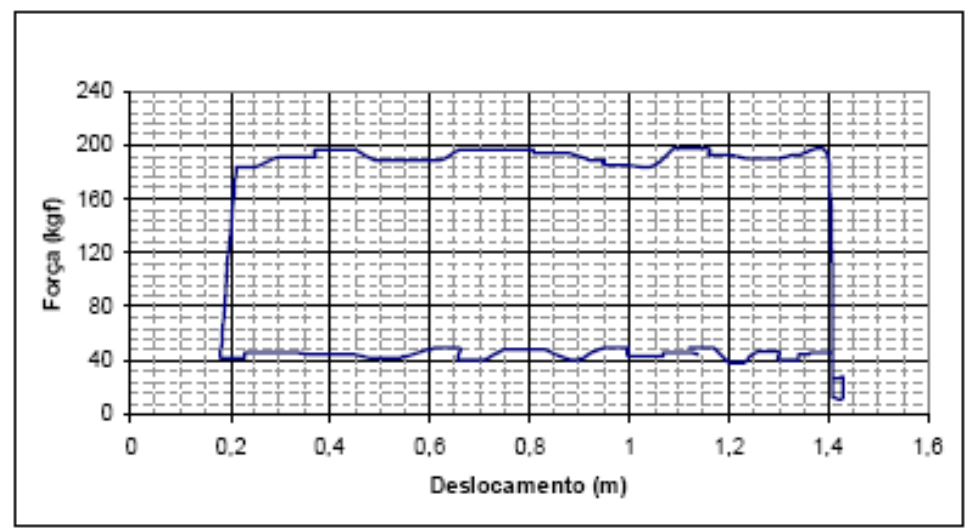

Fig. 4.3. Curva dinamométrica. Parametrização em 230 V/7 Hz. Freqüência de operação 6,5 Hz; Carga: $160 \mathrm{Kgf}$.

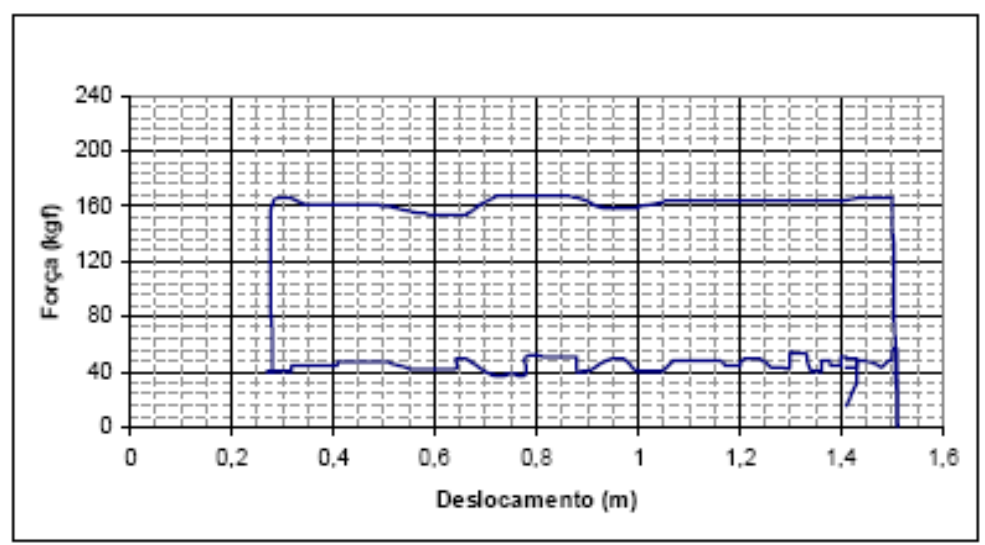

Fig. 4.4. Curva dinamométrica. Parametrização em 230 V/7 Hz. Freqüência de operação 6,5 Hz; Carga: $160 \mathrm{Kgf}$.

\subsubsection{Resultados obtidos com freqüência de operação em $6,0 \mathrm{~Hz}$}

A Tabela 4.3 apresenta os resultados de ensaio, com a freqüência de operação ajustada em $6,0 \mathrm{~Hz}$. 
Tabela 4.3. Parametrização 230 V/7 Hz. Freqüência de operação $6,0 \mathrm{~Hz}$.

\begin{tabular}{|c|c|c|}
\hline Força média medida na subida $F_{M}(\mathrm{Kgf})$ & 195,9 & 159,8 \\
\hline Rendimento (\%) & 8,0 & 15,0 \\
\hline Ciclos por minuto & 8 & 8 \\
\hline Corrente de acionamento $I_{S}(\mathrm{~A})$ & 19,3 & 17,1 \\
\hline Velocidade linear $V_{L}(\mathrm{~m} / \mathrm{s})$ & 0,24 & 0,56 \\
\hline Excursão média (m) & 0,95 & 0,98 \\
\hline Temperatura média da carcaça $\left({ }^{\circ} \mathrm{C}\right)$ & 67,5 & \\
\hline Temperatura média reservatório $\left({ }^{\circ} \mathrm{C}\right)$ & 49,1 & \\
\hline
\end{tabular}

Para a freqüência do inversor ajustada em $6,0 \mathrm{~Hz}$ são dadas as curvas dinamométricas das Figs. 4.5 e 4.6, para as cargas aproximadas de $190 \mathrm{Kgf}$ e 160 Kgf, respectivamente.

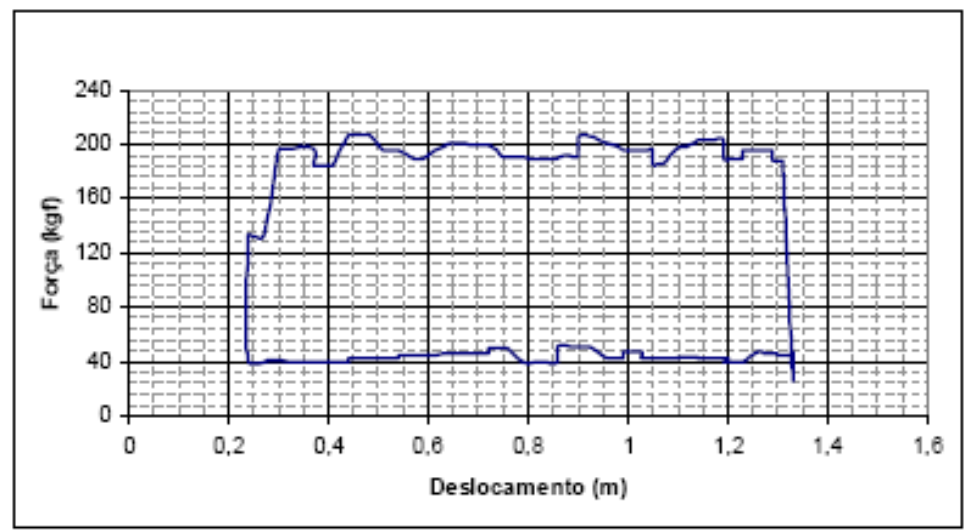

Fig. 4.5. Curva dinamométrica. Parametrização em 230 V/7 Hz. Freqüência de operação 6,0 Hz; Carga: $160 \mathrm{Kgf}$.

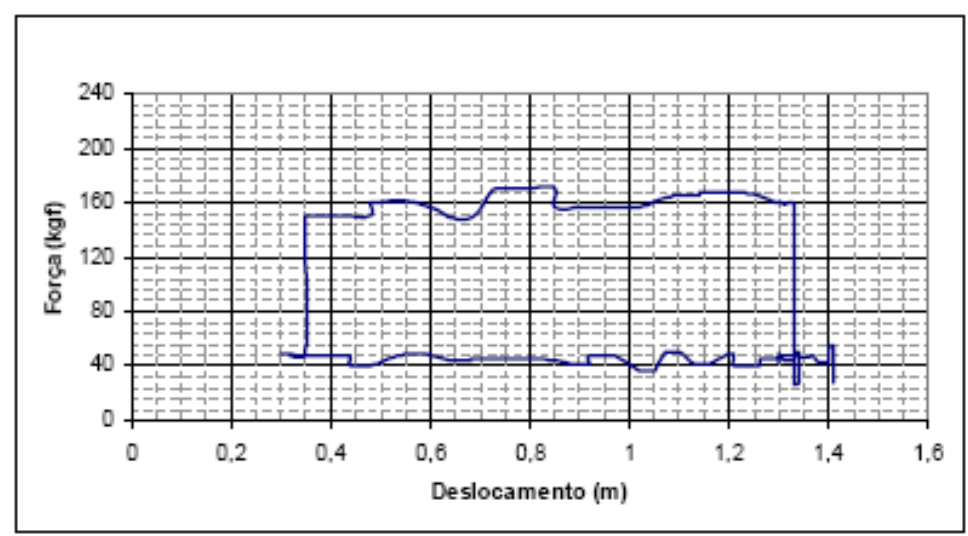

Fig. 4.6. Curva dinamométrica. Parametrização em 230 V/7 Hz. Freqüência de operação 6,0 Hz; Carga: $160 \mathrm{Kgf}$. 


\subsection{Ensaios com inversor parametrizado em 230 V/6 Hz}

A parametrização do inversor em $230 \mathrm{~V} / 6 \mathrm{~Hz}$ estabelece um fluxo magnético um pouco mais intenso no motor, comparado ao ensaio anterior. São testadas freqüências de saída de 6,5, 6,0 e 5,5 Hz. Para a freqüência de saída do inversor ajustada em $6,5 \mathrm{~Hz}$, o fluxo é reduzido, pois a tensão aplicada não pode ser aumentada proporcionalmente à freqüência. Isto determina uma redução na capacidade de produção de força do motor. Nas freqüências de 6,0 e $5,5 \mathrm{~Hz}$ é realizado um ajuste proporcional na tensão de alimentação do motor, o que faz com que o fluxo magnético seja mantido constante. Nestas duas freqüências, portanto, é esperada uma manutenção na capacidade de produção de força.

\subsubsection{Resultados obtidos com freqüência de operação em $6,5 \mathrm{~Hz}$}

A Tabela 4.4 apresenta os dados obtidos no ensaio em questão, com freqüência de operação em $6,5 \mathrm{~Hz}$.

Tabela 4.4. Parametrização $230 \mathrm{~V} / 6 \mathrm{~Hz}$. Freqüência de operação $6,5 \mathrm{~Hz}$.

\begin{tabular}{|r|c|c|}
\hline Força média medida na subida $F_{M}(\mathrm{Kgf})$ & 208,3 & 167,8 \\
\hline Rendimento $(\%)$ & 10,0 & 14,0 \\
\hline Ciclos por minuto & 9 & 11 \\
\hline Corrente de acionamento $I_{s}(\mathrm{~A})$ & 23,1 & 18,7 \\
\hline Velocidade linear $V_{L}(\mathrm{~m} / \mathrm{s})$ & 0,30 & 0,52 \\
\hline Excursão média $(\mathrm{m})$ & 0,91 & 1,10 \\
\hline Temperatura média da carcaça $\left({ }^{\circ} \mathrm{C}\right)$ & 64,1 & \multicolumn{1}{|c}{} \\
\cline { 1 - 2 } Temperatura média reservatório $\left({ }^{\circ} \mathrm{C}\right)$ & 46,3 & \multicolumn{1}{|c}{} \\
\cline { 1 - 2 } &
\end{tabular}

Com a freqüência do inversor ajustada em $6,5 \mathrm{~Hz}$, são obtidas as curvas dinamométricas das Figs. 4.7 e 4.8, para cargas aproximadas de 195 e 175 Kgf, respectivamente. 


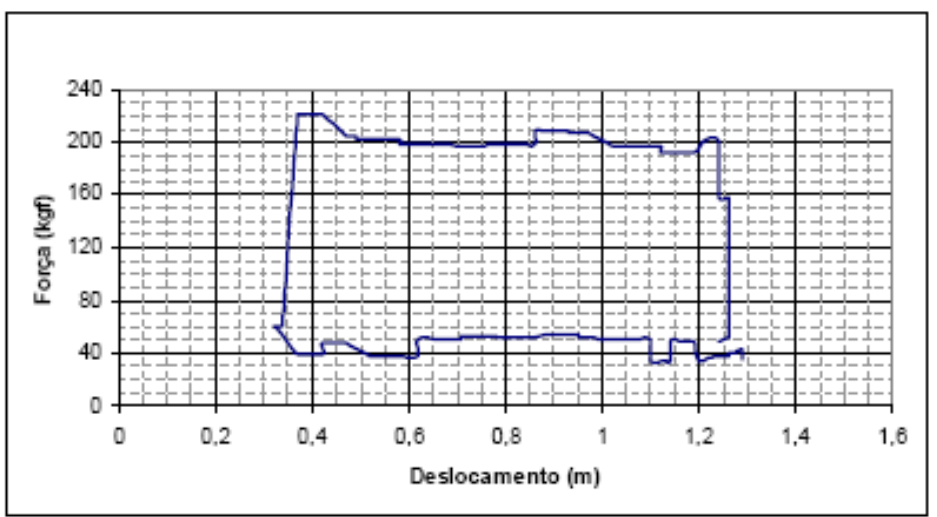

Fig. 4.7. Curva dinamométrica. Parametrização em 230 V/6 Hz. Freqüência de operação 6,5 Hz; Carga: $200 \mathrm{Kgf}$.

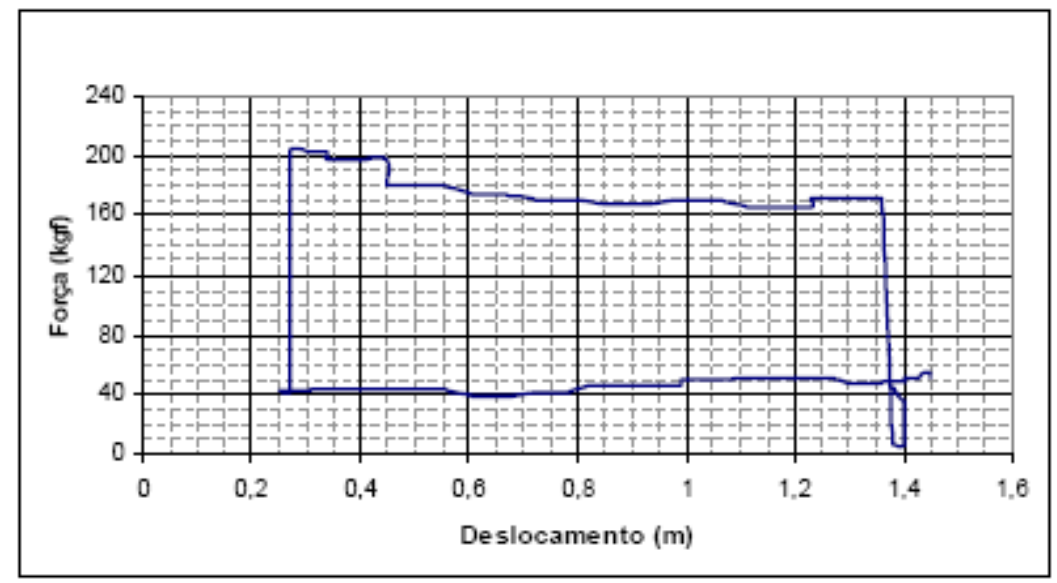

Fig. 4.8. Curva dinamométrica. Parametrização em 230 V/6 Hz. Freqüência de operação 6,5 Hz; Carga: $175 \mathrm{Kgf}$.

\subsubsection{Resultados obtidos com freqüência de operação em $6,0 \mathrm{~Hz}$}

A Tabela 4.5 mostra os resultados obtidos no ensaio, com a freqüência de operação em $6,0 \mathrm{~Hz}$. 
Tabela 4.5. Parametrização 230 V/6 Hz. Freqüência de operação $6,0 \mathrm{~Hz}$.

\begin{tabular}{|r|c|c|}
\hline Força média medida na subida $F_{M}(\mathrm{Kgf})$ & 193,0 & 174,5 \\
\hline Rendimento $(\%)$ & 15,0 & 14,0 \\
\hline Ciclos por minuto & 11 & 12 \\
\hline Corrente de acionamento $I S(\mathrm{~A})$ & 20,1 & 18,7 \\
\hline Velocidade linear $V_{L}(\mathrm{~m} / \mathrm{s})$ & 0,54 & 0,53 \\
\hline Excursão média $(\mathrm{m})$ & 1,14 & 1,14 \\
\hline Temperatura média da carcaça $\left({ }^{\circ} \mathrm{C}\right)$ & 65,5 & \multicolumn{1}{|c}{} \\
\cline { 1 - 2 } Temperatura média reservatório $\left({ }^{\circ} \mathrm{C}\right)$ & 47,5 & \multicolumn{1}{|c}{}
\end{tabular}

Verificam-se nos gráficos das Figs. 4.9 e 4.10 as curvas dinamométricas do motor com a freqüência do inversor ajustada em $6,0 \mathrm{~Hz}$.

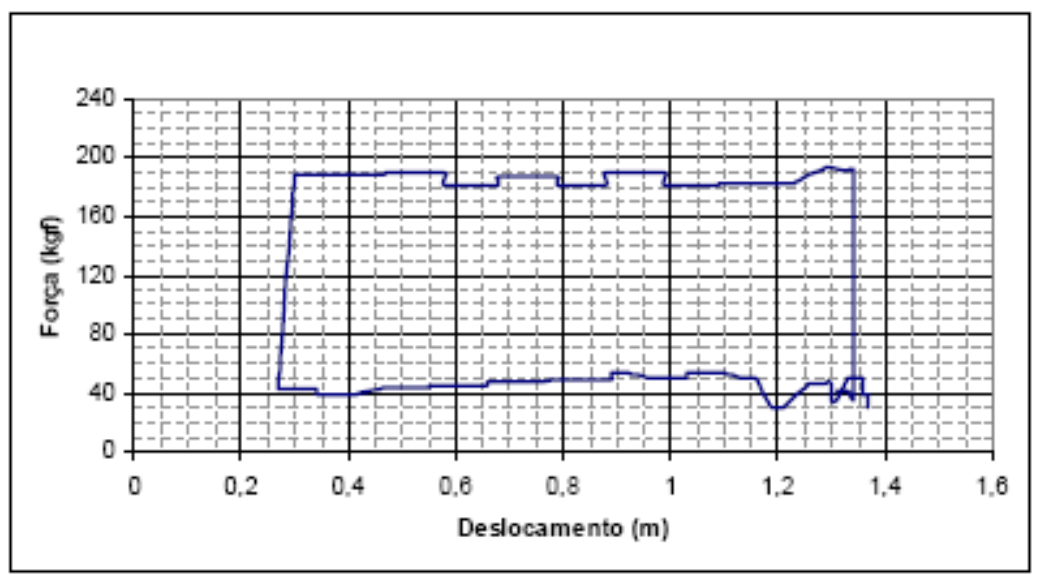

Fig. 4.9. Curva dinamométrica. Parametrização em 230 V/6 Hz. Freqüência de operação $6,0 \mathrm{~Hz}$; Carga: 195 Kgf.

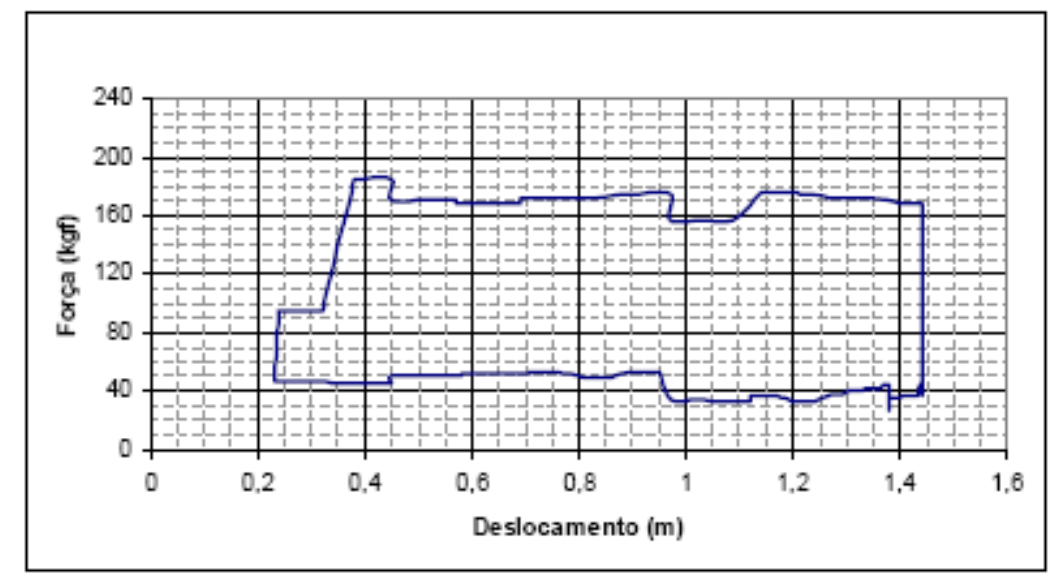

Fig. 4.10. Curva dinamométrica. Parametrização em 230 V/6 Hz. Freqüência de operação 6,0 Hz; Carga: $170 \mathrm{Kgf}$. 


\subsubsection{Resultados obtidos com freqüência de operação em $5,5 \mathrm{~Hz}$}

A Tabela 4.6 resume os resultados obtidos com a freqüência de operação ajustada em $5,5 \mathrm{~Hz}$.

Tabela 4.6. Parametrização 230 V/6 Hz. Freqüência de operação $5,5 \mathrm{~Hz}$.

\begin{tabular}{|r|c|c|}
\hline Força média medida na subida $F_{M}(\mathrm{Kgf})$ & 186,0 & 162,4 \\
\hline Rendimento $(\%)$ & 13,0 & 17,0 \\
\hline Ciclos por minuto & 11 & 13 \\
\hline Corrente de acionamento $I S(\mathrm{~A})$ & 19,2 & 18,2 \\
\hline Velocidade linear $V_{L}(\mathrm{~m} / \mathrm{s})$ & 0,43 & 0,60 \\
\hline Excursão média $(\mathrm{m})$ & 1,06 & 1,15 \\
\cline { 1 - 2 } Temperatura média da carcaça $\left({ }^{\circ} \mathrm{C}\right)$ & 67,3 & \multirow{2}{|c}{} \\
\cline { 1 - 2 } Temperatura média reservatório $\left({ }^{\circ} \mathrm{C}\right)$ & 48,0 & \multicolumn{1}{|c}{}
\end{tabular}

Para a freqüência de operação ajustada em $5,5 \mathrm{~Hz}$ são dadas as curvas dinamométricas.

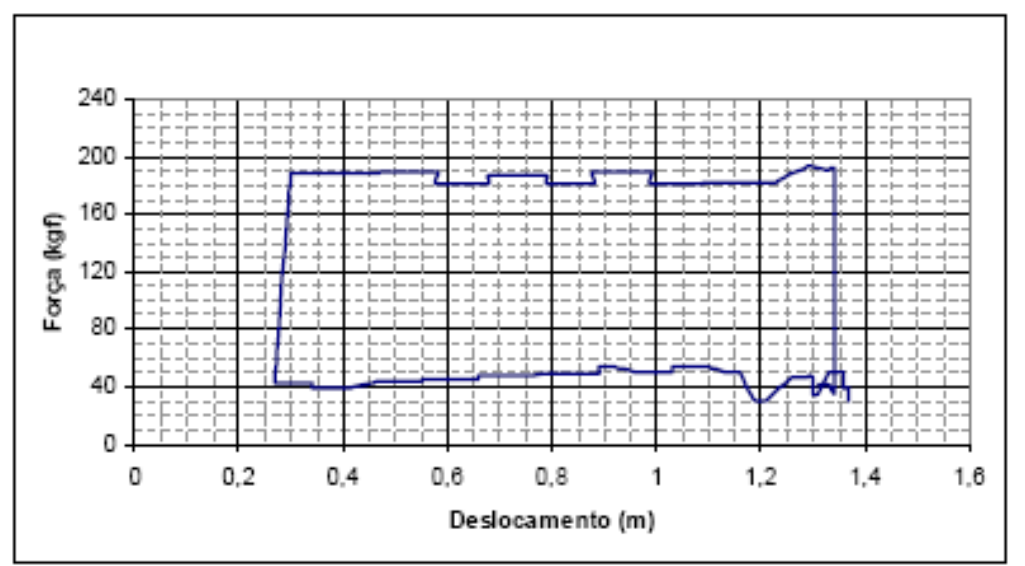

Fig. 4.11. Curva dinamométrica. Parametrização em 230 V/6 Hz. Freqüência de operação 5,5 Hz; Carga: $160 \mathrm{Kgf}$. 


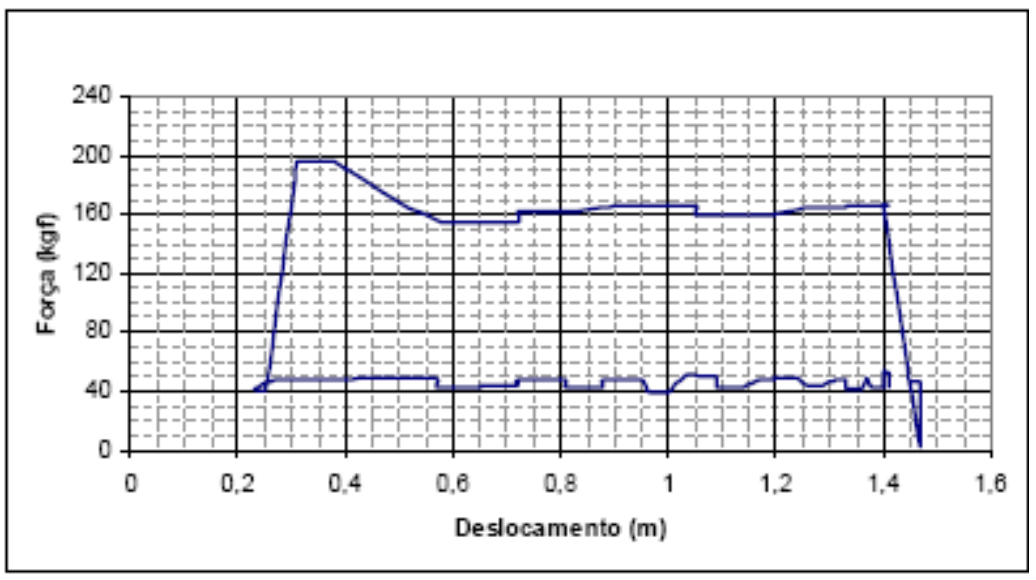

Fig. 4.12. Curva dinamométrica. Parametrização em 230 V/6 Hz. Freqüência de operação $5,5 \mathrm{~Hz}$; Carga: $160 \mathrm{Kgf}$.

\subsection{Ensaios com inversor parametrizado em $230 \mathrm{~V} / 5 \mathrm{~Hz}$}

Esta parametrização do inversor estabelece um fluxo magnético mais intenso no motor, comparado aos ensaios anteriores. As freqüências de saída de teste são 5,5, 5,0 e 4,5 Hz. Observa-se novamente que, para a freqüência de saída do inversor ajustada em $5,5 \mathrm{~Hz}$, o fluxo é reduzido, pois a tensão aplicada não aumenta proporcionalmente. Nesta condição, ocorre a redução da capacidade de produção de força do motor. Nas freqüências de 5,0 e $4,5 \mathrm{~Hz}$ o ajuste proporcional na tensão de alimentação do motor permite a manutenção da capacidade de produção de força do motor.

\subsubsection{Resultados obtidos com freqüência de operação em $5,5 \mathrm{~Hz}$}

Observa-se na Tabela 4.7 os resultados obtidos no ensaio em questão. 
Tabela 4.7. Parametrização $230 \mathrm{~V} / 5 \mathrm{~Hz}$. Freqüência de operação $5,5 \mathrm{~Hz}$

\begin{tabular}{|r|c|c|}
\hline Força média medida na subida $F_{M}(\mathrm{Kgf})$ & 232,6 & 202,0 \\
\hline Rendimento $(\%)$ & 8,0 & 13,0 \\
\hline Ciclos por minuto & 11 & 10 \\
\hline Corrente de acionamento $I s(\mathrm{~A})$ & 21,4 & 20,4 \\
\hline Velocidade linear $V_{L}(\mathrm{~m} / \mathrm{s})$ & 0,29 & 0,41 \\
\hline Excursão média $(\mathrm{m})$ & 1,10 & 1,00 \\
\hline Temperatura média da carcaça $\left({ }^{\circ} \mathrm{C}\right)$ & 73,4 & \multicolumn{1}{|c}{} \\
\cline { 1 - 2 } Temperatura média reservatório $\left({ }^{\circ} \mathrm{C}\right)$ & 50,6 & \multicolumn{1}{|c}{} \\
\cline { 1 - 2 } &
\end{tabular}

Os gráficos mostrados nas Figs. 4.13 e 4.14, ilustram as curvas dinamométricas para as duas condições da Tabela IX, respectivamente.

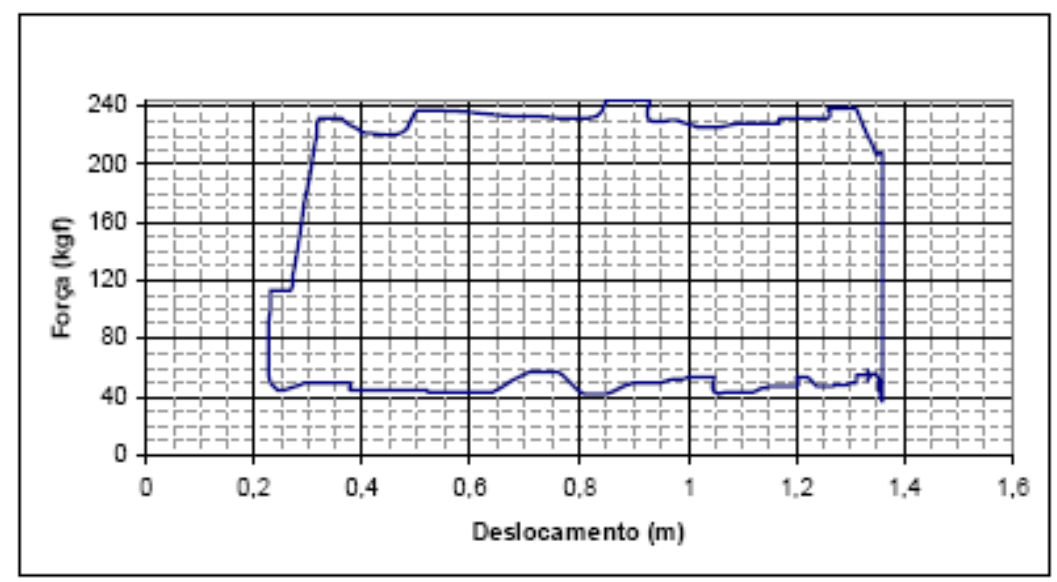

Fig. 4.13. Curva dinamométrica. Parametrização em 230 V/5 Hz. Freqüência de operação $5,5 \mathrm{~Hz}$; Carga: $230 \mathrm{Kgf}$.

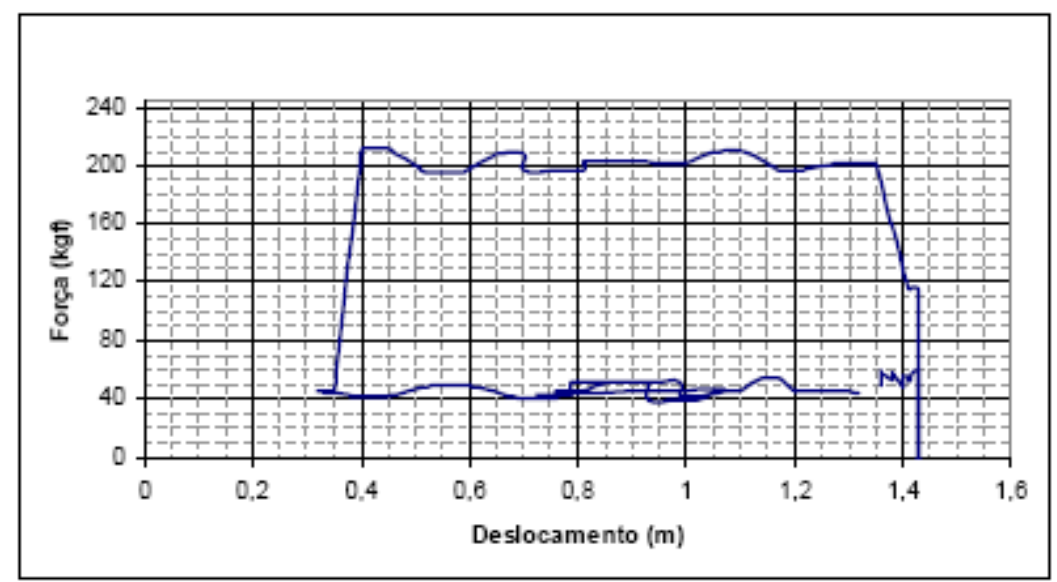

Fig. 4.14. Curva dinamométrica. Parametrização em 230 V/5 Hz. Freqüência de operação 5,5 Hz; Carga: $200 \mathrm{Kgf}$. 


\subsubsection{Resultados obtidos com freqüência de operação em $5,0 \mathrm{~Hz}$}

Observa-se na Tabela 4.8 os resultados do ensaio em questão.

Tabela 4.8. Parametrização 230 V/5 Hz. Freqüência de operação $5,0 \mathrm{~Hz}$.

\begin{tabular}{|r|c|c|}
\hline Força média medida na subida $F_{M}(\mathrm{Kgf})$ & 247,3 & 200,3 \\
\hline Rendimento $(\%)$ & 8,0 & 11,0 \\
\hline Ciclos por minuto & 10 & 13 \\
\hline Corrente de acionamento $I_{S}(\mathrm{~A})$ & 23,8 & 22,1 \\
\hline Velocidade linear $V_{L}(\mathrm{~m} / \mathrm{s})$ & 0,31 & 0,41 \\
\hline Excursão média $(\mathrm{m})$ & 1,10 & 1,20 \\
\cline { 1 - 2 } Temperatura média da carcaça $\left({ }^{\circ} \mathrm{C}\right)$ & 72,6 & \multirow{2}{|c}{} \\
\cline { 1 - 2 } Temperatura média reservatório $\left({ }^{\circ} \mathrm{C}\right)$ & 51,4 & \multicolumn{1}{|c|}{}
\end{tabular}

Observam-se as curvas dinamométricas para as duas condições de carga da Tabela 4.8 nos gráficos das Figs. 4.15 e 4.16, respectivamente.

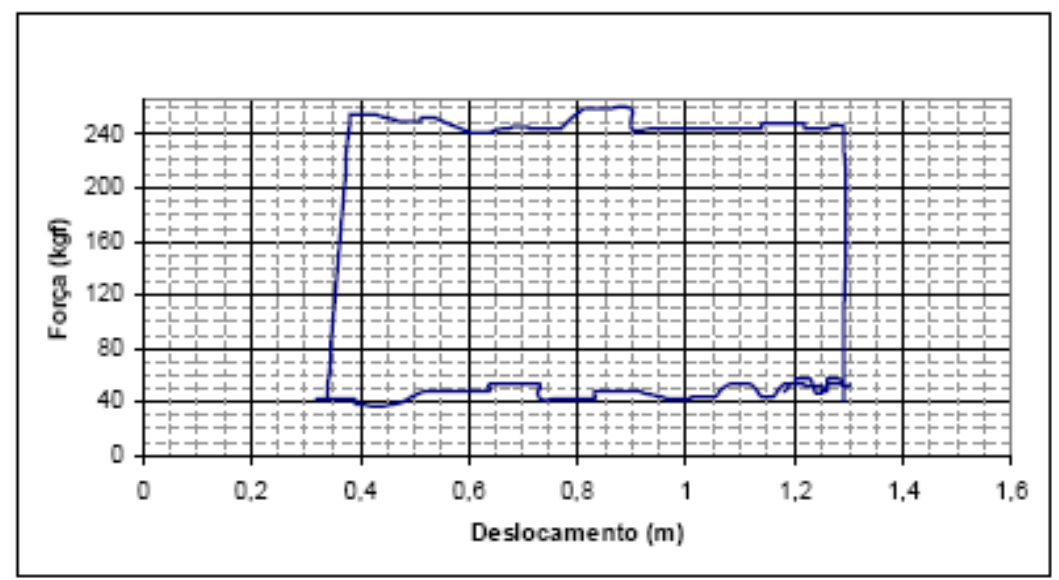

Fig. 4.15. Curva dinamométrica. Parametrização em 230 V/5 Hz. Freqüência de operação 5,0 Hz; Carga: $245 \mathrm{Kgf}$. 


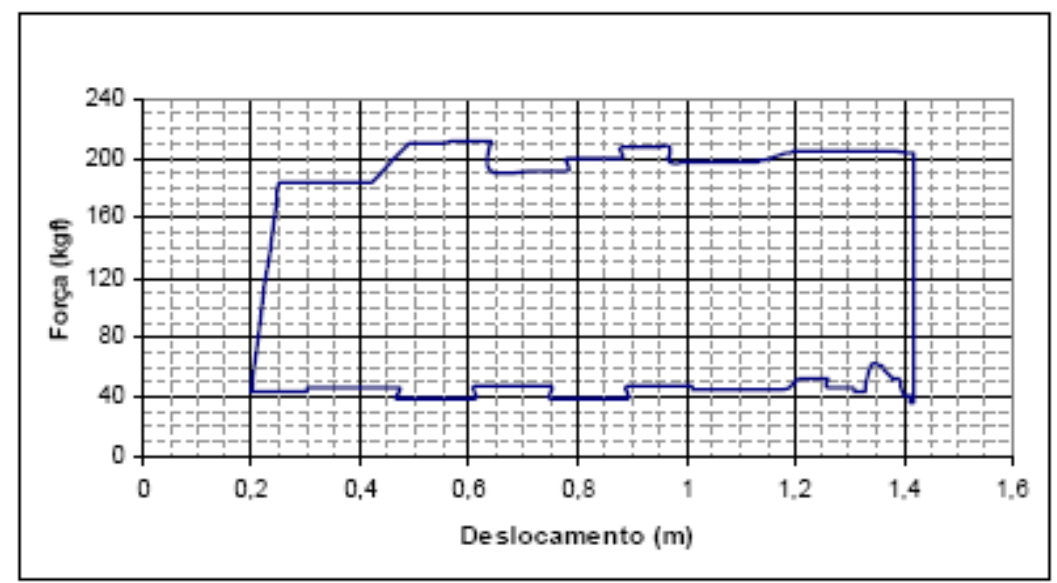

Fig. 4.16. Curva dinamométrica. Parametrização em 230 V/5 Hz. Freqüência de operação 5,0 Hz; Carga: $200 \mathrm{Kgf}$.

\subsubsection{Resultados obtidos com freqüência de operação em $4,5 \mathrm{~Hz}$}

São mostrados na tabela 4.9 os resultados do ensaio para a freqüência de operação em $4,5 \mathrm{~Hz}$.

Tabela 4.9. Parametrização 230 V/5 Hz. Freqüência de operação $4,5 \mathrm{~Hz}$.

\begin{tabular}{|r|c|c|}
\hline Força média medida na subida $F_{M}(\mathrm{Kgf})$ & 232,3 & 201,6 \\
\hline Rendimento $(\%)$ & 8,0 & 6,0 \\
\hline Ciclos por minuto & 10 & 12 \\
\hline Corrente de acionamento $I s(\mathrm{~A})$ & 22,1 & 21,1 \\
\hline Velocidade linear $V_{L}(\mathrm{~m} / \mathrm{s})$ & 0,26 & 0,31 \\
\hline Excursão média $(\mathrm{m})$ & 1,10 & 1,10 \\
\hline Temperatura média da carcaça $\left({ }^{\circ} \mathrm{C}\right)$ & 73,6 & \multicolumn{1}{|c}{} \\
\cline { 1 - 2 } Temperatura média reservatório $\left({ }^{\circ} \mathrm{C}\right)$ & 50,4 & \multicolumn{1}{|c}{} \\
\cline { 1 - 2 } &
\end{tabular}

São apresentadas as curvas dinamométricas para os ensaios em $5 \mathrm{~Hz}$, correspondentes às cargas de 235 e 200 Kgf nos gráficos das Figs. 4.17 e 4.18, respectivamente. 


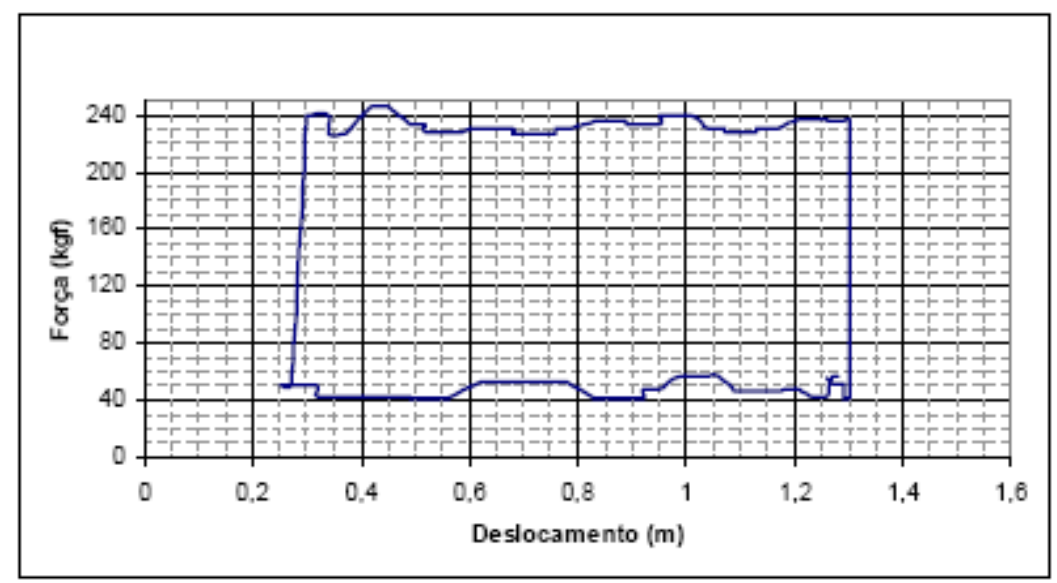

Fig. 4.17. Curva dinamométrica. Parametrização em 230 V/5 Hz. Freqüência de operação 4,5 Hz; Carga: $235 \mathrm{Kgf}$.

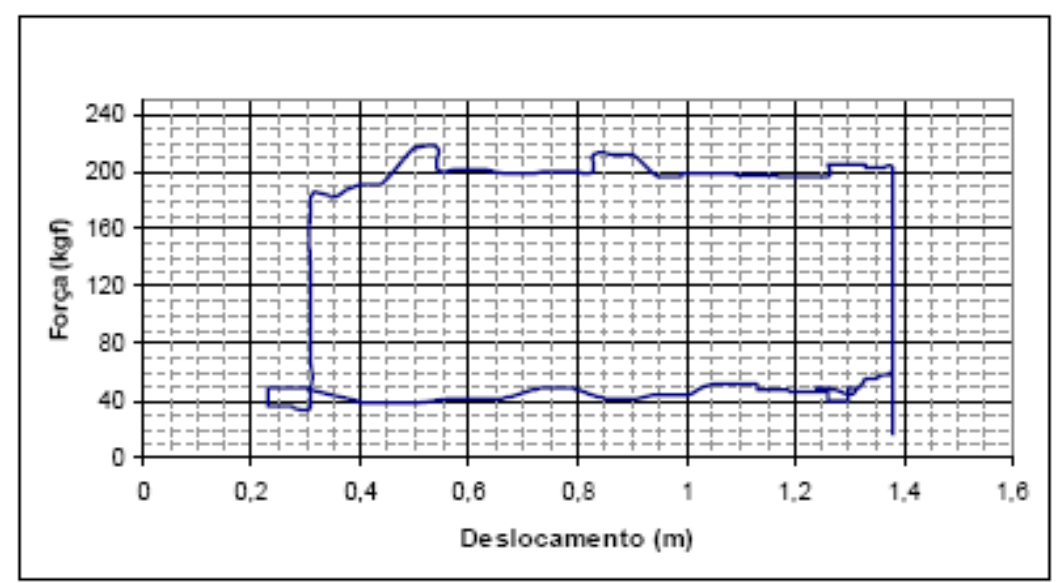

Fig. 4.18. Curva dinamométrica. Parametrização em 230 V/5 Hz. Freqüência de operação 4,5 Hz; Carga: $200 \mathrm{Kgf}$.

\subsection{Ensaio térmico}

Observam-se na Fig. 4.19 as curvas de aquecimento do motor medidas nos diferentes pontos. Especificamente, estas curvas foram obtidas no ensaio parametrizado em $230 \mathrm{~V} / 7 \mathrm{~Hz}$ com freqüência de operação de 7,0 Hz. São mostradas as curvas de aquecimento dos dois pontos do reservatório (entrada e saída de óleo no tanque) e de 4 pontos localizados longitudinalmente na carcaça do motor. 


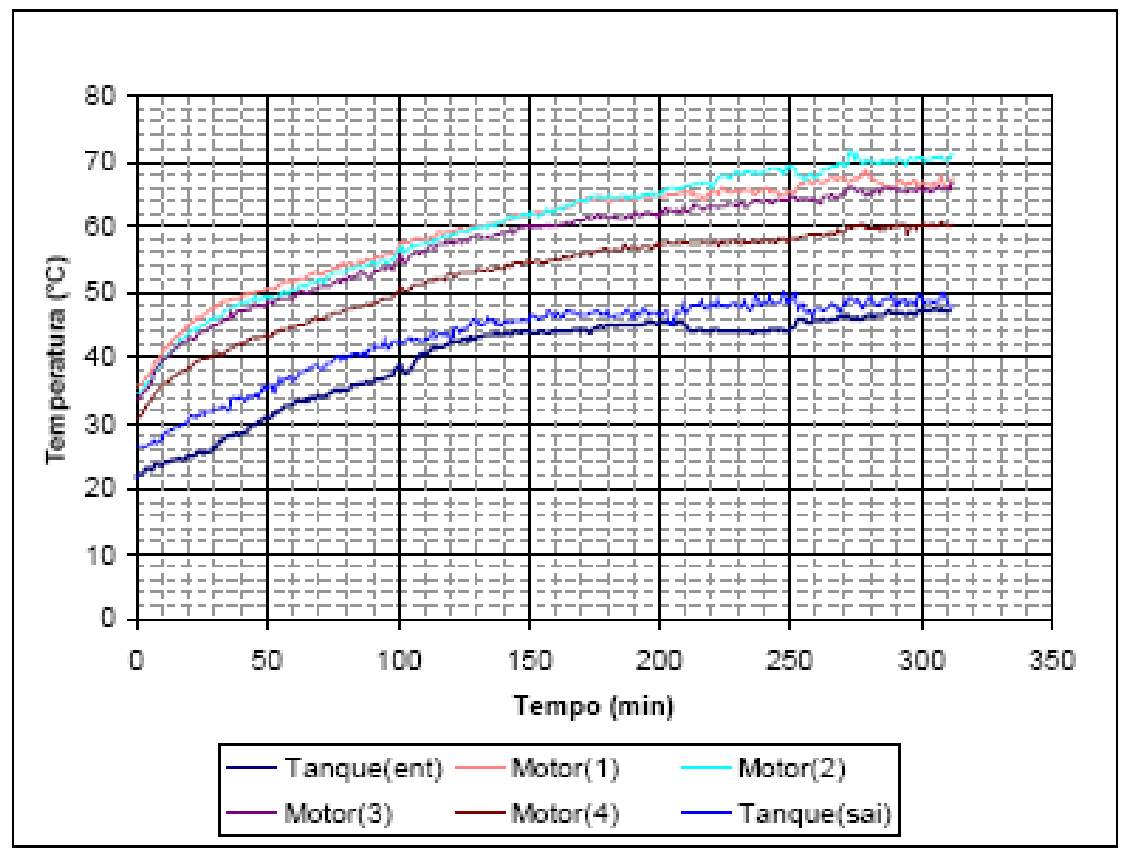

Fig. 4.19. Curva de aquecimento do motor em óleo ao longo do tempo.

Da mesma forma, foi realizada a medição da temperatura média das bobinas do enrolamento primário do MATÆES. Essa medição foi feita a partir da variação da resistência ôhmica por fase dos enrolamentos, utilizando uma ponte de Kelvin. Este ensaio foi realizado com o motor acionado pelo inversor parametrizado em $230 \mathrm{~V} / 7$ Hz. A condição de operação corresponde a uma freqüência de acionamento de $7 \mathrm{~Hz}$, com carga de cerca de 180,5 kgf, corrente de 19,0 A, conforme a Tabela 4.1. O resultado da medição da temperatura média do enrolamento é mostrado na Tabela 4.10 , juntamente com outros resultados medidos.

Tabela 4.10. Medição de temperaturas. Parametrização: $230 \mathrm{~V} / 7 \mathrm{~Hz}$. Freqüência de operação $7,0 \mathrm{~Hz}$

\begin{tabular}{|r|c|}
\hline Força média na subida $F_{M}(\mathrm{Kgf})$ & 180,5 \\
\hline Corrente de acionamento $I_{s}(\mathrm{~A})$ & 19,0 \\
\hline Temperatura absoluta do enrolamento primário $\left({ }^{\circ} \mathrm{C}\right)$ & 103,0 \\
\hline Temperatura média da carcaça $\left({ }^{\circ} \mathrm{C}\right)$ & 66,9 \\
\hline Temperatura média do reservatório & 48,8 \\
\hline
\end{tabular}




\subsection{Curva característica experimental}

$\mathrm{Na}$ Fig. 4.20 a seguir são apresentadas duas curvas características experimentais do motor, uma corresponde ao início do ensaio (motor a frio) e a outra ao término do ensaio (motor a quente). Essa curvas correspondem ao ensaio de 230 V/7 Hz com freqüência de operação de $7 \mathrm{~Hz}$ da Tabela 4.1.

As curvas características são apresentadas para dois módulos acoplados do motor.

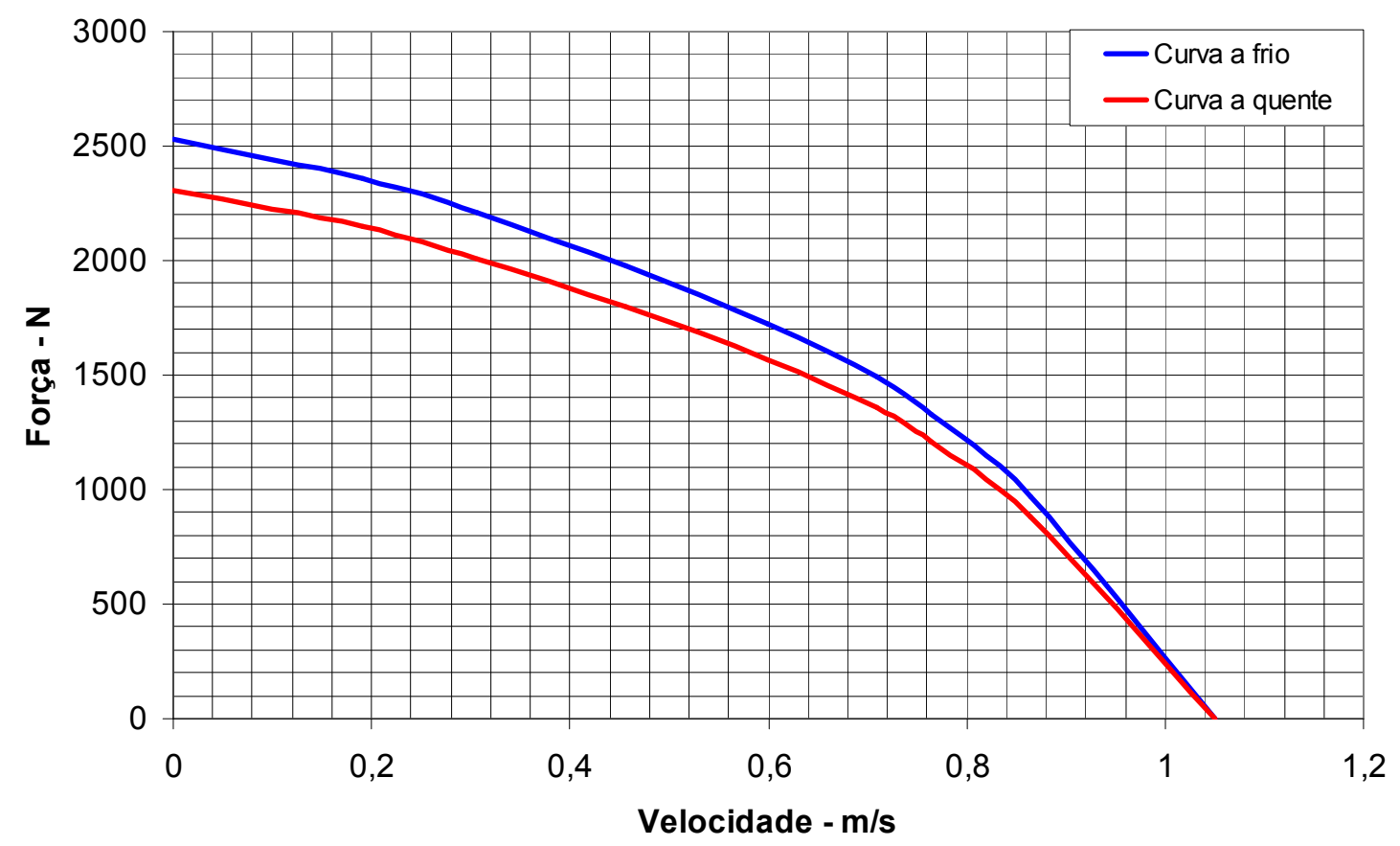

Fig. 4.20. Curvas características experimentais do motor a frio e a quente.

\subsection{Análises e conclusões preliminares}

Esta seção apresenta as análises dos resultados dos ensaios realizados com o motor. As análises dos resultados dos ensaios são apresentados em forma de tabela. Caberá apenas analisar os resultados para a freqüência de projeto de 230 V/7 Hz e freqüência de operação de $7 \mathrm{~Hz}$. As análises em freqüências podem serem vistas em (Relatório de projeto, 2005). 


\subsubsection{Análises de resultados elétricos}

Os resultados teóricos e experimentais para o pior caso podem ser vistos na Tabela 4.11. Os resultados teóricos foram obtidos resolvendo o circuito equivalente (Anexo A) utilizando os valores de projeto dos parâmetros e os experimentais, obtidos da Tabela 4.1 da seção 4.3.1. A analise é feita para dois módulos acoplados e com freqüência de operação de $7 \mathrm{~Hz}$ para dois escorregamentos do motor.

Tabela 4.11. Apresentação dos resultados (pior caso).

\begin{tabular}{|r|c|c|c|c|}
\hline Apresentação dos resultados & \multicolumn{2}{|c|}{$\begin{array}{c}\text { Experimentais } \\
\text { (a quente) }\end{array}$} & \multicolumn{2}{c|}{$\begin{array}{c}\text { Teóricos } \\
\text { (a frio) }\end{array}$} \\
\hline Força média na subida $F_{M}(\mathrm{~N})$ & 1906 & 1558,2 & 2870 & 2237 \\
\hline Rendimento (\%) & 8,0 & 18,0 & 13,09 & 27,0 \\
\hline Corrente de acionamento $I_{S}(\mathrm{~A})$ & 20,6 & 18,2 & 19,81 & 16,01 \\
\hline Velocidade linear média $V_{L}(\mathrm{~m} / \mathrm{s})$ & 0,290 & 0,600 & 0,290 & 0,600 \\
\hline Escorregamento $(s)$ & 0,720 & 0,430 & 0,720 & 0,430 \\
\hline
\end{tabular}

$\mathrm{Na}$ Tabela 4.11 os resultados mostram que o motor não desenvolveu a força e o rendimento esperados para o mesmo escorregamento do motor (teórico e experimental). Traçando a curva característica teórica do motor e confrontado-a com a experimental, comprova-se a tal diferença dos resultados. As curvas podem ser vistas na Fig. 4.21. 


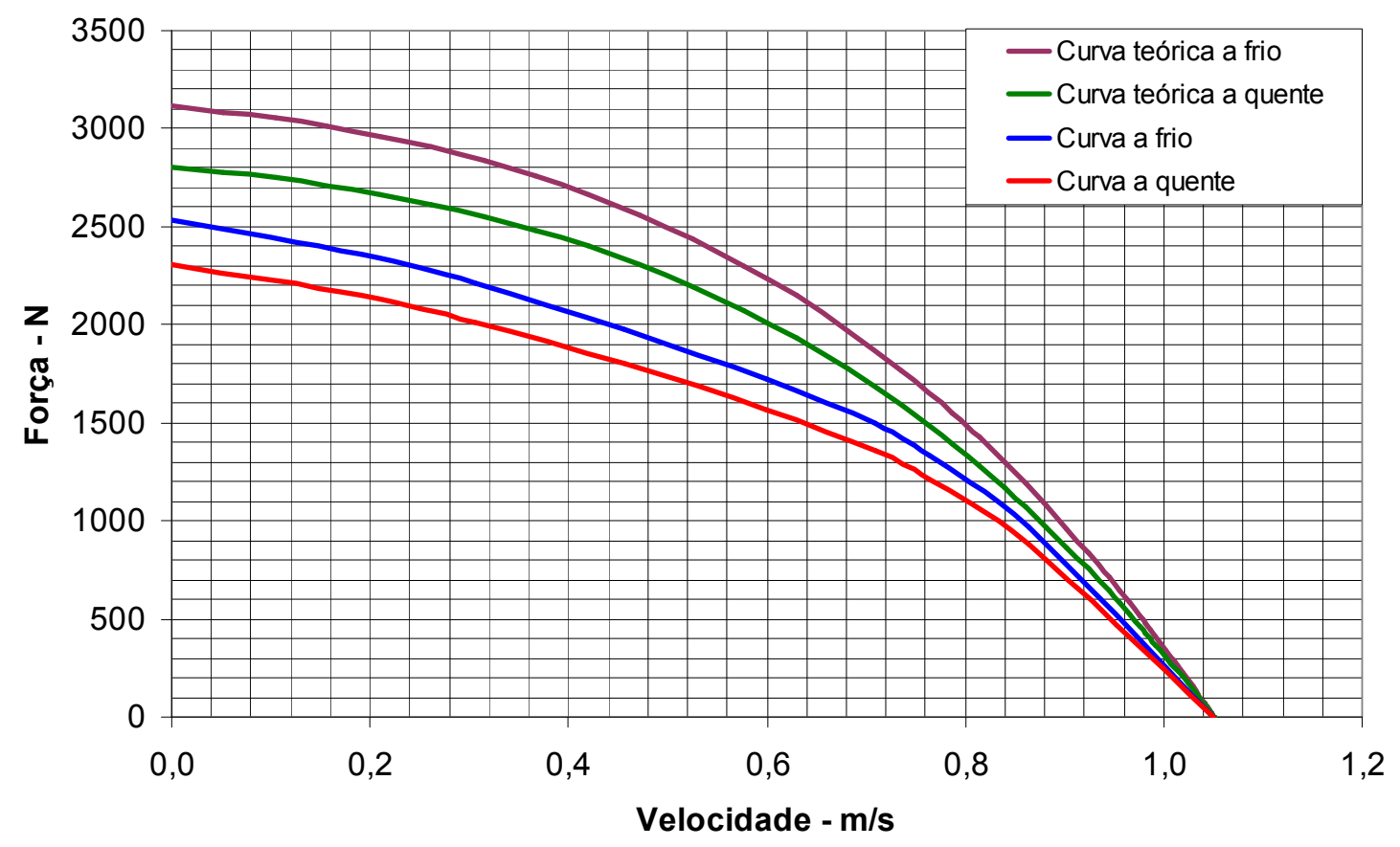

Fig. 4.21. Curva característica teórica e experimental do motor.

Observa-se uma variação da curva experimental entre o início e o término do ensaio em função da temperatura. Essa variação se dá devido ao aquecimento das partes elétricas do motor, notadamente do circuito secundário, diminuindo assim sua disponibilidade de força.

Analisando a curva teórica a frio, pode ser observado que para 0 escorregamento do motor $s=1$, obviamente com o "rotor" (secundário) travado, a diferença de força foi de exatamente $600 \mathrm{~N}$ em relação à curva experimental a frio (no inicio do ensaio) e, chegando a uma diferença de $800 \mathrm{~N}$ no pior caso, comparado com a curva característica a quente (no término do ensaio). Em relação à curva teórica a quente, a variação diminui chegando-se à $300 \mathrm{~N}$, comparado com a curva experimental a frio e, à $500 \mathrm{~N}$ com a curva experimental a quente. Obviamente, as comparações que devem ser feitas são da curva teórica a frio com curva experimental a frio e da curva teórica a quente com curva experimental a quente.

Analisando agora o modelo do circuito equivalente do motor, por parte do circuito do estator (primário), é notável que a diferença entre as correntes de acionamento $\left(I_{s}\right)$ teórica e medida (Tabela 5.1) é relativamente pequena. Então, levanta-se como hipótese que o problema deve estar nos parâmetros de magnetização $\left(R_{p}\right.$ e $\left.X_{m}\right)$, como uma possível causa das curva teórica e experimental 
do motor não coincidirem. Levando em consideração que a hipótese levantada acima seja verdadeira então, pode-se afirmar que, as perdas do motor aumentaram, diminuindo assim o desempenho eletromecânico do mesmo.

\subsubsection{Análises do desempenho térmico}

Com base nas curvas da Fig. 4.19 determina-se a constante de tempo de aquecimento como sendo em torno de 104 minutos. Desta forma, pode se afirmar que após cerca de 7 horas o motor praticamente entra em regime térmico estacionário. Esta conclusão é válida quando o motor está imerso em óleo.

Observando a Tabela 4.10, é considerada como temperatura ambiente para o motor a temperatura média do reservatório $\left(48,8^{\circ} \mathrm{C}\right)$. Verifica-se que o enrolamento apresenta uma elevação de temperatura de $54,2{ }^{\circ} \mathrm{C}$. Para a carcaça, o valor da elevação é de $18,1^{\circ} \mathrm{C}$. Observa-se, portanto, uma diferença de temperatura entre o enrolamento do primário e a carcaça do motor de $\Delta \mathrm{T}=36,1^{\circ} \mathrm{C}$.

\subsubsection{Conclusões preliminares}

São apresentados a seguir os comentários sobre os diferentes resultados obtidos até aqui.

- Curvas dinamométricas. Devido ao sistema de carga construído, as curvas dinamométricas do sistema montado mostram uma grande semelhança com as curvas de sistemas de bombeio mecânico. Isto pode ser observado nas Figs. 4.1 a 4.18. Evidentemente, as distorções típicas do sistema de bombeio mecânico que são devidas à bomba de êmbolo em si não estão presentes neste sistema, devido ao próprio sistema de carga utilizado. Entretanto, as distorções da curva dinamométrica devidas ao carregamento de hastes e de tubulações não são observadas.

Verifica-se, em algumas curvas, que nas faixas de operação em que o motor sofre a ação do freio, a curva dinamométrica apresenta patamares de força em pequenos intervalos, o que se traduz numa vibração longitudinal do secundário. Isto é explicado pela própria ação do tipo de freio utilizado, que depende do contato entre duas superfícies. Isto pode ser observado, por exemplo, nas Figs. 4.15, 4.16 e 4.17. 
Algumas das curvas obtidas em laboratório mostram o efeito da inércia das partes móveis do sistema de carga. Este efeito acontece no instante em que o motor atinge o limite inferior da excursão e reinicia um ciclo de bombeio. A característica deste efeito é apresentar um pico de força em um curto espaço de deslocamento, como é o caso nas Figs. 4.7, 4.8 e 4.10. Para massas de deslocamento maiores, este fenômeno pode ser bastante pronunciado. Esse efeito foi atenuado via software por uma rampa de velocidade. Essa rampa evitou solavancos causados pelo efeito inercia, vide Figs. 3.14 e 3.15 (seção 3.2.1).

- Modelo teórico. Os resultados comparativos apresentados na seção 4.8 indicam a necessidade da criação de um modelo teórico que melhor represente o motor, com o intuito de se obter uma melhor estimativa para o desempenho do MATÆEOS.

- Desempenho térmico. Deve ser destacado que, devido ao fato de que a dimensão longitudinal é muito maior que a dimensão radial do motor, é necessário construir um modelo térmico que permita estudar os gradientes de temperatura na direção axial. Imaginando a operação em um poço, esta tarefa se justifica, pois o calor produzido pelo motor altera a temperatura do fluido, à medida que o óleo bombeado atravessa as regiões em contato com o motor.

Diante das análises realizadas anteriormente, chega-se à conclusão de que há necessidade de identificar os parâmetros a partir do modelo teórico do motor, criando um modelo de circuito equivalente experimental, com o intuito de se obter uma melhor estimativa do desempenho do motor. 


\section{Identificação de parâmetros do MAT/EOS}

Esta seção trata do problema da identificação de parâmetros do MATÆEOS, formulando-o como um problema de otimização.

\subsection{Considerações preliminares}

No que se segue, admitem-se como hipóteses básicas que:

i) as medidas das variáveis são realizadas após o estabelecimento do regime estacionário elétrico do motor;

ii) a freqüência da tensão de alimentação do motor é constante em todos os experimentos realizados.

O modelo utilizado para representar uma fase do motor é o circuito equivalente apresentado na Fig. 5.1 (Falcone, 1985), em que as impedâncias do secundário supõem-se referidas ao primário (estator). $R_{1}$ e $R_{2}$ são as resistências do primário e do secundário ("rotor" do motor linear), respectivamente; analogamente, $X_{1}$ e $X_{2}$ são as reatâncias de dispersão do primário e do secundário; $X_{m}$ é a reatância de magnetização e $R_{p}$ a resistência de perdas no ferro; $s$ é o escorregamento do motor. $V_{S}$ e $I_{s}$ representam, respectivamente, os fasores da tensão e da corrente por fase no primário; $I_{r}$ é o fasor da corrente de fase no secundário referida ao primário; $I_{m}$ e $I_{p}$ são, respectivamente, os fasores das correntes de magnetização e de perdas no ferro por fase. 


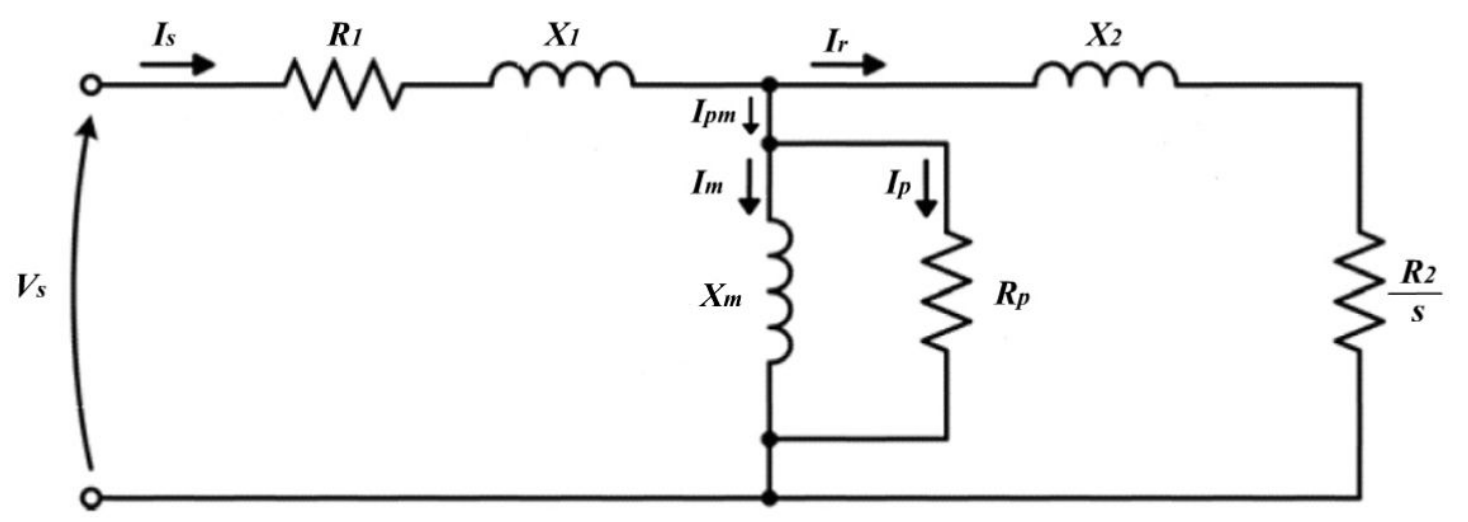

Fig. 5.1. Modelo do circuito equivalente do motor (Falcone, 1985).

Considerando que o valor de $R_{1}$ pode ser medido diretamente com o uso de um ohmímetro no enrolamento do estator, o problema de identificação dos parâmetros do motor consiste em estimar os valores de $R_{2}, X_{1}, X_{2}, R_{p}$ e $X_{m}$.

Para resolver esse problema, propõe-se a realização de diversos experimentos com o motor, cada um deles varrendo um certo conjunto de escorregamentos obtidos variando-se a carga mecânica do motor:

$$
S=\left\{s_{1}, s_{2}, \ldots, s_{n}\right\} .
$$

Seja então o escorregamento $s_{i} \in S,(1 \leq i \leq n)$, para o qual se supõe que sejam medidos os valores das seguintes variáveis por fase: tensão $\left|V_{s}(i)\right|$ e corrente $\left|I_{S}(i)\right|$ no estator, potência elétrica $P_{i n}(i)$ fornecida ao motor e potência mecânica $P_{\text {out }}(i)$ extraída do motor.

Supondo-se que o rendimento do inversor seja de $100 \%$, a potência $P_{i n}(i)$ pode ser medida na sua entrada. A potência mecânica $P_{\text {out }}(i)$ pode ser obtida medindo-se a força desenvolvida pelo motor e a velocidade do secundário e, em seguida, calculando-se seu produto. 
É oportuno observar que, sem perda de generalidade, pode-se adotar $V_{S}(i)$ como tendo fase nula, de maneira que a medida da amplitude da tensão no estator $\left|V_{S}(i)\right|$ determina completamente $V_{S}(i)$.

\subsection{O problema de identificação}

A identificação dos parâmetros do modelo do motor será realizada baseada no balanço energético, ajustando os seus valores de maneira que o modelo represente o motor da forma mais fiel possível. Em outras palavras, o objetivo é determinar um conjunto de valores de parâmetros que sejam tais que a potência elétrica fornecida ao motor seja a mais próxima possível da soma das potências dissipadas pelos componentes do modelo.

Para formular esse problema, considere-se então o escorregamento $s_{i} \in S$, $(1 \leq i \leq n)$. Sejam $P_{R 1}(i)$ e $P_{R 2}(i)$ as potências elétricas correspondentes às perdas Joule nos circuitos do primário e do secundário, respectivamente, e seja $P_{R p}(i)$ a potência elétrica correspondente às perdas no ferro. Definindo

$$
f(i)=\frac{P_{R 1}(i)+P_{R 2}(i)+P_{R p}(i)+P_{o u t}(i)-P_{\text {in }}(i)}{P_{\text {in }}(i)}
$$

uma medida da proximidade entre o modelo e o motor real no que se refere ao balanço energético é

$$
f=\sqrt{\sum_{i=1}^{n} f(i)^{2}}
$$

e o problema de identificação se resume em minimizar $f$.

Um ponto-chave deste problema consiste em notar que há, de fato, apenas três variáveis independentes: é possível exprimir $f$ como função de $X_{1}, X_{2}$ e $R_{2}$. 
Para constatar isto, observe-se primeiramente que a tensão no ramo de magnetização é uma função de $X_{1}$, pois pode ser escrita como

$$
V_{m}(i)=V_{S}(i)-Z_{1} I_{S}(i)
$$

em que

$$
Z_{1}=R_{1}+j X_{1}
$$

é a impedância do primário. Com isso, $I_{r}(i)$ pode ser calculada como função de $X_{1}$, $X_{2}$ e $R_{2}$, pois

$$
I_{r}(i)=\frac{V_{m}(i)}{Z_{2}(i)}
$$

e

$$
Z_{2}(i)=\frac{R_{2}}{s_{i}}+j X_{2}
$$

é a impedância do secundário. É imediato, portanto que a corrente $I_{p m}(i)$, por sua vez, também pode ser calculada quando são dados $X_{1}, X_{2}$ e $R_{2}$, pois

$$
I_{p m}(i)=I_{S}(i)-I_{r}(i)
$$

Além disso, tanto a potência correspondente às perdas no ferro como a potência dissipada por efeito Joule no secundário também podem ser calculadas em função de $X_{1}, X_{2}$ e $R_{2}$, pois

$$
\begin{gathered}
P_{R p}(i)=\operatorname{Re}\left(V_{m}(i) I_{p m}^{*}(i)\right) \\
P_{R 2}(i)=R_{2}\left|I_{r}(i)\right|^{2}
\end{gathered}
$$

sendo que $I_{p m}^{*}(i)$ denota o conjugado de $I_{p m}(i)$. 


\subsection{Solução do problema de otimização}

Com base nas considerações da seção anterior, o problema de otimização para a identificação dos parâmetros do modelo pode ser escrito de forma simbólica como

$$
\min _{Y} f(Y)
$$

em que $f$ é dada pela equação (5.3) e o vetor $Y$ é definido como

$$
Y=\left[\begin{array}{lll}
X_{1} & X_{2} & R_{2}
\end{array}\right]^{T}
$$

e $T$ indica o vetor transposto.

Trata-se, portanto, de um problema não linear de otimização, cuja solução será aqui denotada por $\hat{Y}$.

Naturalmente são conhecidos os valores de projeto desses parâmetros, que serão representados aqui pelo símbolo $Y_{0}$. Além disso, pode-se estabelecer com alguma segurança a região em torno de $Y_{0}$ em que os valores dos parâmetros do modelo devem se localizar. Assim, define-se o extremo inferior da região de busca da solução como sendo

$$
Y_{\min }=0,5 Y_{0}
$$

e o limite superior como

$$
Y_{\max }=1,5 Y_{0}
$$

Tendo em vista o pequeno número de variáveis e o conhecimento prévio dessa região, a solução do problema pode ser obtida numericamente de maneira simples e eficiente por meio de uma busca exaustiva. 
Note-se que a região de busca pode ser visualizada no espaço tridimensional na forma de um paralelepípedo centrado em $Y_{0}$, cujos lados têm comprimentos iguais aos valores das componentes de $Y_{\max }-Y_{\min }$ (veja a Fig. 5.2).

A busca exaustiva é realizada criando-se um reticulado por meio da divisão de cada um dos lados do paralelepípedo em $m-1$ intervalos iguais, avaliando a função $f$ em cada um dos $m^{3}$ pontos do reticulado e calculando o ponto $\hat{Y}$ onde o mínimo de $f$ ocorre.

Se, eventualmente, o ponto de mínimo obtido $\hat{Y}$ se situa em uma das faces do paralelepípedo, é recomendável aumentar a amplitude do intervalo de busca para a variável associada àquela face.

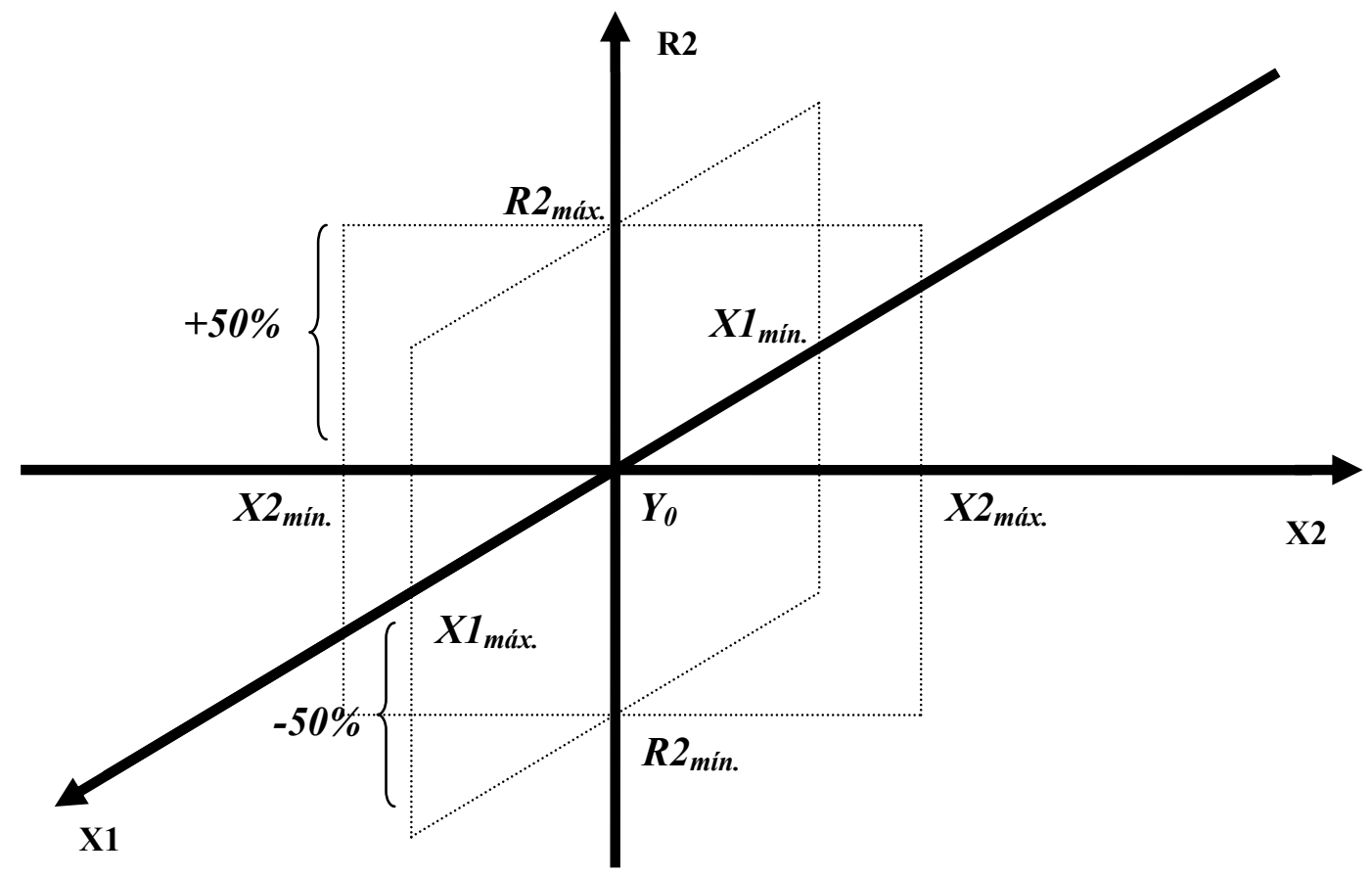

Fig. 5.2 llustração da região de busca do ponto de mínimo.

Tendo obtido as estimativas dos parâmetros $\hat{X}_{1}, \hat{X}_{2}$ e $\hat{R}_{2}$, os dois parâmetros restantes, $\hat{R}_{p}$ e $\hat{X}_{m}$, podem ser calculados da seguinte maneira: 


$$
\hat{R}_{p}=\frac{1}{n} \sum_{i=1}^{n} \frac{\left|V_{m}(i)\right|^{2}}{P_{R p}(i)}
$$

e

$$
\hat{X}_{m}=\frac{1}{n} \sum_{i=1}^{n} \frac{\left|V_{m}(i)\right|}{\left|I_{m}(i)\right|},
$$

em que

$$
I_{m}(i)=I_{p m}(i)-\frac{V_{m}(i)}{\hat{R}_{p}}
$$

\subsection{Resultados}

Esta seção apresenta os diferentes resultados utilizados no processo de identificação dos parâmetros do motor.

\subsubsection{Avaliação preliminar do método de identificação}

Nesta subseção será realizada uma avaliação do método de identificação de parâmetros em duas situações: com medidas isentas de erros e com medidas sujeitas a erros. Para isso, com base no modelo da Fig. 5.1, serão gerados conjuntos de dados simulados que serão fornecidos para o procedimento de identificação de parâmetros descrito anteriormente. O modelo identificado será então comparado com o modelo utilizado para gerar os dados. A intenção do teste no caso em que as medidas estão isentas de erros é avaliar conceitualmente o método de identificação em condições ideais; já no caso de medidas sujeitas a erros, o objetivo é verificar se a degradação nos resultados é significativa ou não.

\subsubsection{Medidas isentas de erros}

Para avaliar o método de identificação utilizam-se como ponto de partida os parâmetros nominais de projeto do motor a frio ( $1^{\mathrm{a}}$. coluna da Tabela 5.1$)$ para uma freqüência de alimentação de $7 \mathrm{~Hz}$. 
Tabela 5.1. Dados do motor linear tubular.

\begin{tabular}{|c|c|c|}
\hline Parâmetro & Valor nominal (a frio) & Valor nominal (a quente) \\
\hline$R_{I}$ & $1,243 \Omega$ & $1,243 \Omega$ \\
\hline$X_{1}$ & $0,820 \Omega$ & $0,876 \Omega$ \\
\hline$R_{2}$ & $1,724 \Omega$ & $1,854 \Omega$ \\
\hline$X_{2}$ & $0,302 \Omega$ & $0,479 \Omega$ \\
\hline$R_{p}$ & $19,20 \Omega$ & $18,694 \Omega$ \\
\hline$X_{m}$ & $3,560 \Omega$ & $3,340 \Omega$ \\
\hline
\end{tabular}

Utilizam-se esses parâmetros nominais a frio e, para $i=1,2, \ldots, 4$, considerase uma tensão de alimentação $V_{S}(i)=64,6 \mathrm{~V}$ para os valores de escorregamento $s(i)$ mostrados na Tabela 5.2. Resolve-se o circuito da Fig. 5.1 e obtêm-se os valores de $I_{S}(i), P_{\text {in }}(i)$ e $P_{\text {out }}(i)$ apresentados na Tabela 5.2., que são as medidas isentas de erros.

Tabela 5.2. Medidas isentas de erros para o modelo a frio.

\begin{tabular}{|c|c|c|c|c|}
\hline $\boldsymbol{i}$ & $\boldsymbol{s}(\boldsymbol{i})$ & $\boldsymbol{I}_{\boldsymbol{s}}(\boldsymbol{i})(\mathbf{A})^{*}$ & $\boldsymbol{P}_{\text {in }}(\boldsymbol{i})(\mathbf{W})^{*}$ & $\boldsymbol{P}_{\text {out }}(\boldsymbol{i})(\mathbf{W})^{*}$ \\
\hline 1 & 0,650 & 19,21 & 1009,50 & 169,05 \\
\hline 2 & 0,450 & 17,08 & 847,99 & 221,74 \\
\hline 3 & 0,250 & 15,06 & 650,57 & 203,21 \\
\hline 4 & 0,160 & 14,36 & 551,34 & 158,67 \\
\hline
\end{tabular}

* Valores medidos por fase $(\varnothing)$

Aplicando-se em seguida o metodologia de identificação descrita anteriormente obtém-se os valores dos parâmetros do motor da Tabela 5.3. 
Tabela 5.3. Parâmetros identificados para as medidas isentas de erros

\begin{tabular}{|c|c|}
\hline Parâmetro & Valor \\
\hline $\boldsymbol{X}_{\boldsymbol{I}}$ & $0,820 \Omega$ \\
\hline $\boldsymbol{R}_{2}$ & $1,724 \Omega$ \\
\hline $\boldsymbol{X}_{\boldsymbol{2}}$ & $0,302 \Omega$ \\
\hline $\boldsymbol{R}_{\boldsymbol{p}}$ & $19,20 \Omega$ \\
\hline $\boldsymbol{X}_{\boldsymbol{m}}$ & $3,560 \Omega$ \\
\hline
\end{tabular}

Comparando-se com os valores da Tabela 5.1, nota-se que os parâmetros do modelo foram identificados com exatidão. Isto confirma, portanto, a validade do método proposto no caso ideal. Para ilustrar, a Fig. 5.3 mostra as curvas características do modelo nominal e do modelo identificado, visualmente indistinguíveis.

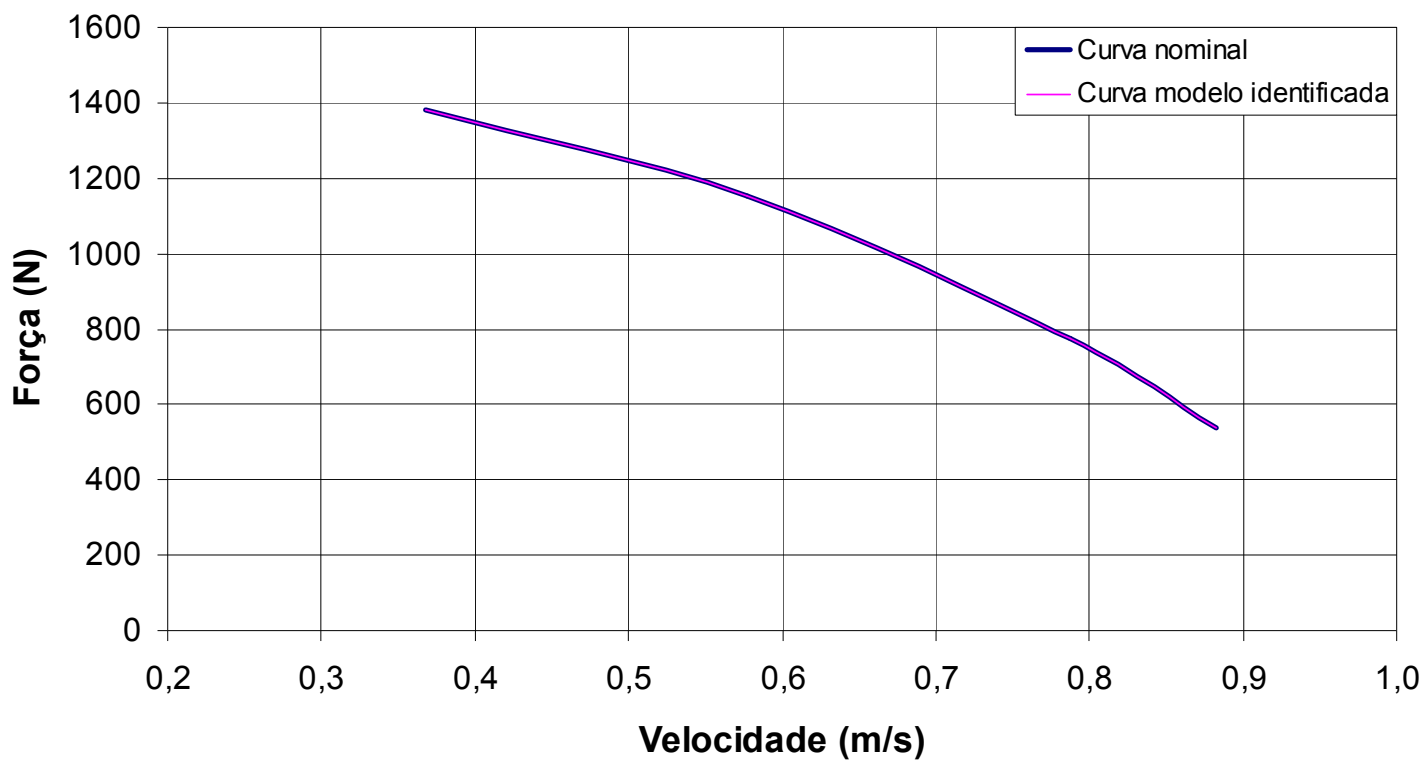

Fig. 5.3. Curvas características do modelo nominal e do modelo identificado para medidas isentas de erros.

Pode-se concluir, portanto, que o método proposto é conceitualmente consistente. 


\subsubsection{Medidas sujeitas a erros}

Como na prática todos os instrumentos de medida estão sujeitos a erros, é importante avaliar o comportamento do método de identificação proposto em uma situação mais realista.

O procedimento de geração dos valores das variáveis medidas é realizado introduzindo-se erros pseudo-aleatórios nas variáveis do problema. Para isso, foram considerados os seguintes escorregamentos: $s_{1}=1.0, s_{2}=0.75, s_{3}=0.5$ e $s_{4}=0.25$; em todos os casos, a tensão aplicada ao estator foi $V_{s}=66 \mathrm{~V}$. Para cada escorregamento $s_{i}, i=1, \ldots, 4$, o circuito equivalente do motor da figura 5.1 foi resolvido adicionando-se erros pseudo-aleatórios normais de média nula e $3 \sigma=1 \%$, sendo $\sigma$ o desvio-padrão, às variáveis calculadas, obtendo-se então os valores de $I_{S}(i), P_{i n}(i)$ e $P_{\text {out }}(i)$. Esse procedimento foi realizado por 10 vezes, gerando-se assim um conjunto de dados de 10 ensaios simulados. O procedimento de identificação aqui proposto foi aplicado a esses conjuntos de dados e foram obtidas 10 estimativas de cada um dos parâmetros do circuito. Por fim, tomaram-se as médias aritméticas desses valores, obtendo-se os resultados que constam na Tabela 5.4 .

Tabela 5.4. Resultados com os ensaios simulados sujeitos a erros de medidas para o modelo a frio

\begin{tabular}{|c|c|c|c|}
\cline { 2 - 4 } \multicolumn{1}{c|}{} & Valor real & Valor estimado & Erro \\
\hline$X_{1}$ & $0,820 \Omega$ & $0.781 \Omega$ & $-4.8 \%$ \\
\hline$X_{2}$ & $0,302 \Omega$ & $0.302 \Omega$ & $0.0 \%$ \\
\hline $\boldsymbol{R}_{2}$ & $1,724 \Omega$ & $1.772 \Omega$ & $2.8 \%$ \\
\hline
\end{tabular}

Conforme se observa, os erros nas estimativas dos parâmetros são relativamente pequenos, o que mostra que o procedimento de identificação proposto é robusto com respeito aos erros de medida. 


\subsubsection{Aplicação do método de identificação ao caso real}

Esta seção apresenta a identificação dos parâmetros experimentais do motor ao caso real. O procedimento para identificação é realizado da seguinte forma:

- São feitos três novos ensaios com o motor e, em seguida, para cada ensaio são registradas as grandezas relevantes para a identificação dos parâmetros.

- De posse das grandezas medidas, traçar-se a curva característica para cada ensaio, aplicar-se o método e identificar-se os parâmetros em cada caso. Toma-se para cada parâmetro do modelo a média dos valores dos três ensaios.

- Comparar-se a curva característica adotada para o modelo com as três curvas características experimentais.

\subsubsection{Novos ensaios}

Conforme dito acima, para a identificação dos parâmetros são realizados três novos ensaios com o motor. Cada ensaio tem em média uma duração de 6 horas, sendo realizado um por dia.

Nas Tabela 5.5 são apresentadas as variáveis medidas dos três ensaios. Essas variáveis foram medidas após o motor ter atingido o regime térmico estacionário. Esse regime foi apresentado na seção 4.6 para a freqüência nominal de operação de $7 \mathrm{~Hz}$, sendo que os novos ensaios foram realizados para mesma freqüência de operação.

As variáveis a seguir são apresentadas por módulo do motor e por fase (Ø).

O procedimento para o levantamento das medidas foi o de submeter o motor a quatro carregamentos distintos, sendo que, para cada carregamento, foram registradas as variáveis $\left|I_{s}\right|, P_{i n}, P_{\text {out }}$ e $s$. Existem duas outras grandezas medidas, $V_{s}$ e $R_{I}$ também utilizadas para a identificação. Como a realização das medidas se dá em regime estacionário, ou seja, durante o intervalo em que a relação $\mathrm{V} / \mathrm{Hz}$ é 
constante, então a grandeza $V_{s}$ é constante durante esse intervalo. $R_{1}$ por sua vez é um parâmetro medido diretamente das bobinas do primário (estator), após o término do ensaio.

$\mathrm{Na}$ Tabela 5.5, são apresentadas as medidas levantadas dos três ensaios com o motor. Como pode ser observado, a Tabela 5.5 contém outras variáveis medidas como, $V_{L}, F$ e $\eta$. Essas medidas são informações úteis no processo de identificação.

Tabela 5.5. Medidas extraídas dos três novos ensaios com o motor

\begin{tabular}{|c|c|c|c|c|c|c|c|c|}
\hline & $i$ & $s(i)$ & $I_{s}(i)(\mathrm{A})$ & $P_{\text {in }}(i)(W)$ & $P_{\text {out }}(i)(\mathrm{W})$ & $F(i)(\mathbf{N})$ & $\eta(i)$ & $V_{L}(i)(\mathrm{m} / \mathrm{s})$ \\
\hline \multirow{4}{*}{$\begin{array}{l}\bar{o} \\
\frac{0}{\widetilde{N}} \\
\stackrel{\mathscr{W}}{\tilde{W}}\end{array}$} & 1 & 0,600 & 17,73 & 845,05 & 125,22 & 894,46 & 0,148 & 0,420 \\
\hline & 2 & 0,439 & 17,14 & 723,14 & 146,60 & 746,63 & 0,203 & 0,589 \\
\hline & 3 & 0,200 & 15,86 & 529,30 & 114,20 & 407,87 & 0,216 & 0,840 \\
\hline & 4 & 0,180 & 15,14 & 543,27 & 111,47 & 388,39 & 0,205 & 0,861 \\
\hline \multirow{4}{*}{ 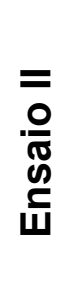 } & 1 & 0,700 & 18,30 & 860,85 & 105,94 & 1009,00 & 0,123 & 0,315 \\
\hline & 2 & 0,538 & 16,75 & 718,53 & 139,38 & 861,99 & 0,194 & 0,485 \\
\hline & 3 & 0,368 & 16,45 & 670,05 & 149,74 & 676,96 & 0,223 & 0,664 \\
\hline & 4 & 0,250 & 16,48 & 603,21 & 130,88 & 498,60 & 0,217 & 0,788 \\
\hline \multirow{4}{*}{ 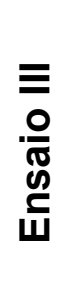 } & 1 & 0,620 & 18,17 & 838,78 & 119,10 & 895,47 & 0,142 & 0,315 \\
\hline & 2 & 0,534 & 16,87 & 764,37 & 133,23 & 816,86 & 0,174 & 0,485 \\
\hline & 3 & 0,350 & 16,59 & 630,19 & 147,10 & 646,58 & 0,233 & 0,664 \\
\hline & 4 & 0,200 & 16,20 & 540,71 & 105,35 & 376,25 & 0,195 & 0,788 \\
\hline
\end{tabular}

Na Fig. 5.4, são expostas as curvas características correspondentes aos três novos ensaios com o motor. 


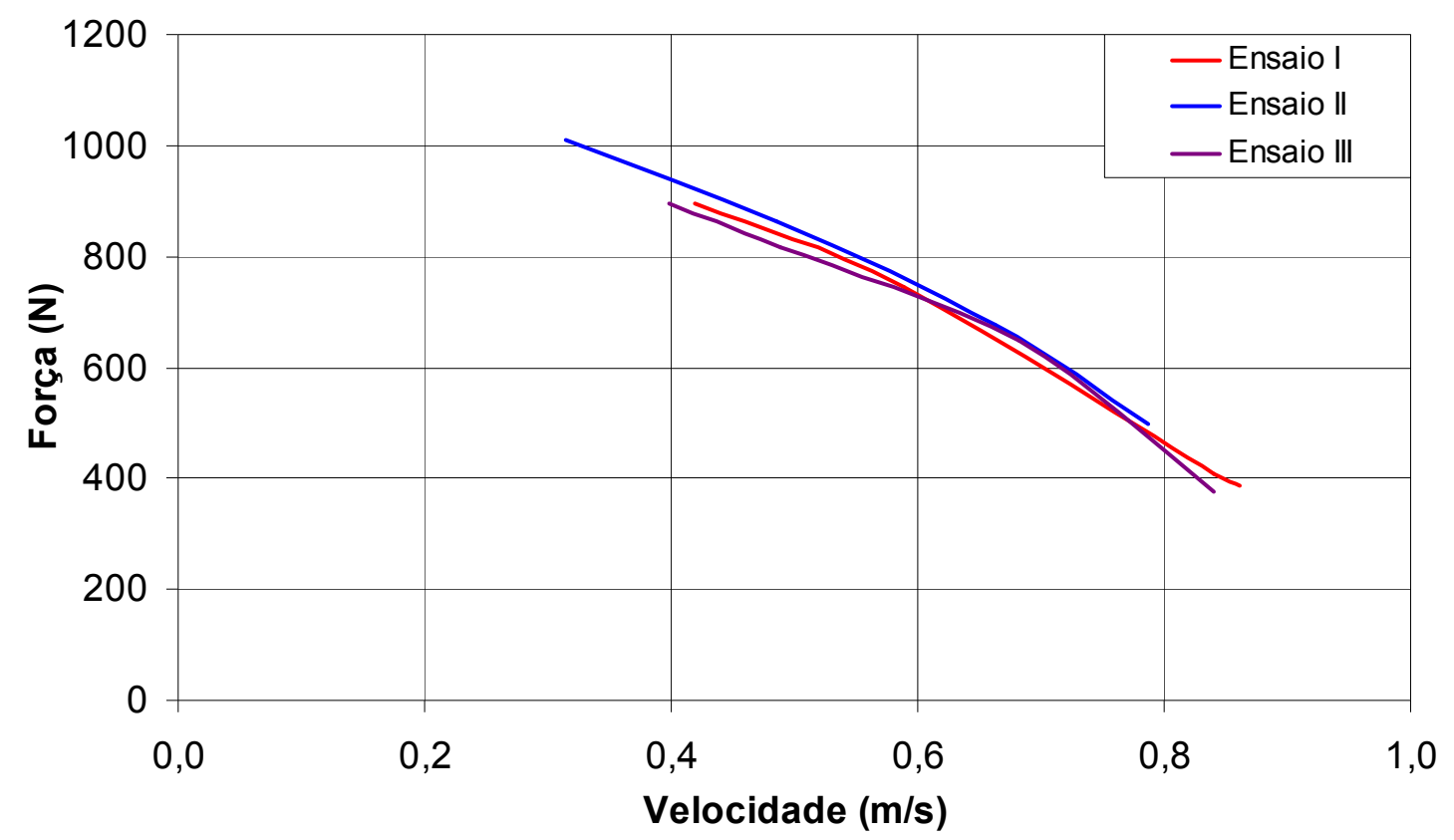

Fig. 5.4. Curvas características experimentais do motor.

Analisando a Fig. 5.4 observa-se que as três curvas apresentam boa concordância entre si. Os pequenos desvios entre as curvas são devidos a erros introduzidos pelos instrumentos de medidas e a variações de temperaturas entre os ensaios.

\subsubsection{Apresentação dos resultados}

Aplicando a metodologia descrita anteriormente, realiza-se o processo de identificação dos parâmetros do motor.

Os resultados são apresentados na Tabela 5.6 a seguir, para os três ensaios realizados. 
Tabela 5.6. Parâmetros identificados do motor.

\begin{tabular}{|c|c|c|c|}
\hline Parâmetros & Ensaio I & Ensaio II & Ensaio III \\
\hline $\boldsymbol{R}_{\boldsymbol{I}}$ & 1,243 & 1,243 & 1,243 \\
\hline $\boldsymbol{R}_{2}$ & 2,172 & 2,586 & 2,586 \\
\hline $\boldsymbol{R}_{\boldsymbol{p}}$ & 14,161 & 20,772 & 17,059 \\
\hline $\boldsymbol{X}_{\boldsymbol{I}}$ & 1,148 & 0,918 & 0,976 \\
\hline $\boldsymbol{X}_{2}$ & 0,453 & 0,453 & 0,453 \\
\hline $\boldsymbol{X}_{\boldsymbol{m}}$ & 2,892 & 2,906 & 2,851 \\
\hline
\end{tabular}

Em razão das diferenças entre os parâmetros observadas na Tabela 5.6, decidiu-se tomar a média de cada parâmetro como valor a ser adotado para o modelo (Tabela 5.7).

Tabela 5.7. Média dos parâmetros identificados

\begin{tabular}{|c|c|}
\hline Parâmetros & Valor médio \\
\hline $\boldsymbol{R}_{\boldsymbol{I}}$ & $1,243 \Omega / \mathrm{F}$ \\
\hline $\boldsymbol{R}_{\boldsymbol{2}}$ & $2,448 \Omega / \mathrm{F}$ \\
\hline $\boldsymbol{R}_{\boldsymbol{p}}$ & $17,331 \Omega / \mathrm{F}$ \\
\hline $\boldsymbol{X}_{\boldsymbol{I}}$ & $1,014 \Omega / \mathrm{F}$ \\
\hline $\boldsymbol{X}_{2}$ & $0,453 \Omega / \mathrm{F}$ \\
\hline $\boldsymbol{X}_{\boldsymbol{m}}$ & $2,883 \Omega / \mathrm{F}$ \\
\hline
\end{tabular}




\subsubsection{Análises de resultados}

Na Fig. 5.5 são confrontadas as três curvas dos ensaios com a do modelo identificado.

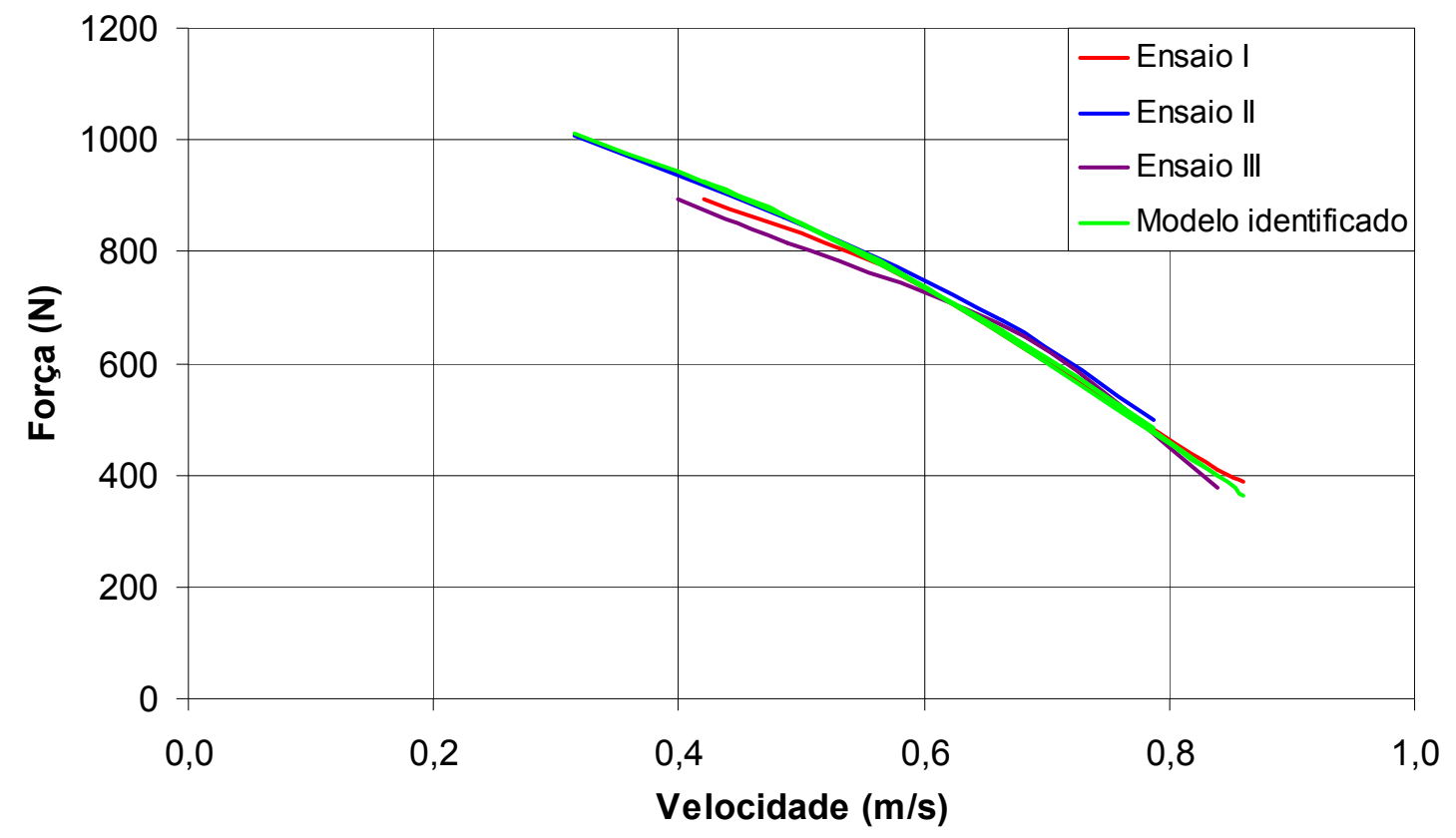

Fig. 5.5. Curvas características do três ensaios e do modelo identificada

Na Fig. 5.6, é realizando uma comparação entre a curva nominal a quente e a do modelo identificada. Observa-se que existe uma diferença razoável, o que implicam uma menor disponibilidade de força do motor real em relação aos valores de projeto.

Por exemplo tomando-se $s=0,428\left(V_{L}=0,6 \mathrm{~m} / \mathrm{s}\right)$ observa-se uma diferença de força de $250 \mathrm{~N}$ entre as curvas, e o que representa uma queda na disponibilidade de força de $25 \%$ do motor real em relação ao previsto no projeto. 


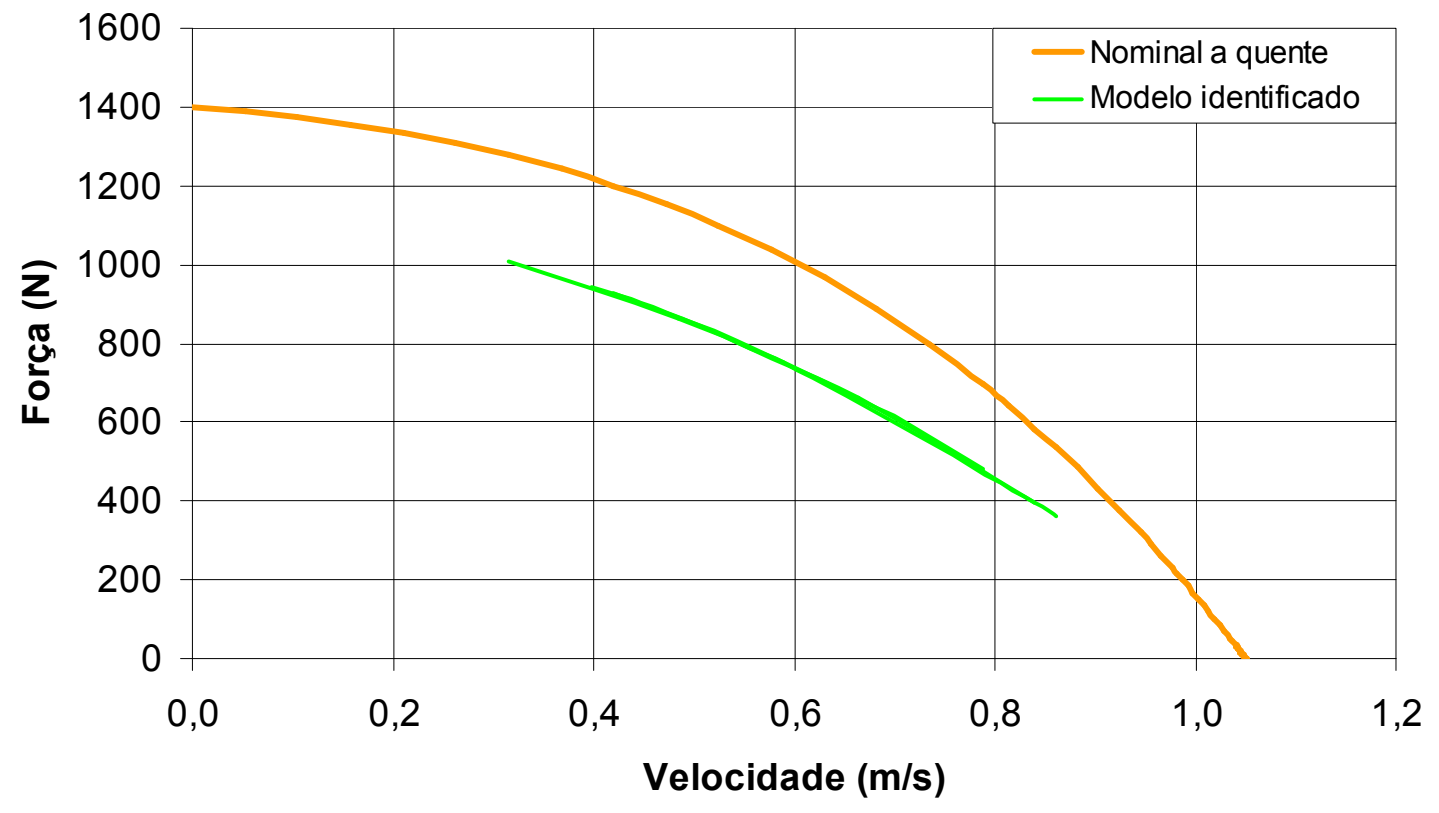

Fig. 5.6. Curva característica nominal a quente e do modelo identificado

Na Tabela 5.8 são apresentados os parâmetros nominais a quente junto com os parâmetros identificados do motor.

Tabela 5.8. Parâmetros nominais a quente e identificados.

\begin{tabular}{|c|c|c|}
\hline Parâmetros & $\begin{array}{c}\text { Nominais } \\
\text { (a quente) }\end{array}$ & $\begin{array}{c}\text { Modelo } \\
\text { identificado }\end{array}$ \\
\hline $\boldsymbol{R}_{\boldsymbol{I}}$ & 1,243 & 1,243 \\
\hline $\boldsymbol{R}_{\boldsymbol{2}}$ & 1,854 & 2,448 \\
\hline $\boldsymbol{R}_{\boldsymbol{p}}$ & 18,694 & 17,331 \\
\hline $\boldsymbol{X}_{\boldsymbol{I}}$ & 0,876 & 1,014 \\
\hline $\boldsymbol{X}_{\boldsymbol{2}}$ & 0,479 & 0,453 \\
\hline $\boldsymbol{X}_{\boldsymbol{m}}$ & 3,340 & 2,883 \\
\hline
\end{tabular}


A seguir, apresenta-se uma análise comparativa dos desempenhos do modelo nominal a quente e do modelo identificado (Tabela 5.9).

Tabela 5.9. Apresentação dos resultados do desempenho do motor.

\begin{tabular}{|c|c|c|c|c|c|}
\hline & & & Experimental & $\begin{array}{c}\text { Modelo } \\
\text { identificado }\end{array}$ & $\begin{array}{c}\text { Modelo } \\
\text { nominal } \\
\text { (a quente) }\end{array}$ \\
\hline & $i$ & $s(i)$ & \multicolumn{3}{|c|}{$\eta(i)$} \\
\hline \multirow{4}{*}{ 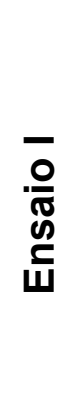 } & 1 & 0,600 & 0,148 & 0,164 & 0,183 \\
\hline & 2 & 0,439 & 0,203 & 0,211 & 0,251 \\
\hline & 3 & 0,200 & 0,216 & 0,203 & 0,279 \\
\hline & 4 & 0,180 & 0,205 & 0,195 & 0,271 \\
\hline \multirow{4}{*}{ 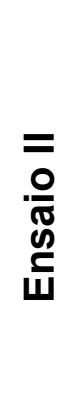 } & 1 & 0,700 & 0,123 & 0,126 & 0,137 \\
\hline & 2 & 0,538 & 0,194 & 0,185 & 0,211 \\
\hline & 3 & 0,368 & 0,223 & 0,223 & 0,274 \\
\hline & 4 & 0,250 & 0,217 & 0,218 & 0,288 \\
\hline \multirow{4}{*}{ 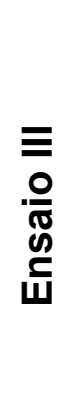 } & 1 & 0,620 & 0,142 & 0,157 & 0,174 \\
\hline & 2 & 0.534 & 0,174 & 0,186 & 0,213 \\
\hline & 3 & 0,350 & 0,233 & 0,224 & 0,278 \\
\hline & 4 & 0,200 & 0,195 & 0,203 & 0,279 \\
\hline
\end{tabular}


Como era de se esperar, observando-se a Tabela 5.9 nota-se que os rendimentos calculados com base no modelo identificado estão mais próximos dos obtidos nos ensaios do que os fornecidos pelo modelo nominal a quente. $O$ rendimento previsto pelo modelo nominal chega a estar quase $40 \%$ acima dos fornecidos pelo modelo identificado. 


\section{Conclusões}

Apresentam-se a seguir conclusões sobre os diferentes resultados obtidos neste trabalho.

- Bancada de testes. O sistema construído para ensaiar o MAT/EOS foi indispensável para o levantamento das características do motor por meio de ensaios em condições similares às que ocorrerão no poço de petróleo.

- O sistema de controle e supervisório. O sistema de controle e supervisório permitiu controlar e supervisionar todo o sistema eletroeletrônico e eletromecânico de bancada. O sistema implantado apresentou grande flexibilidade, possibilitando levantar as características do motor em diversas condições de operação.

O software desenvolvido em "LABVIEW" para o sistema de controle e supervisório do MAT/EOS permitiu monitorar todas as variáveis relevantes do motor, além de automatizar o sistema como um todo. O software apresentou facilidade de operação por meio de uma interface homem-máquina bastante funcional. Os resultados obtidos permitiram caracterizar o motor de uma forma eficaz. A programação em $\mathrm{G}$ (gráfica) possibilitou ao programador manipular e modificar a estrutura de programação de forma fácil e ágil.

- O processo de identificação de parâmetros. A formulação do problema de identificação de parâmetros como um problema de otimização e o método de busca exaustiva utilizado na sua solução possibilitaram a resolução do problema de identificação de parâmetros do motor de maneira simples, rápida e direta.

- Validação do método de identificação. A validação prévia do método de identificação por meio de testes numéricos em condições controladas permitiu comprovar a sua adequação à situação real, em que erros de medida estão presentes. Permitiu também avaliar a influência dos erros introduzidos pelos instrumentos de medidas. 
- Os resultados. Os resultados mostraram que os parâmetros identificados para os três ensaios diferem entre si, às vezes significativamente. Essas diferenças foram produzidas, como já mencionado, por possíveis variações nas características térmicas do motor e por erros de medidas introduzidos pelos instrumentos de medição. Para melhor representar o motor foi adotado o modelo utilizando a média dos valores dos parâmetros identificados nos três ensaios.

- Análises de resultados. A seguir, é feita uma explanação sobre as análises realizadas:

O modelo identificado apresentou uma menor disponibilidade de força e um pior rendimento quando comparado com os valores de projeto fornecidos pelo modelo nominal a quente. A comparação entre os parâmetros nominais a quente e os identificados mostrou uma diferença considerável, principalmente nos parâmetros $X_{1}, X_{m}$ e $R_{2}$.

Foram confrontados os rendimentos obtidos para o modelo nominal a quente para o modelo identificado e para os três ensaios realizados com o motor. Encontrou-se uma diferença não desprezível entre os rendimentos do modelo nominal a quente e do modelo identificado.

- Desenvolvimentos futuros. Deve-se notar que a presença de harmônicas de baixa freqüência não foi considerada no modelo do motor. Os parâmetros identificados experimentalmente representam o circuito tradicional do motor, ou seja, não foi levada em consideração a presença de tensões distorcidas (harmônicas de baixa ordem). Uma análise que as leve em conta requer um novo modelo do motor, onde seja acrescentada a presença de tensões distorcidas.

Deve-se notar que os parâmetros sofrem mudanças em razão das alterações nas condições térmicas de operação do motor, conforme se observa pelas curvas características experimentais. Um modelo de circuito em que seja levada em conta a influência da temperatura seria interessante.

Para uma melhor avaliação do motor poderiam ser identificados os parâmetros para outras freqüências de operação, conseqüentemente alterando o fluxo magnético e disponibilizando mais força. 
Por fim, talvez o prosseguimento mais importante do trabalho seria avaliar as características do motor em condições reais de operação em campo. 


\section{Anexo A. Circuito equivalente do motor}

O circuito equivalente é um modelo do motor de indução em regime estacionário e consiste no circuito contendo resistores e indutores tradicionalmente utilizado para representar motores de indução. É possível fazer uma estimativa do desempenho do motor em qualquer condição de operação. Especialmente, as condições descritas e realizadas no capitulo 4, podem ser analisadas de forma teórica através do circuito equivalente do motor de indução linear tubular.

A representação do circuito equivalente do motor é mostrada na Fig. A.1, onde os diferentes valores do projeto das resistências e reatâncias são obtidos do processo de cálculo elétrico do motor. Os parâmetros mostrados na Fig. A.1 são indicados na Tabela A.1.

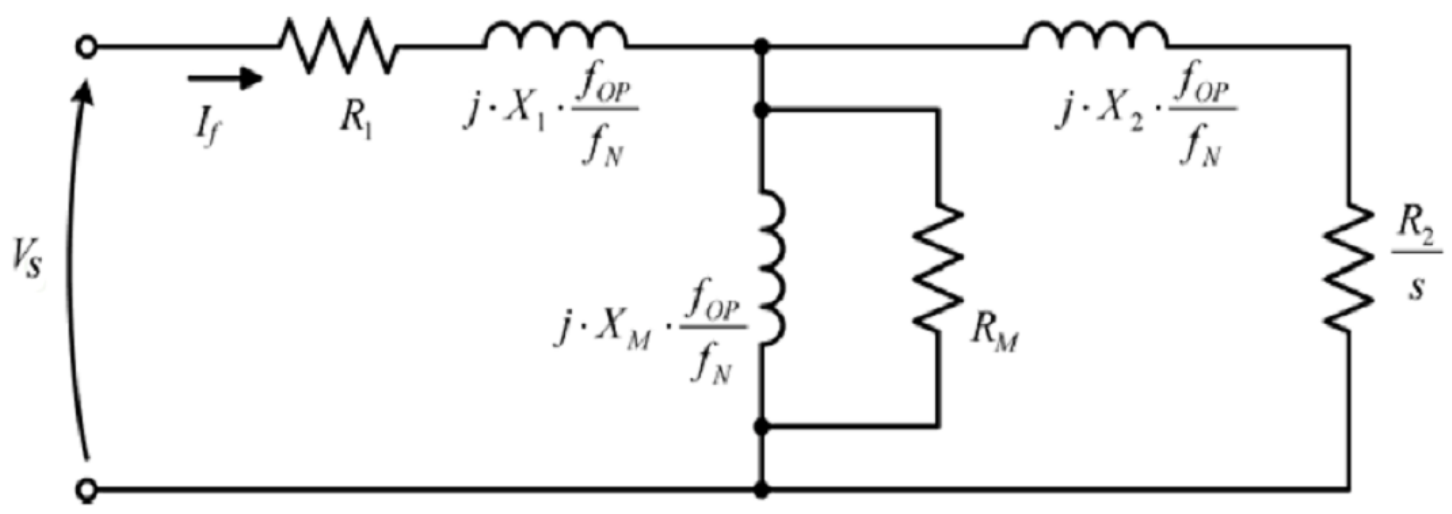

Fig. A.1. Circuito equivalente do motor de indução linear tubular. 
Tabela A.1. Dados de pojeto do circuito equivalente do motor de indução linear tubular (Matæos).

\begin{tabular}{|c|c|l|}
\hline Parâmetro & Valor & \multicolumn{1}{|c|}{ Descrição } \\
\hline$R_{1}$ & $1,243 \Omega$ & Resistência elétrica por fase do primário \\
\hline$R_{2}$ & $1,724 \Omega$ & $\begin{array}{l}\text { Resistência elétrica por fase do secundário, } \\
\text { referida ao primário }\end{array}$ \\
\hline$X_{1}$ & $0,820 \Omega$ & Reatância de dispersão por fase do primário \\
\hline$X_{2}$ & $0,302 \Omega$ & $\begin{array}{l}\text { Reatância de dispersão por fase do secundário, } \\
\text { referida ao primário }\end{array}$ \\
\hline$X_{M}$ & $3,560 \Omega$ & Reatância de magnetização por fase \\
\hline$R_{M}$ & $19,200 \Omega$ & Resistência de perdas no núcleo por fase \\
\hline$f_{N}$ & $7 \mathrm{~Hz}$ & Freqüência nominal do motor \\
\hline$f_{O P}$ & - & Freqüência de operação (Hz) \\
\hline
\end{tabular}

$\mathrm{Na}$ Fig. A.1, a variável $s$ representa o escorregamento do motor, obtido pela relação entre a velocidade média medida $V_{L}(\mathrm{~m} / \mathrm{s})$ e a velocidade síncrona $v_{S}(\mathrm{~m} / \mathrm{s})$, segundo a expressão:

$$
s=\frac{v_{S}-V_{L}}{v_{S}}
$$

A velocidade síncrona $v_{S}$ é função da freqüência de operação e da geometria do motor e é determinada nesse caso, pela equação:

$$
v_{S}=0,15 \cdot f_{O P}
$$

A tensão de fase $V_{s}(\mathrm{~V})$, indicada na Fig. A.1, é a tensão eficaz aplicada ao motor pelo inversor. Estabelecida a parametrização escalar deste dispositivo, quando se ajusta a freqüência de operação, é necessário determinar a tensão de operação $V_{s}$ correspondente, conforme as seguintes regras: 
- Caso a freqüência de operação $f_{O P}$ seja maior ou igual à freqüência de parametrização $f_{P}$, então $V_{s}$ é limitada no valor nominal de tensão do motor (66 V/fase/módulo).

- Caso $f_{O P}$ seja maior que, $f_{P}$ então $V_{s}$ é ajustada proporcionalmente à relação $f_{O P} / f_{P}\left(66 \cdot f_{O P} / f_{P}\right)$.

Desta forma, o circuito deve ser resolvido para diferentes valores de freqüência e de tensão de operação.

O circuito equivalente representado na Fig. A.1, inclui uma estimativa das perdas nas partes magnéticas do motor. Estas perdas são dadas pela potência elétrica e dissipada na resistência elétrica $R_{p}$.

Uma das dificuldades do modelo teórico apresentado, é que o circuito mostrado na Fig. A.1 é válido para tensões e correntes senoidais. A tensão de alimentação fornecida pelo inversor, apresenta um comportamento recortado, gerado por um sistema PWM. Isto produz distorções que, evidentemente, não são levadas em conta no circuito equivalente em estudo.

Um breve resumo da resolução do circuito equivalente é feito a seguir.

- Entrada de dados. São determinados: força média medida $F_{M}$ (Kgf) e velocidade média linear na subida $V_{L}$, valores retirados das Tabelas de 4.1 a 4.9. São também conhecidos o ajuste paramétrico do inversor (relação $\mathbf{V} / \mathbf{H z}$ ) e a freqüência de operação (ajuste de freqüência na saída do inversor).

- Cálculo do ponto de operação. A partir dos dados de entrada, obtémse o circuito equivalente e são determinados: corrente de acionamento $I_{s}(\mathrm{~A})$; força desenvolvida por módulo (Kgf); potência de entrada (W); potência de saída (W) e rendimento. 


\section{Anexo B. Sistema de monitoração em "Off” do MAT/EOS}

O sistema de monitoração do MATÆEOS utiliza-se de outros recursos. Esses recursos podem serem vistos na Fig. B.1, a qual monitora todo o sistema do MATÆEOS em "off", ou seja, com uma tela parecida com a utilizada no sistema de controle e supervisório do motor, é possível monitorar todas as grandezas salvas durante o ensaio com o motor. Essa tela foi desenvolvida em LABVIEW, utilizando um arquivo do tipo .Ivm, para reproduzir de forma virtual todo o funcionamento do sistema de controle e supervisório do MATÆEOS.

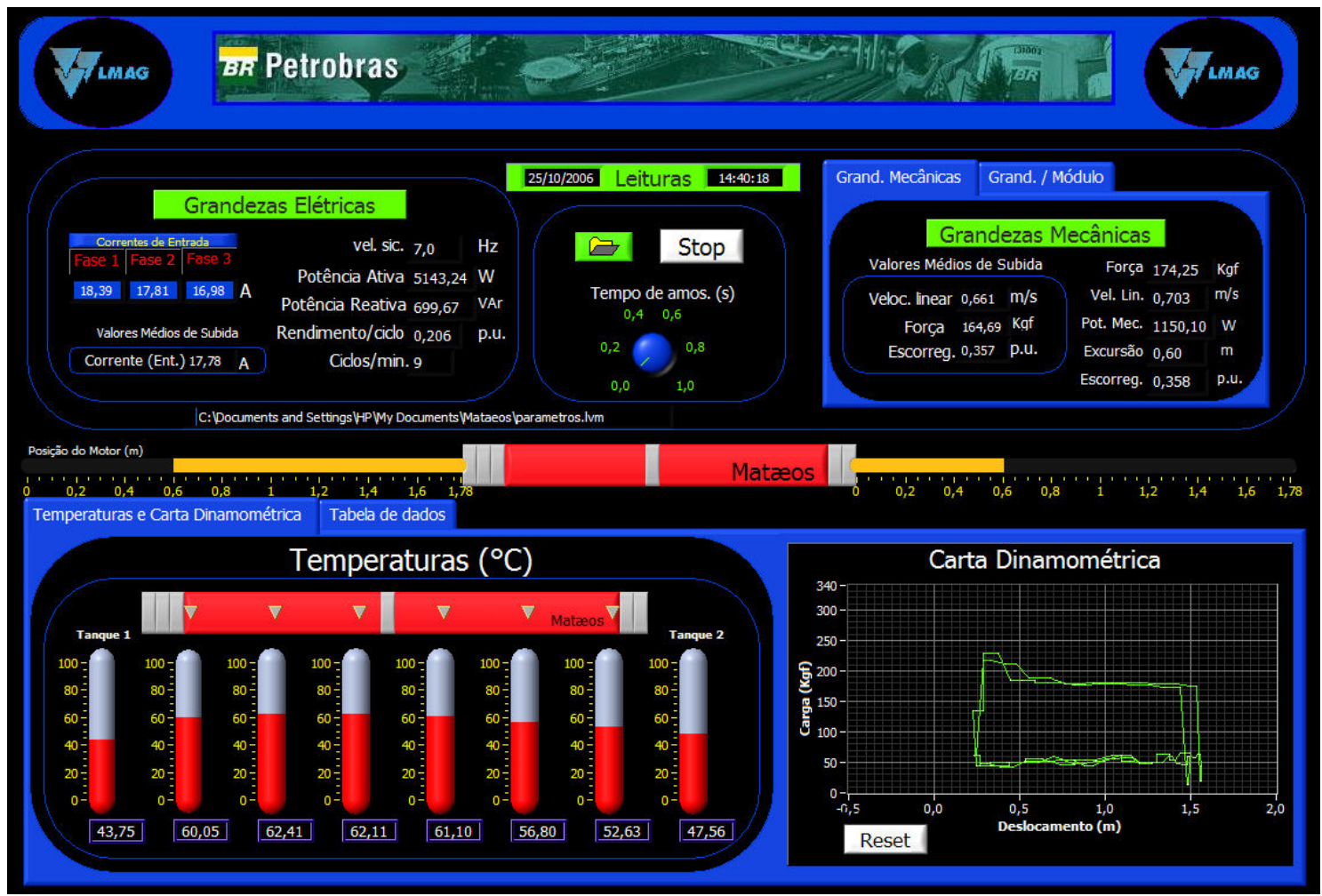

Fig. B.1. Tela que monitora de forma virtual o sistema de controle e supervisório do Matæos.

Na Fig. B.1 observa-se que a tela possui grande semelhança com a tela principal de controle e supervisório do motor exibida na Fig. 3.1 da seção 3. São observadas as grandezas elétricas e mecânicas e também as grandezas por módulo do motor. Estas podem ser vistas com mais detalhes na Fig. B.2. A tela também disponibiliza a monitoração das temperaturas e a apresentação da curva dinamométrica do motor ao logo do ensaio. A leitura das variáveis é disponibilizada na tela ao mesmo tempo, ou seja, ao carregar o arquivo adotado pelo nome de 
parâmetros, e ao clicar no botão Run, inicia-se a leitura de todas as grandezas previamente salvas pelo software de controle e supervisório do MAT/EOS.

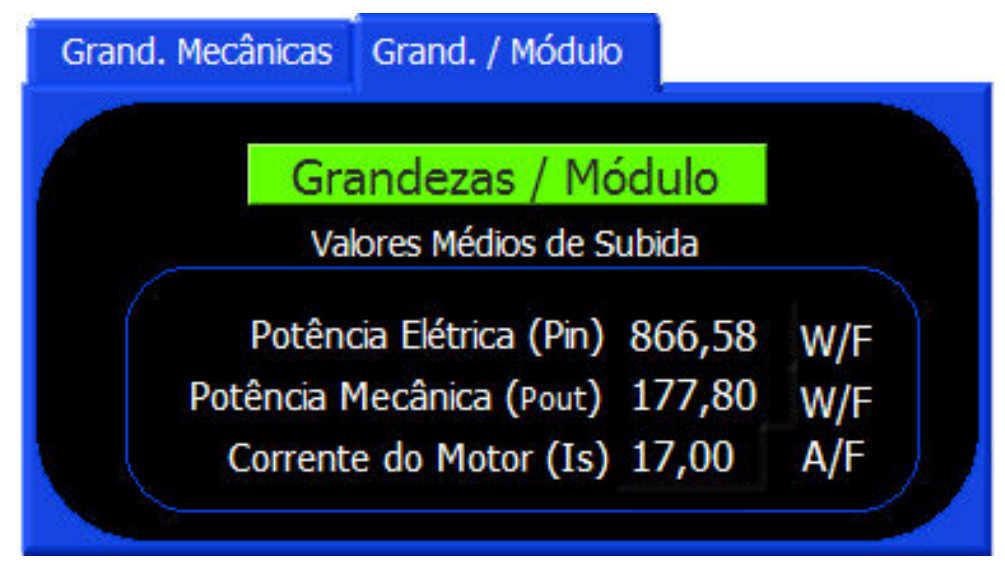

Fig. B.2. Apresentação das grandezas por módulo do motor.

Como apresentado anteriormente, esse aplicativo foi desenvolvido para realizar análises dos resultados obtidos com o motor. Na Fig. B.3 é apresentada uma tabela auxiliar usada para visualizar a monitoração de todas as variaveis.

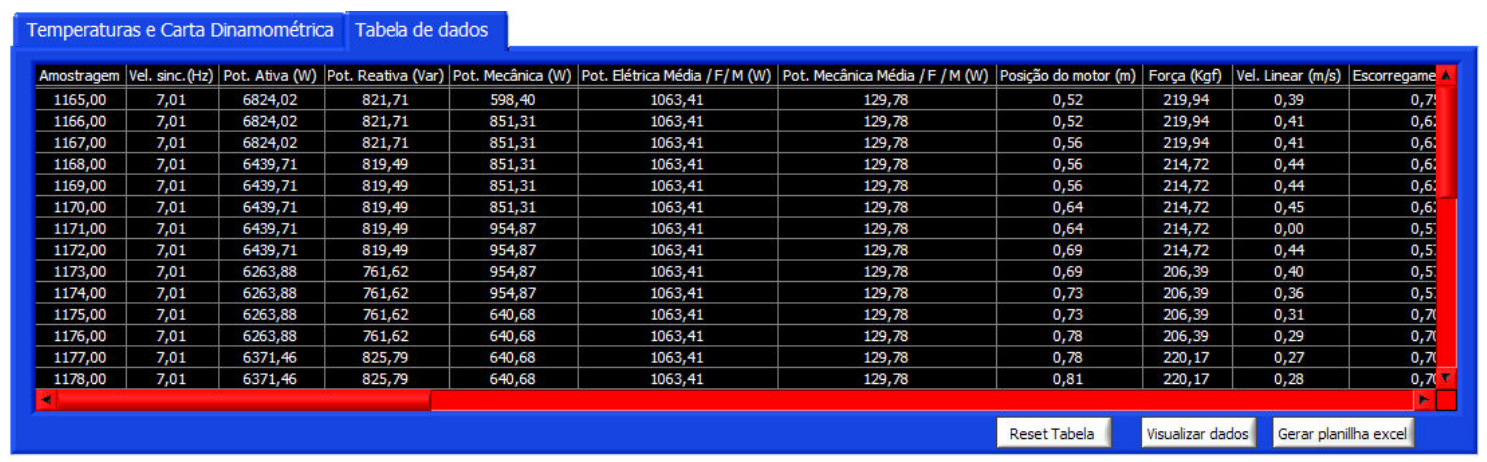

Fig. B.3. Tabela auxiliar da monitoração das grandezas

Como pode ser visto na Fig. B.3, ao clicar no botão Visualizar dados, os dados são transportados para a tabela. E se porventura houver necessidade de transportar a informação para um outro tipo de formatação, clicar no botão gerar planilha Excel, onde todos os dados dispostos na tabela são transferidos automaticamente para a planilha do excel. Com esse recurso disponível, é possível emitir relatórios para análises.

Existe outra ferramenta disponível na tela que monitora o sistema de controle e supervisório do MATÆEOS. Essa ferramenta foi designada pelo nome de tempo de 
amostragem, e pode ser vista na parte central da Fig. B.1. Com este recurso implementado, é possível diminuir o tempo de leitura dos dados, ou seja, os dados são apresentados na tela de forma mais lenta, para uma possível análise visual.

Na Fig. B.4 é apresentada a estrutura de programação utilizada para geração dos dados na tela de monitoração em off do controle e supervisório do MAT/EOS.

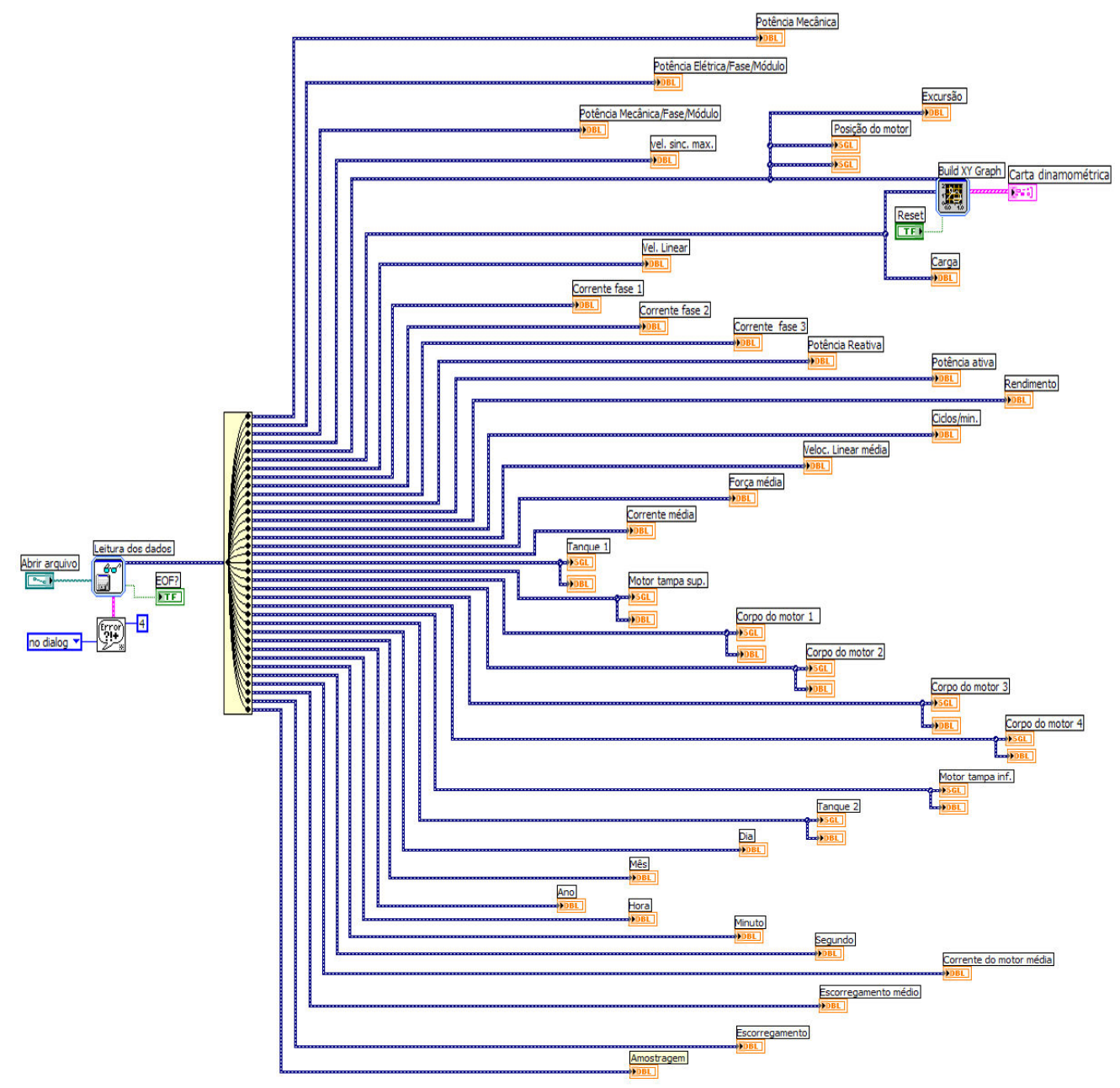

Fig. B.4. Estrutura de programação para a geração de dados.

A estrutura da Fig. B.4 funciona da seguinte maneira: o arquivo parâmetros é carregado no bloco leitura de dados e, ao clicar no botão Run, a leitura se inicia transferindo todos os dados através da função Merge signals, os quais depois são apresentados nas correspondentes caixas de saída. Após o término da leitura, o bloco leitura de dados sinaliza o fim da transmissão de dados através do indicador EOF. 
$\mathrm{Na}$ Fig. B.5, é apresentada a estrutura de programação que executa a visualização dos dados na tabela auxiliar.

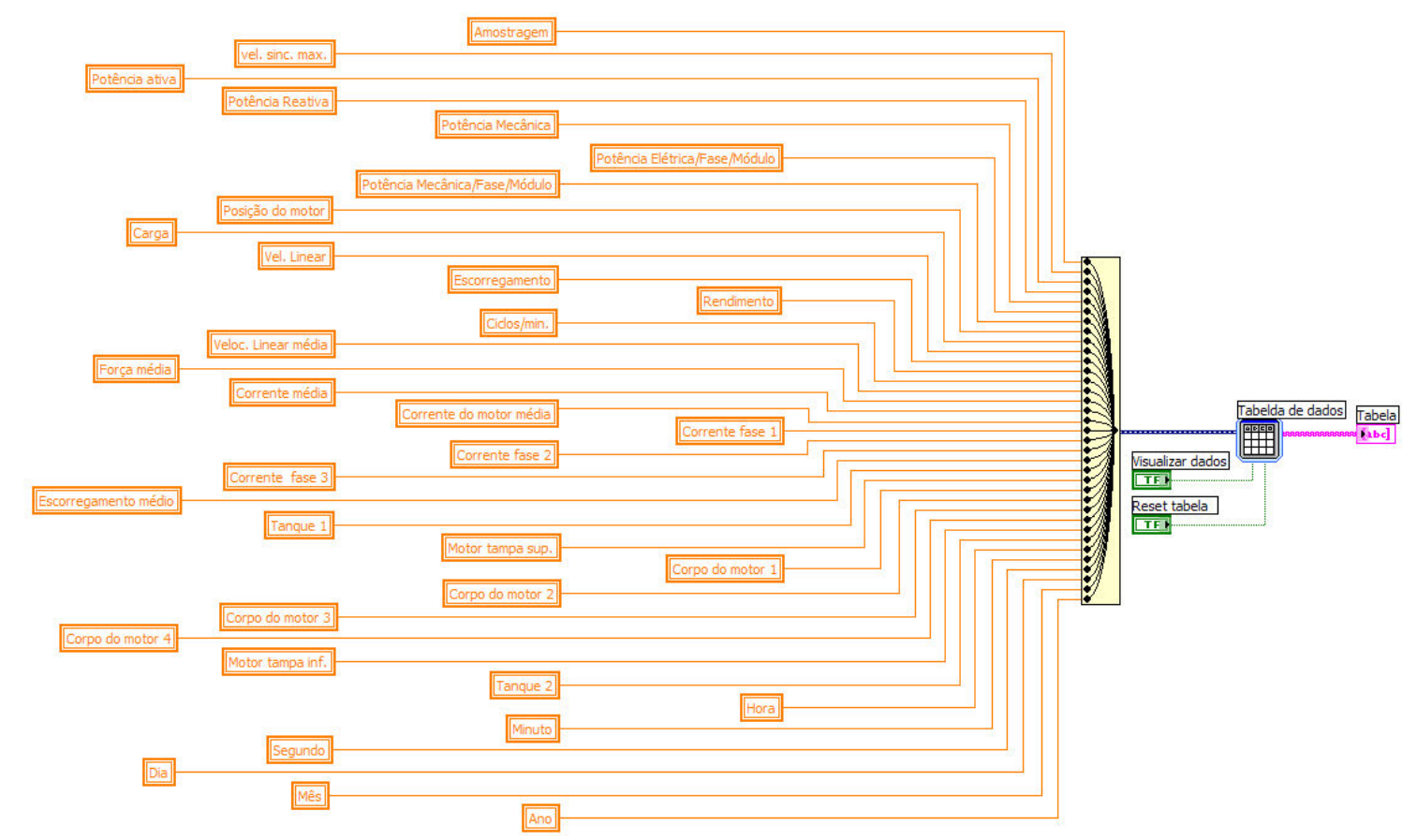

Fig. B.5. Estrutura de programação para a visualização de dados na tabela auxiliar.

A estrutura da Fig. B.5 funciona da seguinte maneira: todos os dados lidos são alocados, através das variáveis de alocação correspondentes a cada variável monitorada, e em seguida, as variáveis alocadas são direcionadas através da função Merge signals e encaminhadas para o bloco Table nomeado como Tabela de dados. Existem dois comandos para o controle do bloco Table: o botão Visualizar dados, que permite disponibilizar os dados lidos na tabela auxiliar, e o botão Reset tabela, que limpa o conteúdo da tabela.

Na Fig. B.6 é apresentada uma outra tela de monitoração em "off" do MATÆEOS. Essa tela é utilizada para monitorar as temperaturas do motor ao longo dos ensaios. A Fig. B.1 mostra que as temperaturas são monitoradas, sendo que esse monitoramento é feito visualmente. Já na tela da Fig. B.6, as temperaturas são monitoradas visualmente e também apresentadas graficamente ao longo do tempo do ensaio. 


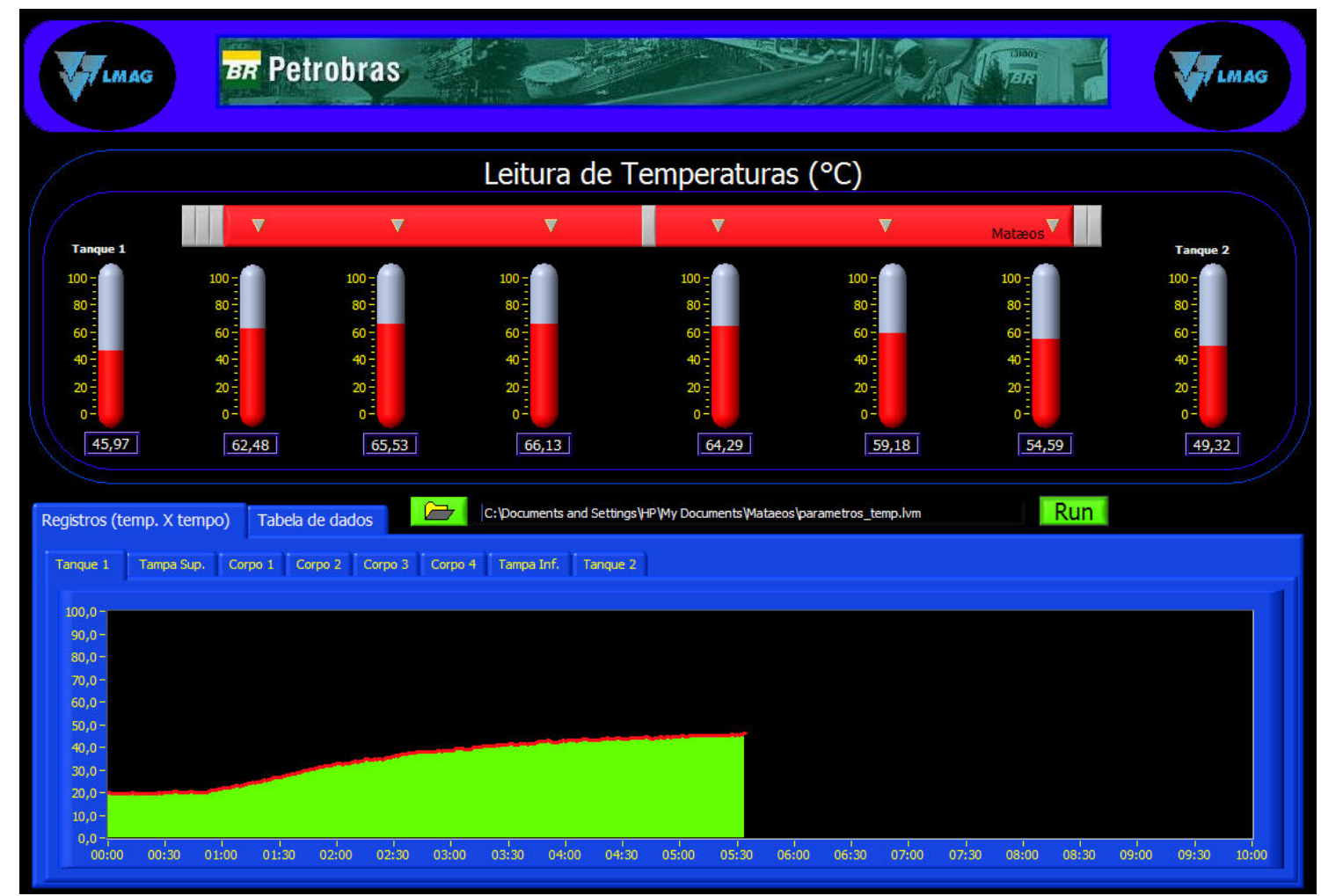

Fig. B.6. Tela que monitora de forma virtual o sistema de aquisição de temperaturas do MATÆEOS

A leitura das temperaturas é disponibilizada na tela ao mesmo tempo, ou seja, ao carregar o arquivo adotado pelo nome de parâmetros_temp e clicar no botão Run, se inicia-se a leitura das temperaturas previamente salvas pelo software de controle e supervisório do MATÆOS.

Na Fig. B.7 é apresentada uma tabela auxiliar usada para visualizar a monitoração de todas as temperaturas.

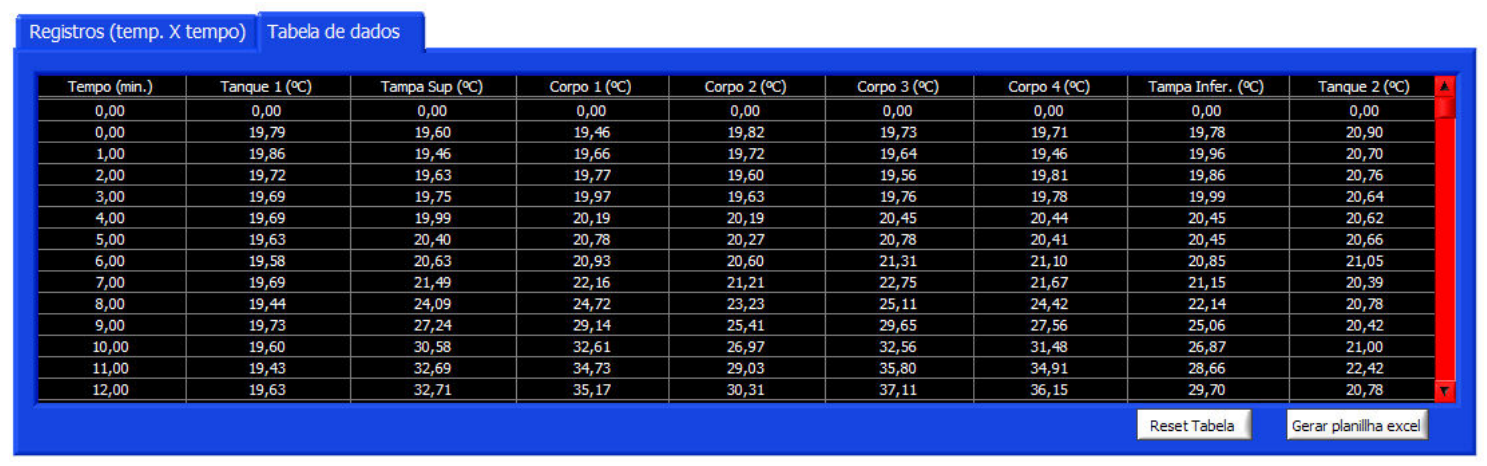

Fig. B.7. Tabela auxiliar da monitoração das temperaturas. 
Como pode ser visto na Fig. B.7, ao clicar no botão Run, os dados são transportados para a tela e também para a tabela. E, se porventura houver necessidade de transportar a informação para um outro tipo de formatação, clicar no botão gerar planilha excel, e todos os dados dispostos na tabela são transferidos automaticamente para a planilha do Excel, como feito anteriormente no caso das variáveis do MAT/EOS. Com esse recurso disponível é possível emitir relatórios para análises das temperaturas.

$\mathrm{Na}$ Fig. B.8 é apresentada a estrutura de programação utilizada para a geração das temperaturas na tela de monitoração em off das temperaturas do MATÆOS.

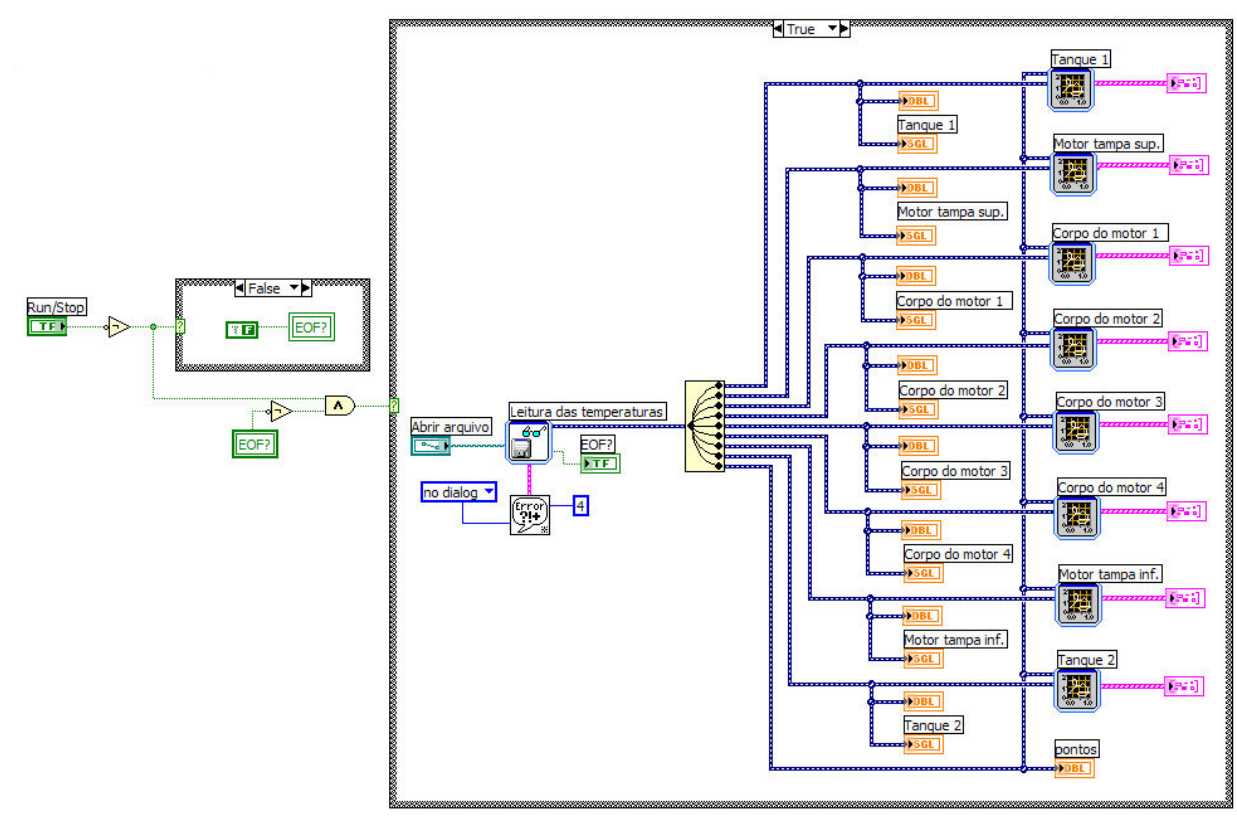

Fig. B.8. Estrutura de programação para a geração das temperaturas.

A estrutura da Fig. B.8 funciona de maneira parecida com a da Fig. B.4: o arquivo parâmetros_temp é carregado no bloco leitura das temperaturas e, ao clicar no botão Run, a leitura se inicia transferindo todas as temperaturas através da função Merge signals, os quais depois são apresentadas nas correspondentes caixas de saída. Ao mesmo tempo as temperaturas também são apresentadas graficamente. Após o término da leitura o bloco Leitura das temperaturas sinaliza o fim da transmissão de dados através do indicador EOF . 
Na Fig. B.9 é apresentada a estrutura de programação que executa a visualização das temperaturas na tabela auxiliar.

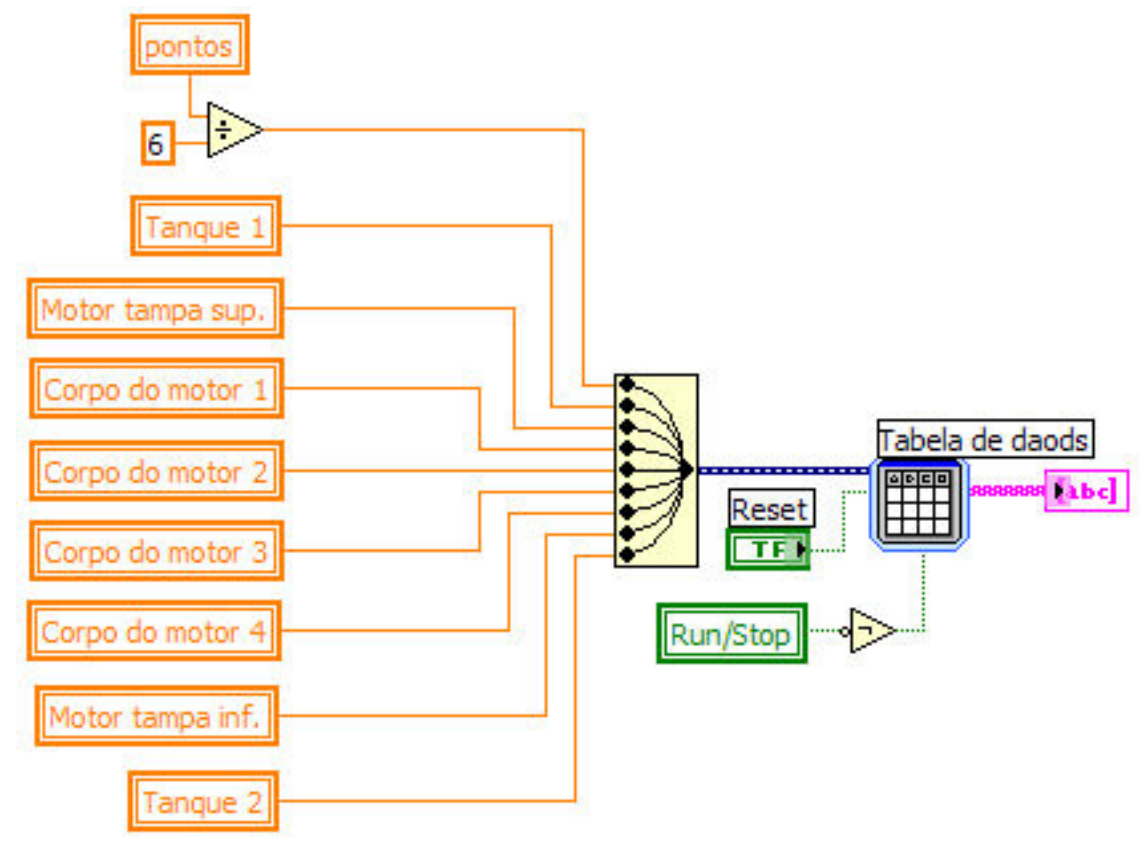

Fig. B.9. Estrutura de programação para a visualização das temperaturas na tabela auxiliar.

A estrutura da Fig. B.9 funciona de maneira parecida com a da Fig. B.5: todas as temperaturas lidas são alocadas através das variáveis de alocação correspondentes a cada variável monitorada e, em seguida, as variáveis alocadas são direcionadas através da função Merge signals, e encaminhadas para o bloco Table, nomeado como Tabela de temperaturas. Existem dois comandos para o controle do bloco Table: o botão Run/Stop com dupla função, que além de permitir disponibilizar os dados lidos na tabela auxiliar, também executa o inicio da leitura das temperaturas, e o botão Reset, que limpa o conteúdo da tabela. 


\section{Referências}

(Alvarenga, 2004) Alvarenga, B. Proposta de aplicação de motor de indução linear tubular na extração de petróleo, Tese de Doutorado, Escola Politécnica da Universidade de São Paulo, fevereiro de 2004.

(Alvarenga, Chabu, Cardoso, 2002) Alvarenga, B.; Chabu I.; Cardoso, J. R. Motor de indução linear tubular com secundário em gaiola anular - modelo e testes. In: Congresso Brasileiro de eletromagnetismo, 5., Gramado, 2002. V CBMAG. Gramado: SBMAG, 2002.p.(52)1-(52). CD-ROM.

(Bagegni, Adams \& Hoft, 1993) Bagegni, A. H.; Adams, G. E.; Hoft, R. G. Tubular linear induction motor for hydraulic capsule pipeline - Part I: Finite element analysis. IEEE Transactions on Energy Conversion, vol. 8 №.2, june 1993.

(Boldea \& Nasar, 1976) Boldea, I.; Nasar, S. A. Optimum goodness criterion for linear induction motor design. Proceedings of the IEE, v. 123, n 1, page 89-92, 1976.

(Bolton, 1969) Bolton, H. Transverse edge effect in sheet-rotor induction motors. Proceedings of the IEE, v. 116, $n^{\circ} 5$, page 725-731, 1969.

(Ducan, 1983) Ducan, J. Linear induction motor - equivalent-circuit model. Proceedings of the IEE, v.130, part B, $n^{\circ} 1$, page 51-57, 1983.

(Falcone, 1985) Falcone, A. G. Eletromecânica - Máquinas elétricas rotativas v. 2, 1985.

(Freeman \& Bland, 1976) Freeman, E. M.; Bland, T. G. Equivalent circuit of concentric cylindrical conductors in an axial alternating magnetic field. Proceedings of the IEE, v. 123, nº 2, page 149-152, 1976.

(Gastli, 1999) Gastli, A. Identification of induction motor equivalent circuit parameters using the single-phase test. IEEE Transactions on Energy Conversion, vol. 14 №.1, march 1999. 
(Mattnawrocki, 2002) Mattnawrocki, R. T., LABVIEW: Advanced Programming techinques 2002.

(Relatório de projeto, 2005) Relatório de projeto, Aplicação do Motor de Indução Linear Tubular em Bombeamento de Petróleo, Evento IV, Fundação Universidade de São Paulo, Petrobras, novembro de 2005.

(Rossini, et al., 2006a) Rossini, W. M.; Alvarenga, B. P.; Chabu, I. E.; Cruz, J. J.; Sales, R. M.; Cardoso, J. R. Bancada de testes de motor linear tubular para extração de petróleo. In: Congresso Brasileiro de Eletromagnetismo., 7, Belo Horizonte 2006. (CD-127) 1-4.

(Rossini, et al., 2006b) Rossini, W. M.; Alvarenga, B. P.; Chabu, I. E., Cruz J. J.; Cardoso, J. R.; Sales R. M. Nova concepção para bombeamento de petróleo em terra. In: I Petroleum and Chemical Industry Conference - Brasil., 1, Rio de Janeiro 2006, (14) 82-91.

(Vadher \& Smith, 1993) Vadher, V. V.; Smith, I. R. Performance of a segmented rotor tubular linear induction motor. IEEE Transactions on Magnetics, vol. 29, $\mathrm{n}^{\circ} 6$, november 1993.

(Vamvakari, Kandianis, Kladas, Manias \& Tegopoulos, 2001) Vamvakari, A.; Kandianis, A.; Kladas, A.; Manias, S.; Tegopoulos, J. Analysis of supply voltage distortion effects on induction motor operation. IEEE Transactions on Energy Conversion, vol. $16 \mathrm{~N}^{\circ} .3$ september 2001. 